Aus der Klinik für Psychosomatische Medizin und Psychotherapie

(Prof. Dr. med. C. Herrmann-Lingen)

der Medizinischen Fakultät der Universität Göttingen

\title{
Charakterisierung von Punktmutanten in der Linker-Domäne des humanen STAT1-Proteins
}

\author{
INAUGURAL-DISSERTATION \\ zur Erlangung des Doktorgrades \\ der Medizinschen Fakultät \\ der Georg-August-Universität zu Göttingen
}

vorgelegt von

Jessica Grebe

aus

Göppingen

Göttingen 2016 
Dekan:

I.Berichterstatter: $\quad$ Prof. Dr. med. Dr. phil. Dr. rer. nat. T. Meyer II.Berichterstatter: $\quad$ Prof. Dr. rer. nat. D. Kube

Prof. Dr. rer. nat. H. K. Kroemer
Tag der mündlichen Prüfung: 19.07.2016 


\section{Inhaltsverzeichnis}

$\begin{array}{ll}\text { Abkürzungsverzeichnis } & 1\end{array}$

$1 \quad$ Einleitung 4

1.1 Geschichte und Entdeckung der STAT-Proteine . . . . . . . . . 5

1.2 Familie der STAT-Proteine . . . . . . . . . . . . . . . . 5

1.3 Zytokine und Interleukine . . . . . . . . . . . . . . . 6

1.4 Charakterisierung der STAT-Mitglieder durch Knockout-Mäuse . . . . 8

1.5 JAK-STAT-Signalweg . . . . . . . . . . . . . . . . . . . . . . . 9

1.5.1 Negative Regulation des JAK-STAT-Signalwegs . . . . . . . . . . . . . 11

1.5.2 Nukleärer Import und Export von STAT-Proteinen . . . . . . . . . . . 12

$1.6 \quad$ Fragestellung . . . . . . . . . . . . . . . . . . . . . . . 14

2 Material und Methoden $\quad 15$

2.1 Methoden .......................... 15

2.1.1 Humane Zellinien . . . . . . . . . . . . . . . . . . . . . . . . 15

2.1 .2 Chemikalienliste . . . . . . . . . . . . . . . . 15

2.1.3 Radiochemikalien . . . . . . . . . . . . . . . . . . . . 17

2.1.4 Puffer, Lösungen und Medien . . . . . . . . . . . . . . . . . 17

2.1.5 Antikörper . . . . . . . . . . . . . . . . . . . . . 17

2.1.6 Reaktionskits . . . . . . . . . . . . . . . . . . . 18

2.1 .7 Zytokine . . . . . . . . . . . . . . . . . . 18

2.1.8 Plasmide . . . . . . . . . . . . . . . . . . . . . . . . . . . . 18

2.1 .9 Oligonukleotide . . . . . . . . . . . . . . . . . . . 20

2.1 .10 Bakterienstämme und Medien . . . . . . . . . . . . . . . 20

2.1.11 Geräte und Verbrauchsmaterialien . . . . . . . . . . . . . . 21

2.2 Zellkulturmethoden . . . . . . . . . . . . . . . . . 21

2.2.1 Kultivierung von Säugerzellen . . . . . . . . . . . . . . . . . . 21

2.2.2 Zellpassage . . . . . . . . . . . . . . . . . . . . 22

2.2.3 Einfrieren und Auftauen von Zellen . . . . . . . . . . . . . . . . 22

2.2.4 Transfektion von Säugerzellen . . . . . . . . . . . . . . . . . . . . 22

2.2.5 Stimulation mit Zytokinen und Behandlung mit Inhibitoren . . . . . . 23

2.3 Molekularbiologische Methoden ... . . . . . . . . . . . 23 
2.3 .1 Mutagenese . . . . . . . . . . . . . . . . . . . . 23

2.3.2 Transformation von Plasmid-DNA in chemisch kompetente Bakterien . 23

2.3.3 Plasmid-DNA-Isolation aus Bakterien . . . . . . . . . . . . . . . . 24

2.3 .4 Sequenzierung . . . . . . . . . . . . . . . . . . . . 24

2.3.5 Bestimmung der Plasmid-DNA-Konzentration . . . . . . . . . . . 24

2.3.6 Aufarbeitung von Zellen und Herstellung von Gesamtzellextrakten . . . 25

2.3.7 SDS-Polyacrylamid-Gelelektrophorese (SDS-PAGE) . . . . . . . . 26

2.3.8 Western Blot und immunchemische Proteindetektion . . . . . . . . 26

2.3.9 Elektrophoretischer Mobilitäts-Shift-Assay (EMSA) . . . . . . . . . 27

2.3 .10 Reportergen-Assay . . . . . . . . . . . . . . . . 28

2.3.11 Fluoreszenzmikroskopische Analyse . . . . . . . . . . . . . . 29

2.3 .12 Immunzytochemie . . . . . . . . . . . . . . . . . . . . . . 30

2.3 .13 RNA-Isolation . . . . . . . . . . . . . . . . . . . . 31

2.3 .14 Synthese von cDNA . . . . . . . . . . . . . . . . . 31

2.3 .15 Real-time-PCR . . . . . . . . . . . . . . . . . . . 31

3 Ergebnis 32

3.1 Sequenzvergleich in der Linkerdomäne . . . . . . . . . . . . . . 32

3.2 Reduzierte Tyrosinphosphorylierung von STAT1-F554A . . . . . . . 35

3.3 Phosphorylierungsniveau der STAT1-Mutanten W504A, F506A und

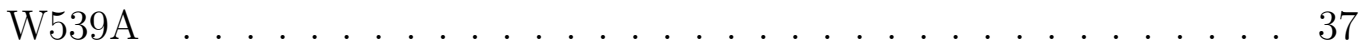

3.4 Kernakkumulation der Linker-Domäne-Mutanten . . . . . . . . . . . 39

3.5 Erhaltene kooperative DNA-Bindung und Dissoziationskinetik der $\mathrm{Mu}-$

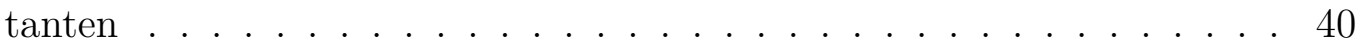

3.6 Vergleichbare DNA-Bindeaffinität von STAT1-WT, STAT1-W504A

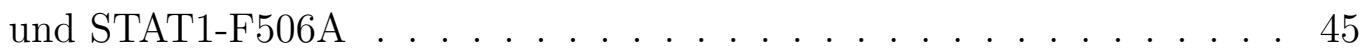

3.7 Reportergenaktivierung von STAT1-W539A und STAT1-F554A $\ldots . .48$

3.8 Genaktivierung von W504A und F506A . . . . . . . . . . 49

3.9 Endogene Zielgenaktivierung von STAT1-W504A, -F506A, -W539A und $-\mathrm{F} 554 \mathrm{~A} \ldots \ldots \ldots \ldots \ldots \ldots \ldots \ldots \ldots \ldots \ldots \ldots \ldots \ldots \ldots$

3.10 Differentielle Genaktivierung von STAT1-W504A . . . . . . . . 52

3.11 Zielgenaktivierung von STAT1-F506A und STAT1-W539A . . . . . . 54

3.12 Verminderte Zielgenaktivierung von STAT1-F554A . . . . . . . . 54

4 Diskussion $\quad 57$

4.1 Struktur und Funktion der Domänen . . . . . . . . . . . . . . 58

4.2 Hypophosphorylierung von STAT1-F554A bewirkt verminderte Genak-

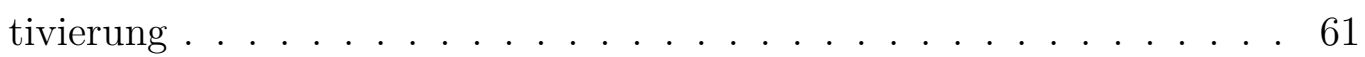

4.3 Genaktivierung von STAT1-F506A und STAT1-W539A . . . . . . . 64 
4.4 STAT1-W504A zeigt eine vom Phosphorylierungsniveau-abhängige Genaktivierung ....................... 66

$5 \quad$ Zusammenfassung $\quad 69$

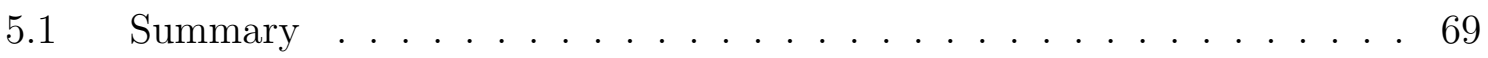

$6 \quad$ Literaturverzeichnis $\quad 71$ 


\section{Abkürzungsverzeichnis}

\begin{tabular}{|c|c|}
\hline${ }^{\circ} \mathrm{C}$ & Grad Celcius \\
\hline$\mu$ & Mikro \\
\hline A & Ampere \\
\hline$\AA$ & Ångström \\
\hline APS & Ammoniumperoxodisulfat \\
\hline AS & Aminosäure \\
\hline ATP & Adenosintriphosphat \\
\hline$\beta$-gal & Beta-Galactosidase \\
\hline $\mathrm{Bp}$ & Basenpaare \\
\hline BSA & Bovines Serumalbumin \\
\hline $\mathrm{Bq}$ & Becquerel \\
\hline $\mathrm{CBP}$ & CREB-bindendes Protein \\
\hline CCD & Coiled-Coil-Domäne \\
\hline cDNA & Komplementäre DNA \\
\hline CIS & engl. Cytokine inducible SH2-domain-containing protein \\
\hline $\mathrm{CO}_{2}$ & Kohlendioxid \\
\hline CREB & engl. cAMP response element-binding protein \\
\hline $\mathrm{Da}$ & Dalton \\
\hline DBD & DNA-Bindedomäne \\
\hline DMEM & $\begin{array}{l}\text { Dulbecco's Modified Eagle's Medium (Dulbeccos modifiziertes Ea- } \\
\text { gle Medium) }\end{array}$ \\
\hline DMSO & Dimethylsulfoxid \\
\hline DNA & Desoxyribonukleinsäure \\
\hline DPBS & Dulbeccos Phosphat-gepufferte Salzlösung \\
\hline dNTP & Desoxyribonukleosidtriphosphate \\
\hline DTT & Dithiothreitol \\
\hline EDTA & Ethylendiamin-N,N,N',N'-Tetraessigsäure \\
\hline EGTA & Ethylendioxy-bis-(ethylennitrilo)-tetraessigsäure \\
\hline EMSA & Elektrophoretischer Mobilitäts-Shift-Assay \\
\hline FCS & Fetales Kälberserum \\
\hline g & Erdbeschleunigung, Gramm \\
\hline GAPDH & Glycerinaldehyd-3-phosphat-Dehydrogenase \\
\hline
\end{tabular}




\begin{tabular}{|c|c|}
\hline GAS & Gamma-aktivierte Sequenz \\
\hline GBP & Guanylat-bindendes Protein \\
\hline GFP & Grün-fluoreszierendes Protein \\
\hline $\mathrm{h}$ & Stunde(n) \\
\hline Hepes & N-(2-Hydroxyethyl)-1-piperazino-ethansulfonsäure \\
\hline $\mathrm{H}_{2} \mathrm{O}$ & Wasser \\
\hline $\mathrm{H}_{2} \mathrm{O}_{2}$ & Wasserstoffperoxid \\
\hline ICAM-1 & Intrazellulares Adhäsions-Molekül 1 \\
\hline IFN & Interferon \\
\hline IFNAR & Interferon- $\alpha / \beta$-Rezeptor \\
\hline IFNGR & Interferon- $\gamma$-Rezeptor \\
\hline IL & Interleukin \\
\hline JAK & Janus-Kinase \\
\hline $\mathrm{k}$ & Kilo \\
\hline KCL & Kalimchlorid \\
\hline $\mathrm{kDa}$ & Kilodalton \\
\hline 1 & Liter \\
\hline $\mathrm{LB}$ & Luria-Broth \\
\hline $\mathrm{LD}$ & Linker-Domäne \\
\hline $\mathrm{m}$ & Milli, Meter \\
\hline M & Molar \\
\hline $\mathrm{MgCl}_{2}$ & Magnesiumchlorid \\
\hline $\mathrm{MgSO}_{4}$ & Magnesiumsulfat \\
\hline $\mathrm{MHC}$ & Haupthistokompatibilitatskomplex \\
\hline MIG & engl.: monokine induced by IFN $\gamma$ \\
\hline Min & Minute(n) \\
\hline mRNA & messenger RNA (Boten-RNA) \\
\hline $\mathrm{n}$ & nano \\
\hline N-Terminus & Aminoterminus \\
\hline $\mathrm{NaCl}$ & Natriumchlorid \\
\hline $\mathrm{NaOH}$ & Natriumhydroxid \\
\hline $\mathrm{Na}_{3} \mathrm{VO}_{4}$ & Natriumorthovanadat \\
\hline $\mathrm{ND}$ & Aminoterminale Domäne \\
\hline NES & Nukleäres Exportsignal \\
\hline NLS & Nukleares Lokalisationssignal \\
\hline NPC & Nukleärer Porenkomplex (engl. Nuclear pore complex) \\
\hline ONPG & ortho-Nitrophenyl- $\beta$-D-Galactopyranosid \\
\hline $\mathrm{p}$ & pico \\
\hline PAGE & Polyacrylamidgelektrophorese \\
\hline
\end{tabular}




\begin{tabular}{|c|c|}
\hline PBS & Phosphat-gepufferte Salzlösung \\
\hline PCR & $\begin{array}{l}\text { Polymerase-Kettenreaktion } \\
\text { (engl.: Polymerase Chain Reaction) }\end{array}$ \\
\hline PIAS & $\begin{array}{l}\text { Protein-Inhibitor von aktiviertem STAT } \\
\text { (engl.: protein inhibitor of activated STAT) }\end{array}$ \\
\hline Poly-dldC & Polydeoxyinosindeoxycytidin-Säure \\
\hline pTyr & Phosphotyrosin \\
\hline PVDF & Polyvinylidenfluorid \\
\hline RNA & Ribonukleinsäure \\
\hline $\mathrm{rpm}$ & $\begin{array}{l}\text { Umdrehungen pro Minute } \\
\text { (engl.: revolutions per minute) }\end{array}$ \\
\hline $\mathrm{RT}$ & Raumtemperatur \\
\hline RT-PCR & real-time-PCR \\
\hline SDS & Natriumdodecylsulfat \\
\hline sec & Sekunde(n) \\
\hline $\mathrm{SH} 2$ & Src-Homologie 2 \\
\hline SHP & SH2-containing phosphatase \\
\hline SOCS & $\begin{array}{l}\text { Suppressor des Zytokin-Signalwegs } \\
\text { (engl.: suppressor of cytokine signalling) }\end{array}$ \\
\hline STAT & Signaltransduktor und Aktivator der Transkription \\
\hline $\mathrm{T}$ & Tera \\
\hline TAD & Transaktivierungsdomäne \\
\hline TBE & Tris-Borsäure-EDTA \\
\hline TBS-T & Tris-gepufferte Salzlösung mit 0,05\% Tween \\
\hline TEMED & $\mathrm{N}, \mathrm{N}, \mathrm{N}^{`}, \mathrm{~N}^{`}-$ Tetramethylethylendiamin \\
\hline Tris & Tris-(hydroxylmethyl)-aminomethan \\
\hline $\mathrm{U}$ & Einheiten \\
\hline UV & ultraviolett \\
\hline $\mathrm{V}$ & Volt \\
\hline WT & Wildtyp \\
\hline
\end{tabular}




\section{Einleitung}

Signaltransduktion umfasst eine Vielzahl von physiologischen und biochemischen Prozessen für die Weiterleitung von Signalen in einzelligen und komplexen mehrzelligen Organismen zur Aufrechterhaltung der physiologischen Zellfunktion. Dabei werden extrazelluläre Botenstoffe wie zum Beispiel Zytokine und Wachstumsfaktoren auf externe Stimuli hin sezerniert und lösen durch Bindung an spezifische Rezeptoren Signalkaskaden aus, welche zu einer gerichteten Zellantwort führen. Extrazellulär gebundene Proteine können nachfolgend die Genexpression einer Zielzelle verändern und somit Einfluss auf Zellwachstum, Entwicklung und Homöostase nehmen.

Ein hoch konservierter und relativ gut untersuchter Signaltransduktionsweg ist der JAK-STAT-Signalweg (Levy, Darnell 2002). Nach Zytokinbindung an extrazellulären Rezeptoren werden durch rezeptor-assoziierte Janus-Kinasen latent im Zytoplasma befindliche Proteine, so genannte Signaltransduktoren und Aktivatoren der Transkription (STATs), an einem spezifischen Tyrosin-Rest phosphoryliert. Die durch Phosphorylierung aktivierten STAT-Proteine bilden tyrosin-phosphorylierte Dimere, wandern anschließend in den Zellkern ein und führen durch DNA-Bindung zur Transkription von STAT-Zielgenen. STAT-Proteine sind somit sowohl an der Signalweiterleitung von der Zellmembran in den Zellkern als auch an der Genregulation beteiligt (Schindler et al. 1992 b; Darnell et al. 1994; Levy, Darnell 2002).

Das empfindliche Gleichgewicht der Informationsübermittlung kann durch Veränderungen in der Struktur wie zum Beispiel durch Mutationen (Änderung der Primärstruktur) im STAT-Protein gestört werden; dieses manifestiert sich beim Menschen unter anderem in Immundefekten, Pilzinfektionen und Tumorgenese (Dupuis 2001; Dupuis et al. 2003; Chapgier et al. 2006; Van de Veerdonk et al. 2011; Tsumura et al. 2012; Takezaki et al. 2012). Im Folgenden wird zunächst ein sehr kurzer Überblick über die Geschichte und Entdeckung der humanen STAT-Proteine gegeben. Im weiteren Verlauf werden sowohl die für den JAK-STAT-Signalweg relevanten Zytokingruppen als auch der JAK-STAT-Signalweg selbst näher betrachtet. 


\subsection{Geschichte und Entdeckung der STAT-Proteine}

Bei der Untersuchung von IFN $\alpha$ - und IFN $\gamma$-induzierten Signaltransduktionswegen wurden zwei ligandenabhängige Transkriptionsaktivatoren entdeckt. ISGF3 (Interferon-stimulated gene factor) und GAF (gamma-activated factor) sind zwei Proteinkomplexe, die sich in Abhängigkeit von Interferonen aus latent im Zytoplasma befindlichen Proteinen zusammenfügen, in den Zellkern wandern und sich durch Bindung an spezifische DNA-Abschnitte direkt an der Genaktivierung beteiligen (Fu et al. 1990; Shuai et al. 1992). IFN $\alpha$-Bindung an extrazellulären Rezeptoren induziert den aus drei verschiedenen Proteinen bestehenden ISGF3 (Fu 1992). Nach Isolation und Sequenzanalyse von ISGF3 wurden drei Proteine mit einem spezifischen Molekulargewicht von $84 \mathrm{kDa}, 91 \mathrm{kDa}$ und $113 \mathrm{kDa}$ identifiziert, welche späterhin als STAT1 $\alpha / \beta$ bzw. STAT2 bezeichnet wurden. Diese wurden einer bis dahin unbekannten Proteinfamilie zugeordnet, den sogenannten Signaltransduktoren und Aktivatoren der Transkription, STATs. Für die beiden Proteine mit dem spezifischen Molekulargewicht von 84 kDa und 91 kDa wurde ein gemeinsamer Genort entdeckt ( Fu 1992; Schindler et al. 1992 a; Schindler et al. 1992 b). Gemeinsam mit den Janus-Kinasen (JAK) gehören STATs einem phylogenetisch sehr alten und hoch konservierten Signaltransduktionsweg an und wurden bisher sowohl in Dictyostelium, Caenorhabditis, Anopheles, Drosophila als auch Mammalia nachgewiesen (Meraz et al. 1996; Yan et al. 1996; Darnell 1997; Barillas-Mury et al. 1999; Liu 1999; Ginger et al. 2000; Levy, Darnell 2002).

\subsection{Familie der STAT-Proteine}

Die Familie der humanen STAT-Proteine umfasst nach heutigem Kenntnisstand mindestens sieben Mitglieder (STAT1, STAT2, STAT3, STAT3, STAT5a, STAT5b und STAT6). Sie umfassen eine Länge von 750-850 Aminosäuren (AS) (Darnell 1997; Teglund et al. 1998; Levy, Darnell 2002). Für die sieben bekannten humanen STATProteine wurde eine Sequenzhomologie von 28-40\% im Verlauf der ersten 700 AS nachgewiesen (Schindler, Darnell 1995; Levy, Darnell 2002). Die Genorte der zur Zeit bekannten humanen STAT-Proteine befinden sich auf den Chromosomen 2, 12 und 17 (Copeland et al. 1995; Darnell 1997). Bei einem vergleichbaren Molekulargewicht von 80-113 kDa zeigen die humanen STAT-Proteine einen charakteristischen Aufbau in sechs funktionelle Domänen (Abb. 1.1). Zwischen den Aminosäuren 600-700 im aminoterminalen Bereich der SH2-Domäne besteht eine Sequenzhomologie von über 50\% (Fu 1992; Schindler, Darnell 1995). Die Variation der Proteine innerhalb der STAT-Familie wird durch alternatives Spleißen weiter erhöht (Darnell 1997). Durch differentielles Spleißen kommen bei STAT1 zwei funktionell unterschiedliche Isoformen vor, STAT1- $\alpha$ und STAT1- $\beta$, welche aus derselben DNA-Sequenz hervor- 


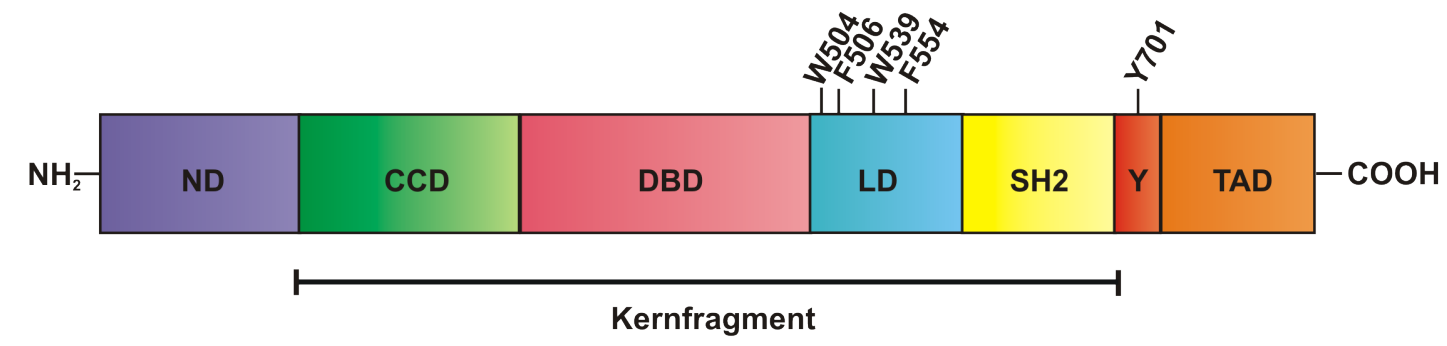

Abbildung 1.1: Domänenstruktur des STAT1-Proteins. Am Beispiel von STAT1 $\alpha$ wird hier die Abfolge der einzelnen Domänen dargestellt. Von links nach rechts: Aminoterminale Domäne (ND), Coiled-Coil-Domäne (CCD), DNA-Bindedomäne (DBD), LinkerDomäne (LD), Src-homolgy2-Domäne (SH2) und die Transaktivierungsdomäne (TAD). Das Kernfragment schließt die Coiled-Coil-Domäne bis zur SH2-Domäne mit ein. Die in dieser Arbeit untersuchten Mutanten befinden sich alle in der Linker-Domäne (LD). Die Phosphorylierung des Proteins erfolgt am Y701.

gehen. Am Beispiel von STAT1 liegt das carboxyterminale Ende der $\beta$-Isoform nach dem Spleißvorgang trunkiert vor und ist im Vergleich zu STAT1- $\alpha$ um 38 AS kürzer (Schindler et al. 1992 a; Darnell 1997; Horvath 2000). Spleißen nimmt direkten Einfluss auf die transkriptionelle Aktivität der verschiedenen STAT-Derivate. Bei speziellen STAT1-, STAT3- und STAT4-Isoformen wird durch alternatives Spleißen ein carboxyterminales Fragment mit einem konservierten Serinrest entfernt. Ist dieser Serin-Rest im STAT-Protein enthalten, so kann dieser durch Serin-ThreoninKinasen phosphoryliert werden. Dieser Schritt der Phosphorylierung ist entscheidend für die maximale transkriptionelle Aktivität und führt bei Verlust des Serin727 zu einer Verminderung der Genexpression durch STAT1 (Horvath 2000).

Durch Bindung von externen Botenstoffen an spezifische Zytokinrezeptoren kommt es zur Tyrosinphosphorylierung und Dimerisierung von STAT-Monomeren. Dabei bilden STAT1, STAT3, STAT4, STAT5a/b und STAT6 bevorzugt Homodimere, während STAT2 Heterodimere bestehend aus STAT1/STAT2 bildet (Shuai et al. 1992; Shuai et al. 1993; Schindler, Darnell 1995; Greenlund 1995).

\subsection{Zytokine und Interleukine}

Durch die Bindung von Zytokinen an spezifische extrazelluläre Rezeptoren erfolgt die Aktivierung von STAT-Molekülen über eine Kaskade von Tyrosinphosphorylierungen. Diese werden von Kinasen der Janus-Familie (JAK) katalysiert. Dieser Mechanismus der Aktivierung besteht bei allen bekannten in Säugern vorkommenden STAT-Proteinen (Levy, Darnell 2002). Zytokine sind Proteine mit einem Molekulargewicht von ca. 15-25 kDa und einer Länge von 100-200 Aminosäureresten. Als extrazelluläre Botenstoffe dienen sie dem Informationsaustausch zwischen den Zellen. Aktuell sind über 50 Zytokine bekannt, unter anderem Interferone, Interleukine, Ery- 
thropoetin, Somatotropin, Prolaktin und Thrombopoetin, welche durch Bindung an spezifische transmembrane Rezeptoren zur Aktivierung des JAK-STAT-Signalweges führen (Darnell et al. 1994; Schindler, Darnell 1995; Gao 2005). Daneben existieren Rezeptoren mit intrinsischer Tyrosinkinaseaktivität, durch welche STAT-Proteine direkt phosphoryliert werden. Dazu gehören u.a. der Rezeptor für den epidermalen Wachstumsfaktor (EGF), der Plättchenwachstumsfaktor (PDGF) sowie der Rezeptor für den Kolonie-stimulierenden Faktor-1 (CSF-1) (Wen et al. 1995; Darnell 1997; Levy, Darnell 2002).

Eine für diese Dissertation relevante und für die STAT-Aktivierung wichtige Zytokin-Familie sind die Interferone. Namensgebend war ihre Fähigkeit zur Interferenz mit Virusinfektionen (Isaacs, Lindenmann 1957). Sie besitzen vielfältige immunmodulatorische, antiproliferative und antivirale Eigenschaften und nehmen dabei Einfluss auf immunologische Prozesse (Cook et al. 1992). Interferon Typ-I wird von virusbefallenen Zellen sezerniert, wohingegen Interferon Typ-II (IFN $\gamma$ ) unter anderem von aktivierten T-Zellen und natürlichen Killerzellen freigesetzt wird (Boehm et al. 1997).

Besondere Beachtung findet in dieser Arbeit die IFN $\gamma$-induzierte STAT1Aktivierung. IFN $\gamma$ ist das bislang einzig bekannte Mitglied der Typ-II-Interferone. Der Gruppe der Typ-I-Interferone gehören unter anderem mehrere Subtypen von $\operatorname{IFN} \alpha$ sowie IFN $\beta, \operatorname{IFN} \kappa, \operatorname{IFN} \varepsilon, \operatorname{IFN} \omega$ und $\operatorname{IFN} \tau$ an (Sheppard et al. 2003). Die Typ-I-Interferone weisen untereinander strukturelle Ähnlichkeiten auf und besitzen die Fähigkeit an einen gemeinsamen heterodimeren Rezeptor zu binden (Oritani, Tomiyama 2004; Schroder et al. 2004; Pestka 2007). Zusätzlich ist die Existenz einer dritten Gruppe bekannt, die sogenannten Typ-III-Interferone (IFN $\lambda 1$, IFN $\lambda 2$ und IFN $\lambda 3$ ). Röntgenstruktur-Untersuchungen der Interferone ergaben deren Vier-HelixStruktur, die ebenfalls bei über 50 weiteren Zytokinen experimentell nachgewiesen werden konnte (Senda et al. 1990; Ealick et al. 1991; Schindler, Plumlee 2008). Sowohl Typ-I-Interferone als auch Typ-II-Interferone sind an der Hochregulierung der Haupthistokompatibilitätskomplex I Proteine (MHC I) an der Zelloberfläche kernhaltiger Zellen zur Immunabwehr beteiligt (Chang et al. 1992). Dahingegen ist die Expression von MHC II Komplexen allein unter dem Einfluss von IFN $\gamma$ möglich. Unter IFN $\gamma$-Stimulation wird das Expressionsniveau von MHC II bei Zellen angehoben, welche MHC II konstitutiv exprimieren. Die Expression von MHC II auf der Zelloberfläche kann durch IFN $\gamma$-Stimulation auch de novo induziert werden. CIITA (class II transactivator) ist hierbei Hauptregulator der MHC II Transkription und wird in reifen B-Zellen sowie in dendritischen Zellen konstitutiv exprimiert (Boehm et al. 1997; Schroder et al. 2004; Drozina et al. 2005). 


\subsection{Charakterisierung der STAT-Mitglieder durch Knockout-Mäuse}

Trotz ihres strukturell ähnlichen Aufbaus unterscheiden sich die verschiedenen STAT-Proteine im Ausmaß ihres Einflusses auf physiologische Prozesse. Mithilfe von Experimenten an STAT-defizienten Mäusen wurde ihre biologische Bedeutung näher beschrieben. STAT6 induziert die IL4- und IL13-abhängige Genexpression zur Differenzierung von Typ-II T-Helferzellen (TH2) und spielt eine wichtige Rolle in der IL4-abhängigen B-Zellproliferation. STAT6-defiziente (STAT6 ${ }^{-/-}$) T-Lymphozyten können sich folglich nicht zu TH2-Zellen ausdifferenzieren. Bei STAT6 $^{-/-}$B-Lymphozyten kommt es zu keiner Ausschüttung von IgE-Antikörpern nach einer In-vivo-Immunisierung mit anti-IgD (Kaplan et al. 1996 b; Horvath 2000).

STAT5a und STAT5b haben eine Übereinstimmung von über 95\% in ihrer murinen Aminosäuresequenz. Es konnte nachgewiesen werden, dass sie trotz der strukturellen Ähnlichkeiten nicht vom gleichen Genort stammen (Liu et al. 1995; Grimley 1999). Auch kann das Fehlen des einen STAT5-Proteins nicht wie vorerst angenommen durch die Anwesenheit des jeweils anderen STAT5 kompensiert werden (Liu et al. 1997; O’Shea 1997). STAT5a ist entscheidend für die Entwicklung der murinen Brustdrüse. Die Weibchen der STAT5a-Knockout-Mäuse sind im Vergleich zu den STAT5a-Wildtyp-Mäusen gleich groß, gleich schwer und fruchtbar. Aufgrund der fehlenden Brustdrüsenentwicklung sind die Weibchen der STAT5a-Knockout-Mäuse postpartal jedoch nicht laktationsfähig (Liu et al. 1997). STAT5b-defiziente männliche Mäuse zeigen ein eingeschränktes Ansprechen auf Wachstumshormone (Grimley 1999).

STAT4 wird durch die Rezeptorbindung von IL12 und IFN $\alpha$ phosphoryliert (TypI-Interferone) (Kaplan et al. 1996 a; Nguyen et al. 2002), vermittelt die IL12-Antwort in Lymphozyten und reguliert somit die Differenzierung von Typ-I T-Helferzellen (TH1). STAT4-defiziente (STAT4-/-) Mäuse sind fruchtbar, lebensfähig und haben eine normale Hämatopoese. Es zeigt sich jedoch ein fehlender Anstieg der TH1-Zellen sowie eine fehlende IFN $\gamma$-Antwort auf IL12 und somit eine relevante Beeinträchtigung der zellulären Immunantwort (Kaplan et al. 1996 a; Thierfelder et al. 1996; Horvath 2000; Ivashkiv, $\mathrm{Hu} 2004$ ).

STAT3 ist an der embryonalen Entwicklung von Mäusen beteiligt. Aufgrund der frühen embryonalen Letalität zwischen dem sechsten und siebten embryonalen Tag ist die Untersuchung von lebendigen STAT3-Knockout-Mäusen nicht möglich (O'Shea 1997; Takeda et al. 1997).

STAT2 und das in dieser Arbeit näher untersuchte STAT1 sind wichtige Mediatoren in der Interferon-vermittelten Immunantwort. Eine STAT2-Defizienz äußert sich in einer Abwehrschwäche gegenüber viralen Erregern (Park et al. 2000; Levy, 
Darnell 2002). STAT1-/- Mäuse zeigten kein Ansprechen auf die Stimulation mit Interferon Typ I/II. Die untersuchten STAT1 ${ }^{-/-}$Mäuse zeigten ebenso eine deutlich erhöhte Anfälligkeit auf virale und bakterielle Infektionen sowie zur Tumorgenese (Bowman et al. 2000; Park et al. 2000; Shankaran et al. 2001). Die weitere physische Entwicklung blieb unauffällig (Durbin et al. 1996; Meraz et al. 1996).

\subsection{JAK-STAT-Signalweg}

An dieser Stelle soll die durch IFN $\alpha$ - und die IFN $\gamma$-induzierte Signaltransduktion näher betrachtet werden (Abb. 1.2 und Abb. 1.3). Die Weiterleitung von externen Stimuli erfolgt durch die Bindung des jeweiligen Interferons an die aminoterminale Seite des Rezeptors. Zytokinrezeptoren bestehen aus einer aminoterminalen, einer transmembranen sowie einer intrazellulären, carboxyterminalen Domäne (Bach et al. 1997). Die Rezeptoren für IFN $\alpha$ und IFN $\gamma$ gehören zu den Klasse-IIZytokinrezeptoren (Schindler, Darnell 1995) und setzen sich aus den Untereinheiten IFNAR1/IFNAR2 bzw. IFNGR1/IFNGR2 zusammen. Der IFN $\gamma$-Rezeptor besteht aus je einer zusätzlichen $\alpha$ - und $\beta$-Kette (Greenlund 1995; Boehm et al. 1997). Beide Rezeptoren verfügen über keine intrinsische Kinaseaktivität. Zur Auto- bzw. Transphosphorylierung des Rezeptors und zur anschließenden Tyrosinphosphorylierung der im Zytoplasma befindlichen STAT-Proteine dienen die Janus-Kinasen (JAKKinasen). Diese befinden sich auf der zytoplasmatischen Seite der Zellmembran und sind nicht-kovalent am Rezeptor gebunden (Velazquez et al. 1992; Müller et al. 1993; Novick 1994; Schindler, Darnell 1995; Bach et al. 1997).

Die Familie der JAK-Kinasen umfasst vier Mitglieder (JAK1, JAK2 und JAK3 sowie TYK2). Eine gemeinsame Eigenschaft aller vier genannten Kinasen ist, dass sie eine Pseudo-Kinase-Domäne und eine Kinase-Domäne, jedoch keine SH2- oder SH3Domäne besitzen (Wilks et al. 1991; Schindler, Darnell 1995; Imada, Leonard 2000; Leonard, Lin 2000; Rane, Reddy 2000; Hou et al. 2002). Durch Rezeptorbindung von IFN $\alpha / \gamma$ kommt es zur Dimerisierung der Rezeptoruntereinheiten. Dadurch wird eine Kaskade von Tyrosinphosphorylierungen in Gang gesetzt, die unter anderem zur Tyrosinphosphorylierung an der Position 440 der $\alpha$-Kette des IFN $\gamma$-Rezeptors sowie des Tyrosins an Position 701 im STAT1-Protein führt.

Unter IFN $\gamma$-Stimulation kommt es zur Ausbildung von STAT1-Homodimeren, welche im Zellkern an spezifische palindromische Promotersequenzen (GAS-Stellen gamma-activated site) binden und die Transkription von IFN $\gamma$-abhängigen Genen induzieren (Abb. 1.3) (Darnell et al. 1994). Bei der Ausbildung von Hetero- bzw. Homodimeren reagiert das Phosphotyrosin des einen Protomers mit einem spezifischen Argininrest in der SH2-Tasche des zweiten Interaktionspartners (Greenlund 1995; Chen et al. 1998; Becker et al. 1998). Nach der Stimulation mit IFN $\alpha$ kommt 


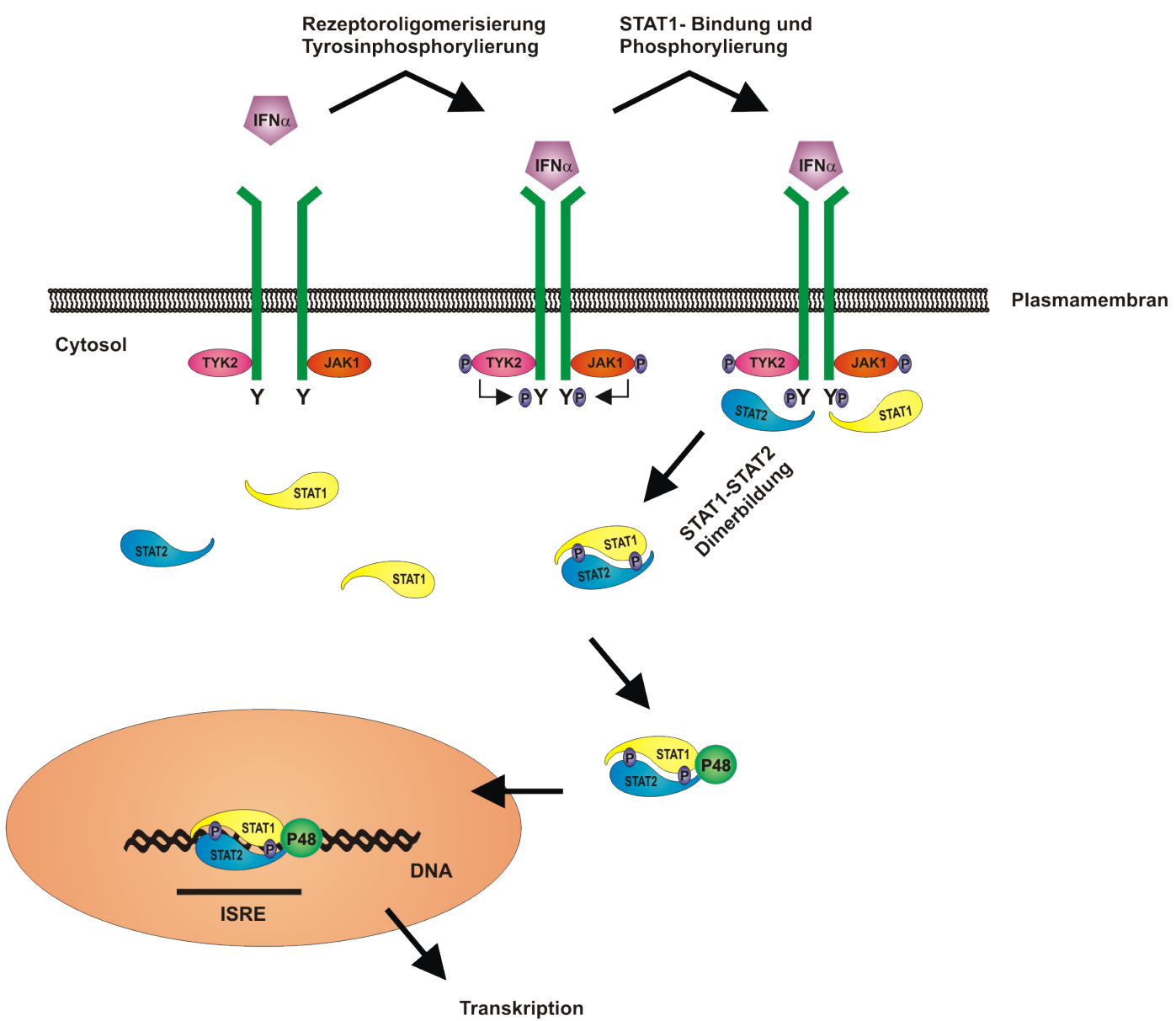

Abbildung 1.2: Der JAK-STAT-Signalweg mit IFN $\alpha$-induzierter Zielgenaktivierung. Bindung von IFN $\alpha$ bewirkt die Rezeptoroligomerisierung, Auto- und Transphosphorylierungen der Kinasen TYK2 und JAK1 sowie die Phosphorylierung des Rezeptors. STAT1/2 Monomere werden am kritischen Tyrosin-Rest phosphoryliert, bilden STAT1/STAT2-Heterodimere und lagern sich mit p48 zum IFN-stimulierten Genfaktor 3 (ISGF3) zusammen. Dieser wandert in den Zellkern ein und induziert durch Bindung an ISRE-Sequenzen (interferon-stimulated response element) die Genaktivierung.

es zur Ausbildung von trimeren Komplexen aus im Zytoplasma befindlichen Faktoren. Diese Komplexe bestehen aus STAT1-STAT2-Heterodimeren sowie p48/IRF-9 und bilden den ISGF3 (interferon-stimulated gene factor) (Greenlund 1995; Horvath 2000; Ihle 2001). ISGF3 wandert in den Zellkern ein und leitet durch Bindung an palindromische Sequenzen, die sogenannten ISRE-Sequenzen (interferon-stimulated response element), die IFN $\alpha$-abhängige Zielgenaktivierung ein (Abb. 1.2) (Fu et al. 1990; Fu 1992; Bluyssen 1996). 


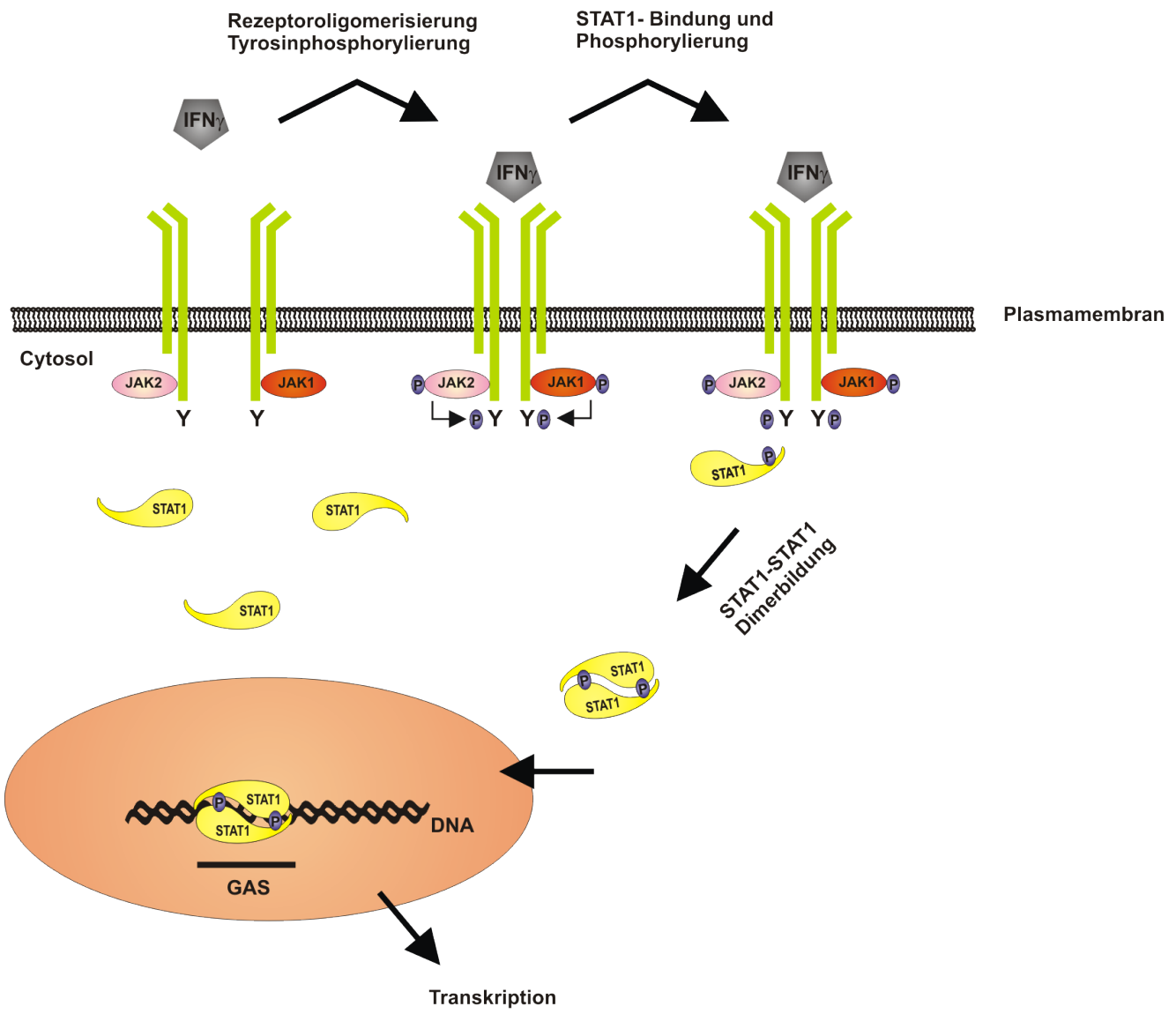

Abbildung 1.3: Der JAK-STAT-Signalweg (IFN $\gamma$-induzierte Zielgenaktivierung). Bindung von IFN $\gamma$ bewirkt Rezeptoroligomerisierung, Auto- und Transphosphorylierung der Kinasen JAK1 und JAK2 sowie die Phosphorylierung des Rezeptors. Die am kritischen Tyrosin-Rest phosphorylierten STAT1-Monomere bilden STAT1/STAT1-Homodimere, wandern in den Zellkern ein und induzieren durch Bindung an Gamma-aktivierende Sequenzen (GAS-Bindestelle) die Genaktivierung.

\subsubsection{Negative Regulation des JAK-STAT-Signalwegs}

Um eine überschießende Immunreaktion zu verhindern, unterliegt der JAK-STATSignalweg strikten regulatorischen und autoregulatorischen Prozessen (Wormald, Hilton 2004; Shuai, Liu 2005). Regulatorische Proteine greifen auf unterschiedlichen Ebenen des JAK-STAT-Signalwegs ein. Auf zytoplasmatischer Ebene agieren die konstitutiv exprimierten Tyrosinphosphatasen SHP-1, SHP-2 (SH2-containing phosphatase) und PTP1B. Durch Dephosphorylierung der JAK-Kinasen und ihren Rezeptoren unterbinden diese weitere STAT Phosphorylierung (Starr, Hilton 1999; Krebs, Hilton 2001; Levy, Darnell 2002; Wormald, Hilton 2004). SHP-2 hat zu ihrer zytoplasmatischen Aktivität eine zusätzliche nukleäre dephosphorylierende Aktivität. So wurde berichtet, dass SHP-2 im Zellkern mit aktiviertem STAT1 interagiert und dieses sowohl am Tyrosin als auch am Serinrest deaktiviert (Wu et al. 2002). 
Der weiteren zytoplasmatischen Negativregulierung der Signaltransduktion dienen die SOCS-Proteine 1-7 (suppressor of cytokine signaling) und CIS (cytokineinducible SH2-domain-containing protein). Aus der direkten Bindung an den Rezeptor bzw. an die katalytische Region der JAK-Kinasen resultiert eine Unterdrückung der Autophosphorylierung bzw. eine Hemmung der weiteren Tyrosinphosphorylierung der STAT-Proteine (Levy, Darnell 2002). Die Expression der SOCS-Proteine wird durch das Transkriptionsniveau der Zelle reguliert und unterliegt folglich einem negativen Feedbackmechanismus. Auf den Promotorregionen der SOCS-Proteine wurden bei weiteren Untersuchungen STAT-bindende Sequenzen identifiziert. Weiterhin wurde gezeigt, dass die mangelnde Phosphorylierung von STAT via mutierter JAK-Kinasen zu einem verminderten Expressionsniveau der SOCS-Proteine führt (Starr, Hilton 1999; Krebs, Hilton 2001; Larsen, Ropke 2002).

Die nukleäre Inhibition des JAK-STAT-Signalwegs erfolgt durch PIAS (protein inhibitor of activated STATs), welche aktivierte STAT-Proteine hemmen. Die Familie der PIAS-Proteine umfasst vier bekannte Mitglieder (PIAS1, PIAS2, PIAS3 und PIAS4) (Shuai, Liu 2005; Rytinki et al. 2009). Es wurde gezeigt, dass PIAS1 und STAT1 sowie PIAS3 und STAT3 spezifische Interaktionspartner darstellen (Chung 1997; Liu, Jiayu 1998; Starr, Hilton 1999). Durch die Bindung von PIAS an aktivierte STAT-Dimere wird deren transkriptionelle Aktivität gehemmt (Liao et al. 2000). Im Gegensatz zu den SOCS-Proteinen werden PIAS-Proteine konstitutiv exprimiert (Starr, Hilton 1999; Larsen, Ropke 2002). PIAS stellen keine exklusiven Interaktionspartner der STAT-Proteine dar. Vielmehr haben sie eine wichtige Rolle in der post-translationalen Modifikation von Proteinen und in der Rekrutierung von transkriptionellen Ko-Aktivatoren. Darüber hinaus wurde gezeigt, dass PIAS als E3-Enzym die Sumoylierung von Proteine fördern (Levy, Darnell 2002; Shuai, Liu 2005; Rytinki et al. 2009).

\subsubsection{Nukleärer Import und Export von STAT-Proteinen}

Beim JAK-STAT-Signalweg kommt es durch extrazelluläre Zytokinstimulation zur Dimerisierung des Rezeptors und durch eine Kaskade von Tyrosinphosphorylierungen zur Aktivierung und Dimerbildung von latent im Zytoplasma befindlichen STAT-Monomeren (Darnell et al. 1994). Die entstandenen Dimere gelangen in den Zellkern, wo sie durch Bindung an spezifische DNA-Sequenzen die Genexpression STAT-abhängiger Zielgene initiieren (Darnell et al. 1994; Levy, Darnell 2002). Der Transport von Molekülen vom Zytoplasma in den Zellkern geschieht über den sogenannten nukleären Porenkomplex (NPC), welcher als Filter für den nukleären Transport höher molekularer Makromoleküle dient. Ionen und Moleküle bis zu einer Größe von 40-60 kDa können den NPC durch freie Diffusion passieren (Rout, Wente 1994; Mattaj, Englmeier 1998; Weis 1998; Meyer, Vinkemeier 2004). Größere 
Makromoleküle wie die STAT-Dimere bedürfen aufgrund ihres größeren molekularen Gewichts ( 180 kDa) eines aktiven Transportmechanismus (Nigg 1997; Weis 1998; Mattaj, Englmeier 1998).

Der nukleäre Porenkomplex fungiert als eine Art Tunnel durch die Kernmembran bestehend aus Nukleoporinen. Diese weisen phenylalanin- und glycinreiche Sequenzen auf, welche die Interaktion zwischen Nukleoporinen und löslichen Transportrezeptoren übernehmen (Fahrenkrog et al. 2004; Wente, Rout 2010). Diese löslichen Transportfaktoren lassen sich in die Gruppe der Importine und der Exportine untergliedern, die zur Gruppe der Karyopherine zählen (Macara 2001). Jene erkennen Kargoproteine über spezifische NLS-Sequenzen (nukleäres Lokalisationssignal), binden an Nukleoporine und importieren diese in den Nukleus (Weis 1998; Macara 2001).

Bei der Familie der STAT-Proteine konnte kein klassisches NLS nachgewiesen werden. Stattdessen wurde gezeigt, dass STAT1- und STAT2-Proteine einen konservierten arginin- und lysinreichen Abschnitt im Bereich der DNA-Bindedomäne besitzen, ein dimerspezifisches NLS (dsNLS), welches als Erkennungssignal für den nukleären Import dient (Melen et al. 2001; Fagerlund et al. 2002). Voraussetzend für die Interaktion zwischen Importinen und STAT-Proteinen ist ein phosphoryliertes, als Dimer vorliegendes STAT-Protein, da das dsNLS den Importinen nur in Dimerkonfiguration zugänglich ist (Mowen, David 1998; Meyer et al. 2002; Fagerlund et al. 2002). STAT-Dimere gehen dabei einen Komplex mit Importin- $\alpha 5$-Molekülen ein. Der durch weitere Bindung eines Importin- $\beta$ gebildete NLS-haltige KargoproteinImportin- $\alpha$ - $\beta$-Komplex tritt mit den Nukleoporinen in Wechselwirkung und leitet den nukleären Import ein (Görlich et al. 1995; Fagerlund et al. 2002; McBride et al. 2002). Die für den nukleozytoplasmatischen Transport von STAT-Proteine benötigte Energie liefert die Ran-GTPase (Mattaj, Englmeier 1998; Görlich, Kutay 1999; McBride, Reich 2003; Meyer, Vinkemeier 2004).

In der Coiled-coil-Domäne des STAT-Proteins wurde ein spezifisches leucinreiches nukleäres Exportsignal (NES) entdeckt, welches mit dem Exportin CRM1 (chromosome region maintenance 1) in Verbindung tritt und somit durch die Kernporen zurück ins Zytoplasma geschleust werden kann (Mattaj, Englmeier 1998; Begitt et al. 2000; Levy, Darnell 2002; Meyer et al. 2003). Für den nukleären Export müssen STAT-Moleküle in unphosphoryliertem Zustand vorliegen. Anhand von vorausgegangenen Veröffentlichungen über die Linker-Domäne konnte gezeigt werden, dass diese am nukleären Transport von unphosphoryliertem STAT1 beteiligt ist (Marg et al. 2004). In dem Prozess der Dephosphorylierung sind nukleäre Phosphatasen, wie die TC45 (T-cell PTP) beteiligt (Haspel et al. 1996; Levy, Darnell 2002; ten Hoeve et al. 2002). DNA-gebundene STAT-Dimere sind vor enzymatischem Angriff durch Tyrosin-Phosphatasen geschützt und können nur im ungebundenen Zustand von 
ihnen erkannt und dephosphoryliert werden (Meyer et al. 2003). McBride veröffentlichte, dass CRM1 als Hauptexportin für den nukleären Export von STAT-Proteinen verantwortlich ist und dass dessen Hemmung mit Leptomycin B (LMB) die Relokalisation von STAT-Proteinen ins Zytoplasma verzögert (McBride et al. 2000), jedoch nicht vollständig unterbinden kann.

\subsection{Fragestellung}

In dieser Arbeit werden die Auswirkungen von Punktmutationen in der LinkerDomäne auf die physiologischen Eigenschaften des STAT1-Proteins untersucht. Dafür wurden an ausgewählten, hoch konservierten Stellen in der Sequenz des STAT1Proteins Punktmutationen nach Alanin eingeführt. Anschließend wurde der Grad der Interferon-induzierten Phosphorylierung der STAT1-Mutanten, die Fähigkeit der DNA-Bindung, die transkriptionelle Aktivität (in vivo und in vitro) sowie die Fähigkeit zur Kernakkumulation näher betrachtet. 


\section{Material und Methoden}

\subsection{Methoden}

Im Folgenden werden die für diese Arbeit verwendeten Materialien aufgeführt.

\subsubsection{Humane Zelllinien}

$\begin{array}{lll}\text { HeLa-S3 } & \begin{array}{l}\text { Humane Epithelzellinie eines } \\ \text { Zervixkarzinoms }\end{array} & \begin{array}{l}\text { zur Verfügung gestellt von Prof. } \\ \text { Dr. U. Vinkemeier, University of } \\ \text { Nottingham, UK }\end{array} \\ \text { U3A } & \begin{array}{l}\text { STAT1-defiziente Zellinie, aus } \\ \text { 2fTGH entstanden (Fibrosarkom- Verfügung gestellt von Prof. } \\ \text { Zelllinie) }\end{array}\end{array}$

\subsubsection{Chemikalienliste}

$\begin{array}{ll}\text { Agar } & \text { Carl Roth, Karlsruhe } \\ \text { Ammoniumperoxodisulfat (APS) } & \text { Carl Roth } \\ \text { Ampicillin } & \text { Sigma-Aldrich, Taufkirchen } \\ \text { Borsäure } & \text { Amersham Pharmacia Biotech, Frei- } \\ & \text { burg } \\ \text { Bromphenol-Blau } & \text { Sigma-Aldrich } \\ \text { Dimethylsulfoxid (DMSO) } & \text { Carl Roth } \\ \text { Dithiothreitol (DTT) } & \text { AppliChem, Darmstadt } \\ \text { Ethanol } & \text { Carl Roth } \\ \text { Ethylendiamin-N,N,N',N'- } & \text { Acros Organics, Geel, Belgien } \\ \text { Tetraessigsäure (EDTA) } & \\ \text { Ethylendioxy-bis-(ethylennitrilo)- } & \text { Carl Roth } \\ \text { tetraessigsäure (EGTA) } & \\ \text { Ficoll-Paque Plus } & \text { Amersham Bioscience, Freiburg } \\ \text { Formaldehyd } 37 \% \text { in } \mathrm{H}_{2} 0 & \text { Sigma-Aldrich } \\ \text { Glucose } & \text { Carl Roth } \\ \text { Glycin } & \text { Carl Roth }\end{array}$




\begin{tabular}{|c|c|}
\hline Glycerin & Carl Roth \\
\hline Glycylglycin & Sigma-Aldrich \\
\hline $\begin{array}{l}\text { N-(2-Hydroxyethyl)-1-piperazino- } \\
\text { ethansulfonsäure (Hepes) }\end{array}$ & Carl Roth \\
\hline Hefeextrakt & Carl Roth \\
\hline IGEPAL-CA-360 & Sigma-Aldrich \\
\hline Kaliumchlorid & Carl Roth \\
\hline Kaliumdihydrogenphosphat & Merck \\
\hline Kaliumhydroxid & Carl Roth \\
\hline Kanamycin & Sigma-Aldrich \\
\hline Magnesiumchlorid-6-hydrat & Sigma-Aldrich \\
\hline Magnesiumsulfat & Carl Roth \\
\hline$\beta$-Mercaptoethanol & Sigma-Aldrich \\
\hline Methanol & Carl Roth \\
\hline Natriumcarbonat & Carl Roth \\
\hline Natriumchlorid & Sigma-Aldrich \\
\hline Natriumhydrogenphosphat & Merck \\
\hline Natriumdodecylsulfat (SDS) & Carl Roth \\
\hline Natrium-ortho-vanadat & Sigma-Aldrich \\
\hline $\begin{array}{l}\text { ortho-Nitrophenyl- } \beta \text {-D-Galactopyranosid } \\
\text { (ONPG) }\end{array}$ & Sigma-Aldrich \\
\hline Pefabloc & Carl Roth \\
\hline 2-Propanol & Carl Roth \\
\hline Rinder-Serumalbumin (BSA) & Carl Roth \\
\hline Rotiphorese & Carl Roth \\
\hline Salzsäure & Carl Roth \\
\hline Staurosporin & Sigma-Aldrich \\
\hline $\begin{array}{l}\text { N,N,N`,N`,-Tetramethylethylendiamin } \\
(\text { TEMED) }\end{array}$ & Carl Roth \\
\hline Tris-Hydrochlorid (Tris-HCl) & Carl Roth \\
\hline $\begin{array}{l}\text { Tris-(hydroxymethyl)-aminomethan } \\
\text { (Tris-Base) }\end{array}$ & Carl Roth \\
\hline Triton X-100 & Sigma-Aldrich \\
\hline Trypton & Carl Roth \\
\hline Tween-20 & Sigma-Aldrich \\
\hline Wasserstoffperoxid $\left(\mathrm{H}_{2} \mathrm{O}_{2}\right)$ & Carl Roth \\
\hline
\end{tabular}




\subsubsection{Radiochemikalien}

Die von der Firma Hartmann Analytic (Braunschweig) stammenden $\alpha-\left[{ }^{32} \mathrm{P}\right]$ markierten Desoxynukleotide besitzen eine spezifische Aktivität von 111 TBq (3000Ci/mmol). Diese wurden vor dem Ablauf ihrer Halbwertszeit eingesetzt.

\subsubsection{Puffer, Lösungen und Medien}

Für die Herstellung von Puffern, Lösungen und Medien wurde entionisiertes Wasser verwendet. Dieses stammt aus der Millipore Anlage PURELAB Plus (ELGA, Celle) mit einem Molekülfilter der Porengröße von $22 \mathrm{~mm}$. Der spezifische pH-Wert wurde mit einem pH-Meter (Sartorius, Göttingen) eingestellt. Bei Bedarf wurden einzelne Lösungen steril filtriert.

\subsubsection{Antikörper}

$\begin{array}{ll}\text { STAT1 } \alpha \text {-p91 (C-24) } & \text { Santa Cruz Biotechnology, Santa Cruz, } \\ & \text { CA, USA } \\ \text { Phospho-STAT1 (Tyr 701) } & \text { Cell Signaling, Danvers, MA, USA } \\ \text { STAT3 (H-190) } & \text { Santa Cruz Biotechnology } \\ \text { IRDye 800 CW Anti-Kaninchen-IgG } & \text { LI-COR Bioscience, Bad Homburg } \\ \text { aus Ziege } & \\ \text { Cy3-gekoppelter Anti-Kaninchen-IgG } & \text { Jackson ImmunoResearch, Suffolk, UK } \\ \text { aus Ziege } & \end{array}$

Für die Western-Blot-Experimente wurden der polyklonale Antikörper STAT1 $\alpha$-p91 (C-24) und der Phospho-STAT1 (Tyr 701) als Primärantikörper eingesetzt und im Verhältnis 1:2000 bzw. 1:000 in 4 \% BSA in TBS-T (137 mM NaCl, 10 mM Tris$\mathrm{HCl}, 0,05 \%$ Tween-20, pH 7,3) verdünnt. Als Sekundärantikörper für die WesternBlot-Experimente diente jeweils der polyklonale IRDye $800 \mathrm{CW}$ Anti-KaninchenIgG Antikörper aus Ziege. Dieser wurde hierfür in einem Verhältnis von 1:10.000 ebenfalls in $4 \%$ BSA in TBS-T verdünnt. Für die Supershift-Reaktion bei EMSAExperimenten wurden die STAT1 $\alpha$-p91 (C-24) und STAT3 (H190) Antikörper in der Verdünnung 1:10 (in PBS, Gibco, Karlsruhe) verwendet. Für den Immunfluoreszenzversuch wurde der STAT1 $\alpha$-p91 Antikörper (C-24) im Verhältnis 1:1000 in 25 \% FCS (fetales Kälberserum) in PBS verdünnt. In diesem Fall diente der Cy3gekoppelte Anti-Kaninchen-IgG als Zweitantikörper, ebenfalls in $25 \%$ FCS in PBS in einer Verdünnung von 1:500. 


\subsubsection{Reaktionskits}

$\begin{array}{ll}\text { Absolute-Blue-QPCR-SYBR-Green Mix } & \text { Thermo Scientific, Dreieich } \\ \text { Luciferase-Assay-System } & \text { Promega, Mannheim } \\ \text { peqGold Plasmid Miniprep Kit I } & \text { PEQLAB Biotechnologie, Erlan- } \\ & \text { gen } \\ \text { peqGold Total RNA Kit } & \text { PEQLAB Biotechnologie } \\ \text { QIAGEN Plasmid Maxi Kit } & \text { QIAGEN, Hilden } \\ \text { QuikChange II Site-Directed Mutagenesis Kit } & \text { Stratagene, La Jolla, USA } \\ \text { Verso cDNA Kit } & \text { Thermo Scientific }\end{array}$

\subsubsection{Zytokine}

Die Zellen wurden ausschließlich mit humanem IFN $\gamma$ stimuliert. Das hierfür verwendete IFN $\gamma$ stammt von der Firma Biomol (Hamburg). Sofern nicht anders angegeben wurde IFN $\gamma$ im Verhältnis 1:1000 im dazugehörigen Zellkulturmedium verdünnt und direkt auf die Zellen pipettiert.

\subsubsection{Plasmide}

$\begin{array}{ll}\text { pEGFP-N1 } & \text { optimierter Vektor mit verbes- Clonetech, Mountain } \\ & \text { serter Fluoreszenz zur Expres- View, USA } \\ & \text { sion von N-terminalen GFP- } \\ & \text { Fusionsplasmiden in Säugerzellen } \\ \text { pSTAT1 } \alpha \text {-GFP } & \text { Humane STAT1 } \alpha \text {-cDNA (AS 1- (Begitt et al. 2000) } \\ & 747) \text { in pEGFP-N1 } \\ \operatorname{pSTAT1} \alpha(\text { W504A)- } & \text { durch sequenzspezifische Muta- diese Arbeit } \\ \text { GFP } & \text { tion entstandenes Derivat, ver- } \\ & \text { wendetes Primerpaar W504AF / } \\ & \text { W504AR } \\ \text { pSTAT1 } \alpha(\text { F506A)- } & \text { durch sequenzspezifische Muta- diese Arbeit } \\ \text { GFP } & \text { tion entstandenes Derivat, ver- } \\ & \text { wendetes Primerpaar F506AF / } \\ & \text { F506AR } \\ \text { durch sequenzspezifische Muta- diese Arbeit } \\ \text { tion entstandenes Derivat, ver- } \\ \text { GFP } & \text { wendetes Primerpaar W539AF / } \\ & \text { W539AR }\end{array}$




\begin{tabular}{|c|c|c|}
\hline $\begin{array}{l}\operatorname{pSTAT} 1 \alpha(\mathrm{F} 554 \mathrm{~A})- \\
\text { GFP }\end{array}$ & $\begin{array}{l}\text { durch sequenzspezifische Muta- } \\
\text { tion entstandenes Derivat, ver- } \\
\text { wendetes Primerpaar F554AF / } \\
\text { F554AR }\end{array}$ & it \\
\hline pcDNA3.1 & eukaryotischer Expressionsvektor & Invitrogen \\
\hline pcDNA3.1-STAT1 $\alpha$ & $\begin{array}{l}\text { humane STAT1 } \alpha \text {-cDNA kloniert } \\
\text { in pcDNA3.1 }\end{array}$ & $\begin{array}{l}\text { Dr. James E. Dar- } \\
\text { nell, New York, USA }\end{array}$ \\
\hline $\begin{array}{l}\text { pcDNA3.1- } \\
\text { STAT1 } \alpha(\text { W504A })\end{array}$ & $\begin{array}{l}\text { durch sequenzspezifische Muta- } \\
\text { tion entstandenes Derivat, ver- } \\
\text { wendetes Primerpaar W504AF / } \\
\text { W504AR }\end{array}$ & diese Arbeit \\
\hline $\begin{array}{l}\text { pcDNA3.1- } \\
\operatorname{STAT} 1 \alpha(\mathrm{F} 506 \mathrm{~A})\end{array}$ & $\begin{array}{l}\text { durch sequenzspezifische Muta- } \\
\text { tion entstandenes Derivat, ver- } \\
\text { wendetes Primerpaar F506AF / } \\
\text { F506AR }\end{array}$ & diese Arbeit \\
\hline $\begin{array}{l}\text { pcDNA3.1- } \\
\text { STAT1 } \alpha(\text { W539A })\end{array}$ & $\begin{array}{l}\text { durch sequenzspezifische Muta- } \\
\text { tion entstandenes Derivat, ver- } \\
\text { wendetes Primerpaar W539AF / } \\
\text { W539AR }\end{array}$ & diese Arbeit \\
\hline $\begin{array}{l}\text { pcDNA3.1- } \\
\text { STAT1 } \alpha(\mathrm{F} 554 \mathrm{~A})\end{array}$ & $\begin{array}{l}\text { durch sequenzspezifische Muta- } \\
\text { tion entstandenes Derivat, ver- } \\
\text { wendetes Primerpaar F554AF / } \\
\text { F554AR }\end{array}$ & \\
\hline $\mathrm{p} \beta \mathrm{Gal}$ & $\begin{array}{l}\text { Expressionsvektor der } \quad \beta \text { - } \\
\text { Galaktosidase }\end{array}$ & $\begin{array}{l}\text { Stratagene, La Jolla, } \\
\text { USA }\end{array}$ \\
\hline pGAS3xLy6E & $\begin{array}{l}\text { Reportergenkonstrukt mit drei } \\
\text { GAS-Bindestellen }\end{array}$ & Wen et al., 1995 \\
\hline pIC-339 & $\begin{array}{l}\text { Reportergenvektor mit dem trun- } \\
\text { kierten Promotor des humanen } \\
\text { ICAM-1-Gens }\end{array}$ & $\begin{array}{l}\text { Prof. Dr. P. T. van } \\
\text { der Saag, Utrecht, } \\
\text { Niederlande }\end{array}$ \\
\hline pIC-1352 & $\begin{array}{l}\text { Reportergenvektor mit dem Pro- } \\
\text { motor des humanem ICAM-1- } \\
\text { Gens }\end{array}$ & $\begin{array}{l}\text { Prof. Dr. P. T. van } \\
\text { der Saag }\end{array}$ \\
\hline
\end{tabular}

In dieser Arbeit wurden ausschließlich Plasmide verwendet, die für STAT1 $\alpha$ kodieren. Plasmide werden aus diesem Grund im weiteren Verlauf als pSTAT1 bezeichnet. Ferner steht der Zusatz -GFP (grün fluoreszierendes Protein) für die Verwendung von pSTAT1 $\alpha$-GFP Plasmiden und diese Plasmide werden im weiteren Verlauf als pSTAT1-GFP bezeichnet. Das pcDNA3.1-STAT1 $\alpha$ wurde unter dem Akronym pSTAT1 verwendet. 


\subsubsection{Oligonukleotide}

Folgende Primer wurden für die sequenzspezifische Mutagenese verwendet:

$\begin{array}{ll}\text { Name } & \text { Sequenz } \\ \text { W504A F } & 5^{\prime} \text {-ctttcagaagtgctgagtgcgcagtttcttctgtcac-3' } \\ \text { W504A R } & 5^{\prime} \text {-gtgacagaagaaaactgcgcactcagcacttctgaaag-3' } \\ \text { F506A F } & 5^{\prime} \text {-gtgctgagttggcaggcttcttctgtcaccaaaagagg-3' } \\ \text { F506A R } & 5^{\prime} \text {-cttcttttggtgacagaagaagcctgccaactcagcac-3' } \\ \text { W539A F } & 5^{\prime} \text {-ccgatggtctcattccggccacgaggttttgtaagg-3' } \\ \text { W539A R } & 5^{\prime} \text {-ccttacaaaacctcgtcgccggaatgagaccatcggg-3' } \\ \text { F554A F } & 5^{\prime} \text {-gataaaaattttccegctggctttggattgaaagcatc-3' } \\ \text { F554A R } & 5^{\prime} \text {-gatgctttcaatccaaagccaggcgggaaaatttttatc-3' }\end{array}$

Als Primer für die Sequenzierung diente:

$\begin{array}{ll}\text { Name } & \text { Sequenz } \\ 484 \mathrm{~F} & 5^{\prime} \text {-cettcttcctgactccacca-3' }\end{array}$

Oligonukleotid-Sonden für den elektrophoretischen Mobilitäts-Shift-Assay sind die Folgenden:

$\begin{array}{ll}\text { Name } & \text { Sequenz } \\ \text { M67 F } & \text { 5'-ttttcgacatttcccgtaaatctg-3' } \\ \text { M67 R } & \text { 5'-ttttcagatttacgggaaatgtcg-3' } \\ \text {-nonGAS F } & \text { 5'-ttttcgtttcccgaaattgacggatttaccccaac-3' } \\ \text { GAS-nonGAS R } & 5^{\prime} \text {-ttttgttggggtaaatccgtcaatttcggggaaacg-3' } \\ \text { 2xGAS F } & 5^{\prime} \text {-tttttgtttccccgaaattgacggatttccccgaaac-3' } \\ \text { 2xGAS R } & \text { 5'-tttttgtttcggggaaatccgtcaatttcggggaaac-3' } \\ \text { 2xnonGAS F } & \text { 5'-ttttcgtttacccaaattgacggatttaccccaac-3' } \\ \text { 2xnonGAS R } & \text { 5'-ttttgttggggtaaatccgtcaatttggggtaaacg-3' }\end{array}$

\subsubsection{Bakterienstämme und Medien}
E. $\operatorname{coli} \mathrm{DH} 5 \alpha$
Stratagene, La Jolla, USA
Genotyp: F- $\phi$ 80dlacZDM15 D(lacZYA-argF) U169 recA1 endA1 hsdR17(rk- mk+) phoA supE44 $\lambda$ thi-1 gyrA96 re- lA1
E. coli XL1-Blue
Stratagene
Genotyp: recA1 endA1 gyrA96 thi-1 hsdR17 supE44 relA1 lac [F'proAB $\left.\lambda \alpha \chi \Gamma \mathrm{Z} \Delta \mathrm{M} 15 \operatorname{Tn} 10\left(\mathrm{Tet}^{\mathrm{r}}\right)\right]$ 
Die Bakterienstämme wurden entweder auf LB-Agarplatten in LB-Flüssigmedium oder in SOC-Medium angezüchtet. Dabei waren die Platten und Medien wie folgt zusammengesetzt: LB-Agarplatten: $1 \%$ Trypton, 0,5 \% Hefeextrakt und 1,5\% Agar. LB-Flüssigmedium: $1 \%$ Trypton, 0,5\% Hefeextrakt und $1 \% \mathrm{NaCl}$. Beide wurden mit $\mathrm{NaOH}$ auf einen $\mathrm{pH}$-Wert von 7,0 eingestellt und anschließend bei $121^{\circ} \mathrm{C}$ und 1,5 bar autoklaviert. Für die LB-Agarplatten wurde dem LB-Medium zusätzlich $15 \mathrm{~g} / \mathrm{L}$ Agar hinzugefügt. Sowohl zu dem LB-Medium als auch zu dem LB-Agar-Medium wurde nach dem Autoklavieren und Abkühlen Kanamycin $(50 \mu \mathrm{g} / \mathrm{mL})$ bzw. Ampicillin $(100 \mu \mathrm{g} / \mathrm{mL})$ als Selektionsmarker hinzugegeben. Das für die Transformation erforderliche SOC-Medium hatte folgende Zusammensetzung: 2 \% Trypton, 0,5 \% Hefeextrakt, $10 \mathrm{mM} \mathrm{NaCl}, 2,5 \mathrm{mM} \mathrm{KCl}, 10 \mathrm{mM} \mathrm{MgCl}_{2}, \mathrm{MgSO}_{4}, \mathrm{pH} 7,4$. Nach 20-minütiger Autoklavierung wurde dem Medium steril gefilterte Glucose in einer Endkonzentration von $20 \mathrm{mM}$ zugesetzt.

\subsubsection{Geräte und Verbrauchsmaterialien}

Sämtliche Geräte und Verbrauchsmaterialien, die in dieser Arbeit verwendet wurden, sind bei der Beschreibung der einzelnen Methoden angegeben. Falls nicht weiter angegeben, stammten die Verbrauchsmaterialien von folgenden Firmen: B.Braun (Melsungen), Biometra (Göttingen), Carl Roth (Karlsruhe), Eppendorf (Hamburg), Greiner Bio-One (Frickenhausen), Nunc (Roskilde, Dänemark), PEQLAB (Erlangen), Sarstedt (Nümbrecht), Thermo-Fisher (Dreieich) und VWR (Darmstadt).

\subsection{Zellkulturmethoden}

\subsubsection{Kultivierung von Säugerzellen}

In dieser Arbeit wurde mit zwei humanen Zelllinien gearbeitet: U3A- und HeLa-S3Zellen. Die Zellkulturarbeiten erfolgten aseptisch unter mikrobiologischen Sicherheitswerkbänken (Herasafe K2, Thermo Scientific, Dreieich). Die Zellkultivierung erfolgte im Brutschrank (Heraus, Thermo Scientific) bei $37^{\circ} \mathrm{C}$ in einer mit Wasserdampf gesättigten $5 \%$-igen $\mathrm{CO}_{2}$-Atmosphäre in $75 \mathrm{~cm}^{2}$ Zellkulturflaschen (Cellstar, Greiner Bio-One, Frickenhausen). Die Vollmedien waren wie folgt zusammengesetzt:

- U3A-Zellen, Dulbeccos modifiziertem Eagle Medium (DMEM, Biochrom, Berlin) supplementiert mit $10 \%$ fetalem Kälberserum (FCS) (Biochrom), $1 \%$ Penicillin-Streptomycin (PAA, Pasching, Österreich) und 0,04 $\mu \mathrm{g} / \mathrm{mL}$ Puromycin (Sigma-Aldrich, Taufkirchen).

- HeLa-Zellen, Quantum 101 HeLa - Medium (PAA) mit 1 \% PenicillinStreptomycin (PAA). 


\subsubsection{Zellpassage}

Das Passagieren der adhärenten Zellen erfolgte alle zwei bis drei Tage. Dafür wurden die Zellen einmal mit Phosphat-gepufferter Salzlösung (PBS ohne $\mathrm{Ca}^{2+}$ und $\mathrm{Mg}^{2+}$ ) gewaschen und anschließend mit einer EDTA-Lösung (0,05\% Trypsin, 0,2 g/L EDTA, Biochrom) inkubiert und somit vom Boden der Zellkulturflasche gelöst. Die Trypsinreaktion wurde nach kurzer Inkubation bei $37^{\circ} \mathrm{C}$ im Brutschrank durch die Zugabe von serumhaltigem Vollmedium gestoppt und die Zellen im Verhältnis 1:4 bis 1:6 ausplattiert.

\subsubsection{Einfrieren und Auftauen von Zellen}

Bei einer Konfluenz von $\sim 70 \%$ wurden die Zellen einmalig mit DBPS gewaschen, trypsinisiert und in PBS aufgenommen. Anschließend wurden die Zellen durch Zentrifugation für $10 \mathrm{~min}$ bei $10.000 \mathrm{rpm}$ und $20^{\circ} \mathrm{C}$ pelletiert (Centrifuge $5415 \mathrm{R}$, Eppendorf). Das entstandene Pellet aus einer $75 \mathrm{~cm}^{2}$-Zellkulturflaschen wurde in $1 \mathrm{~mL}$ Einfriermedium (20 \% FCS, 10 \% Dimethylsulfoxid in DMEM) resuspendiert und über Nacht in einem mit Isopropanol (Carl Roth) gefüllten Gefriercontainer (Nalgene, Heidelberg) bei $-80^{\circ} \mathrm{C}$ gelagert. Alternativ kann der Gefriercontainer auch in flüssigem Stickstoff gelagert werden. Mithilfe dieses Kühlsystems wurden die Zellen $-1 \mathrm{C}^{\circ}$ bis $-3 \mathrm{C}^{\circ}$ pro Stunde herunter gekühlt. Die langsame Kühlung und die Verwendung von DMSO verhindert die intrazelluläre Eiskristallbildung und somit eine durch das Einfrieren generierte Zellschädigung. Die Zellen wurden in einem Wasserbad bei $37^{\circ} \mathrm{C}$ wieder aufgetaut, um im jeweiligen Vollmedium aufgenommen zu werden. Die Resuspension wurde bei $1000 \mathrm{rpm}$ und $20^{\circ} \mathrm{C}$ für $5 \mathrm{~min}$ zentrifugiert und der Überstand verworfen. Das entstandene Pellet wurde erneut in Vollmedium resuspendiert und die Zellen wieder in Kultur genommen.

\subsubsection{Transfektion von Säugerzellen}

Für die Transfektion der humanen Zelllinien (U3A-Zellen und HeLa-Zellen) mit Plasmid-DNA wurde für diese Arbeit das Transfektionsreagenz MegaTran (Origen, Rockville, USA) verwendet. Die Transfektion erfolgte hierbei gemäß den Herstellerangaben. Für eine 6-Lochplatte wurden demnach je Loch 1,6 $\mu \mathrm{g}$ Plasmid-DNA, bei einer 48-Lochplatte je Loch 0,25 $\mu \mathrm{g}$ Plasmid-DNA und bei einem 8-KammerObjektträger je 0,1 $\mu \mathrm{g}$ pro Kammer eingesetzt. Für den Transfektionsansatz wurde die DNA mit 150 mM NaCl-Lösung verdünnt, mit der jeweiligen Menge MegaTran versetzt, $10 \mathrm{sec}$ gevortext und anschließend für 10 min bei RT inkubiert. Der Ansatz wurde daraufhin direkt zu dem auf den Zellen befindliche Vollmedium gegeben. Nach 16-20 h wurde die Transfektionseffizienz der pSTAT-GFP-Konstrukte mittels Mikroskop (ZEISS, Axiovert 40 CFL) verifiziert und die STAT1-exprimierenden Zel- 
len weiterverarbeitet.

\subsubsection{Stimulation mit Zytokinen und Behandlung mit Inhibitoren}

Die verwendeten Zytokine und Inhibitoren wurden für die Stimulation bzw. Behandlung der Zellen immer im jeweiligen Zellmedium verdünnt, anschließend wurde die benötigte Menge direkt auf die Zellen pipettiert. Wenn nicht anders angegeben erfolgte die Stimulation der Zellen mit $10 \mathrm{ng} / \mathrm{mL}$ humanem rekombinanten IFN $\gamma$ (Biomol) und die Inhibition der Kinasen durch $1 \mu \mathrm{M}$ Staurosporin (Sigma-Aldrich). Die Tyrosinphosphatase wurde durch die Behandlung mit 0,8 mM Vanadat und 0,2 $\mathrm{mM} \mathrm{H} \mathrm{H}_{2} \mathrm{O}_{2}$ gehemmt. Die Herstellung einer 0,8 mM Stammlösung erfolgte dabei nach den Angaben von Kypta et al. (1988). Diese wurde auf einen pH-Wert von 10 eingestellt.

\subsection{Molekularbiologische Methoden}

\subsubsection{Mutagenese}

Mithilfe des QuikChange II Mutagenesis Kit wurde in STAT1-kodierende Plasmide eine Punktmutation eingeführt. Dies erfolgte nach Herstellerangaben. Der PCRAnsatz bestand aus $50 \mathrm{ng}$ Matrizen-DNA, $5 \mu \mathrm{L}$ 10x Reaktionspuffer, je $125 \mathrm{ng}$ komplementären Primer, 1 mL dNTP-Mix sowie 2,5 Einheiten PfuTurbo DNA Polymerase. Der Ansatz wurde mit $\mathrm{H}_{2} \mathrm{O}$ auf eine Gesamtmenge von $50 \mu \mathrm{L}$ aufgefüllt. Das PCR-Programm des T3000 Thermocylers (Biometra) umfasste eine initiale Denaturierungsphase von $30 \mathrm{sec}$ bei $95^{\circ} \mathrm{C}$. Darauf folgten 16 weiteren Zyklen bestehend aus einer Denaturierungsphase bei $95^{\circ} \mathrm{C}$, einem einminütigen Annealing-Schritt bei $55^{\circ} \mathrm{C}$ und einer 14-minütigen Elongation bei $68^{\circ} \mathrm{C}$. Es folgte ein einstündiger DpnI-Verdau bei $37^{\circ} \mathrm{C}$, um die Entfernung der parentalen methylierten DNA-Matrize sicherzustellen. Hierfür wurde das PCR-Amplifikat mit 10 Einheiten DpnI-Restriktionsenzym substituiert.

\subsubsection{Transformation von Plasmid-DNA in chemisch kompetente Bakterien}

Die Transformation von Plasmid-DNA in kompetente E. coli DH5 $\alpha$ bzw. in superkompetente XL1-blue E. coli-Bakterien erfolgte nach der Hitzeschockmethode (Cohen et al. 1972). Dafür wurden $50 \mu \mathrm{L}$ superkompetente XL1-blue E. coliBakterienzellen bzw. $100 \mu \mathrm{L}$ kompetente E. coli langsam auf Eis getaut. Zu der aufgetauten Bakteriensuspension wurde 10 ng Plasmid-DNA ( $1 \mu \mathrm{L}$ des Mutageneseprodukts) gegeben und für $30 \mathrm{~min}$ auf Eis inkubiert. Für den Hitzeschock bei 
$42^{\circ} \mathrm{C}$ wurden die DH5 $\alpha$-Bakterien für 30 sec, die XL1-Blue Bakterien für $45 \mathrm{sec}$ im Wasserbad, und anschließend 2 min auf Eis inkubiert. Darauffolgend wurde die Zellsuspension in $1000 \mu \mathrm{L}$ vorgewärmtes SOC-Medium aufgenommen und $1 \mathrm{~h}$ bei $225 \mathrm{rpm}$ und $37^{\circ} \mathrm{C}$ in den Inkubationsschüttler (Innova 42) gestellt. Ferner wurden $250 \mu \mathrm{L}$ der Bakterienkultur auf LB-Agarplatten mit dem jeweiligen Antibiotikum als Selektionsmarker ausplattiert und über Nacht bei $37^{\circ} \mathrm{C}$ inkubiert.

\subsubsection{Plasmid-DNA-Isolation aus Bakterien}

Analytische Präparation von Plasmid-DNA Für die analytische Präparation von Plasmid-DNA wurde eine einzelne transformierte Bakterienkolonie gepickt, in $2 \mathrm{~mL}$ LB-Medium mit entsprechendem Antibiotikum als Selektionsmarker inokuliert und für $7 \mathrm{~h}$ bei $225 \mathrm{rpm}$ und $37^{\circ} \mathrm{C}$ im Bakterienschüttler inkubiert. Anschließend wurde der komplette Inhalt in ein $2 \mathrm{~mL}$ Eppendorfgefäß überführt und bei RT und 13.000 rpm für 5 min sedimentiert. Mithilfe des peqGold Plasmid Miniprep Kit (PEQLAB Biotechnologie) wurde die Plasmid-DNA für die spätere Sequenzierung aus dem Pellet isoliert. Dies erfolgte nach den Herstellerangaben.

Gewinnung von Plasmid-DNA für präparative Zwecke Nach Bestätigung der Mutation wurde ein präparativer Ansatz gewählt, um große Mengen Plasmid-DNA zu isolieren. Hierfür wurden $150 \mathrm{~mL}$ LB-Medium mit entsprechendem Selektionsmarker versetzt und mit einer einzelnen transformierten Bakterienkolonie inokuliert. Der Ansatz wurde über Nacht bei $37^{\circ} \mathrm{C}$ und $225 \mathrm{rpm}$ im Bakterienschüttler inkubiert. Schließlich folgte eine Zentrifugation der Zellsuspension bei $6000 \mathrm{~g}$ und RT für 15 min sowie eine Isolation der Plasmid-DNA mithilfe des QIAGEN Plasmid Maxi Kit (QIAGEN, Hilden) nach Herstellerangaben. Nach Eluation der DNA in $\mathrm{H}_{2} \mathrm{O}$ wurde die Konzentration bestimmt (siehe unten) und mit $\mathrm{H}_{2} \mathrm{O}$ auf $1 \mu \mathrm{g} / \mu \mathrm{L}$ verdünnt. Die verdünnte DNA wurde aliquotiert und bei $-20^{\circ} \mathrm{C}$ gelagert.

\subsubsection{Sequenzierung}

Zur Bestätigung der eingefügten Punktmutation wurde bei allen Mutationen eine Sequenzierung der Plasmid-DNA vorgenommen. Diese erfolgte über SeqLabSequence Laboratories (Göttingen). Für den Ansatz wurden 700 ng Plasmid-DNA und 20 pmol des jeweiligen Sequenzierprimers gemischt und die Probe mittels $\mathrm{H}_{2} \mathrm{O}$ auf ein Gesamtvolumen von $7 \mu \mathrm{L}$ aufgestockt.

\subsubsection{Bestimmung der Plasmid-DNA-Konzentration}

Die Bestimmung der Plasmid-DNA-Konzentration erfolgte photometrisch bei einer Wellenlänge von $\lambda=260 \mathrm{~nm}$. Dafür wurde eine $70 \mathrm{~mL}$ UV-Küvette (Brand, 
Wertheim) und ein BioPhotometer Plus (Eppendorf) verwendet. Die Konzentration wurde wie folgt berechnet: DNA-Konzentration $[\mu \mathrm{g} / \mu \mathrm{L}]=\mathrm{A}_{260} \times 50 \times$ Verdünnungsfaktor. Eventuelle Verunreinigungen lassen sich bei der Absorption bei $\lambda=$ $280 \mathrm{~nm}$ und der Berechnung des Quotienten $\mathrm{A}_{260} / \mathrm{A}_{280}$ nachweisen. Bei reinen, nicht kontaminierten Proben beträgt dieser Quotient $\sim 1,8$.

\subsubsection{Aufarbeitung von Zellen und Herstellung von Gesamtzellextrakten}

In dieser Arbeit wurden sowohl bei Western-Blot-Analysen als auch bei EMSAExperimenten und In-vitro-Phosphorylierungsversuchen Gesamtzellextrakte benötigt. Dabei fand die gesamte Aufarbeitung der Zellen auf Eis statt. Die zuvor behandelten Zellen wurden zunächst mit PBS gewaschen und anschließend mit $50 \mu \mathrm{L}$ eiskaltem zytosolischen Extraktionspuffer per Loch (20mM Hepes, pH 7,4, $10 \mathrm{mM}$ $\mathrm{KCl}, 10 \%$ (v/v) Glycerin, $1 \mathrm{mM}$ EDTA, 0,1 $\mathrm{mM} \mathrm{Na}_{3} \mathrm{VO}_{4}$ ) lysiert. Unmittelbar vor der Verwendung wurden dem zytosolischen Extraktionspuffer 0,1 \% IGEPALCA-360, 3 mM DTT, 0,4 Pefabloc und Complete-Mini-Protease-Inhibitoren hinzugefügt. Nach erfolgter Inkubation wurden die lysierten Zellen mit einem Zellschaber gelöst und in ein 1,5 mL Reaktionsgefäß überführt. Die Zelllysate wurden direkt im Anschluss bei $16.000 \mathrm{~g}$ und $4^{\circ} \mathrm{C}$ für $15 \mathrm{sec}$ zur Sedimentierung der Zellkerne zentrifugiert und die durch das Zentrifugieren entstandenen Zellpellets auf Eis gelagert. Die Überstände wurden in neue 1,5 mL Reaktionsgefäße überführt und bei 16.000 $\mathrm{g}$ und $4^{\circ} \mathrm{C}$ für 5 min zentrifugiert. Dabei handelt es sich um den zytosolischen Teil der Gesamtextrakte. Diese wurden entweder mit äquivalenter Menge an nukleären Gesamtzellextrakten gemischt oder bei $-80^{\circ} \mathrm{C}$ für weitere Experimente eingefroren. Das während der ersten Zentrifugation entstandene Zellpellet wurde mit je $50 \mu \mathrm{L}$ nukleärem Extraktionspuffer (20 mM Hepes, 420 mM KCl, 20 \% (v/v) Glycerin, 1 mM EDTA, 0,1 $\mathrm{mM} \mathrm{Na}_{3} \mathrm{VO}_{4}$, pH 7,4) resuspendiert und für 30 min auf Eis inkubiert. Der nukleäre Extraktionspuffer wurde ebenfalls kurz vor Anwendung mit 3 mM DTT, 0,4 mM Pefabloc und Complete-Mini-Protease-Inhibitoren komplementiert. Auf die Inkubation erfolgte eine Zentrifugation bei $16.000 \mathrm{~g}$ und $4^{\circ} \mathrm{C}$ für 15 min. Die nuklären Zellextrakte wurden entweder mit der gleichen Menge zytosolischen Extrakten gemischt oder für weitere Experimente bei $-80^{\circ} \mathrm{C}$ eingefroren. Um die Extrakte für Western-Blot-Experimente zu verwenden, wurden diese zusätzlich mit 6x SDS-Probenpuffer (350 mM TrisHCl, pH 6,8, 8 \% SDS, $30 \%$ Glycerin, $10 \%$ $\beta$-Mercaptoethanol, 0,04\% Bromphenolblau) versetzt, bei $95^{\circ} \mathrm{C}$ für 3 min denaturiert und bei $-20^{\circ} \mathrm{C}$ gelagert. 


\subsubsection{SDS-Polyacrylamid-Gelelektrophorese (SDS-PAGE)}

Mithilfe der SDS-Polyacrylamid-Gelelektrophorese wurden STAT-Proteine elektrophoretisch aufgetrennt und in Immunoblotting-Experimenten detektiert. Als Trägermaterial für die Gelelektrophorese wurde ein Polyacrylamidgel mit Trenn- und Sammelgel verwendet. Das Trenngel bestand aus $10 \%(\mathrm{v} / \mathrm{v})$ Rotiphorese 30 (Acrylamid/Bisacrylamid 37, (5:1)), 0,03\% APS, 0,16\% TEMED und 4x Trenngelpuffer (1,5 M Tris-Hydrochlorid, 0,04\% SDS, pH 8,8). Das Sammelgel bestand aus 5 $\%$ Rotiphorese 30, 0,06 \% APS, 0,2 \% TEMED und 4x Sammelgelpuffer (0,5 M TrisHydrochlorid, 0,4 \% SDS, pH 6,8). Das Polyacrylamidgel wurde wie folgt hergestellt. Zuerst wurde das Trenngel in den Raum zwischen zwei Glasplatten gegossen. Um eine gleichmäßige Polymerisierung des Gels zu gewährleisten wurde Isopropanol auf das Gel gegeben. Dieses wurde anschließend wieder entfernt. Anschließend wurde das Sammelgel auf das Trenngel gegossen. Ein Plastikkamm diente zur Konstruktion der Geltaschen. Die bei $-20^{\circ} \mathrm{C}$ gelagerten Gesamtzellextrakte wurden erneut bei $95^{\circ} \mathrm{C}$ für $3 \mathrm{~min}$ erhitzt und je $10-20 \mathrm{~mL}$ pro Geltasche aufgetragen. In einem vertikalen Elektrophoresesystem (Minigel-Twin, Biometra, Göttingen) wurden die Proteine bei einer konstanten Spannung von $11 \mathrm{~mA} / \mathrm{Gel}$ in SDS-Laufpuffer $(25 \mathrm{mM}$ Tris-Base, 192 mM Glycin, 0,1 \% SDS) aufgetrennt.

\subsubsection{Western Blot und immunchemische Proteindetektion}

Die mithilfe der SDS-PAGE aufgetrennten Proteine wurden im Anschluss auf eine Polyvinylidenflourid (PVDF)-Membran (Millipore, Schwalbach/Ts.) transferiert. Dies erfolgte nach der Semi-Dry-Methode für 90 min bei $80 \mathrm{~mA}$ mit dem Fastblot B44 (Biometra). Die zuvor hydrophobe PVDF-Membran wurde hierfür 5 min in Methanol (Carl Roth) hydrophyilisiert und zweimal für je 15 min in Transferpuffer (25 mM Tris-Base, 150 mM Glycin, $10 \%$ Methanol, pH 8,0) gewaschen. Nach dem Transfer wurde die Membran 5 min in TBS-T (137 mM NaCl, 10 mM Tris-HCl, 0,05 $\%$ Tween-20, pH 7,4) gewaschen, um anschließend für $1 \mathrm{~h}$ mit $4 \%$ BSA (Albumin Fraktion V, Carl Roth) in TBS-T blockiert zu werden. Dies diente der Absättigung freier unspezifischer Bindungsstellen. Die Inkubation mit dem Primärantikörper erfolgte bei $4^{\circ} \mathrm{C}$ über Nacht auf dem Schüttler. Nach Entfernung des Primärantikörpers folgten 5 Waschschritte von je 5 min in TBS-T und schließlich eine einstündige Inkubation mit dem IRDye-gekoppelten Sekundärantikörper bei RT auf dem Schüttler. Zur Detektion der Proteine diente das LI-COR Odyssey Sa Imaging System von Bioscience, Bad Homburg. Um die membrangebundenen Proteine mit einem weiteren Erstantikörper analysieren zu können, wurde die Membran bei $60^{\circ}$ für $1 \mathrm{~h}$ in Ablösepuffer (2 \% SDS, 0,7 \% $\beta$-Mercaptoethanol, 62,5 mM Tris-HCl, pH 6,8) inkubiert, um gebundenen Antikörper zu entfernen. Nach vier Waschschritten mit 
TBS-T von je 15 min und einstündigem Blockieren mit $4 \%$ BSA in TBS-T konnte die Membran erneut mit einem anderen Erstantikörper inkubiert werden.

\subsubsection{Elektrophoretischer Mobilitäts-Shift-Assay (EMSA)}

Spezifische STAT1-DNA-Bindung wurde mithilfe des elektrophoretischen Mobilitäts-Shift-Assays (EMSA) nachgewiesen (Begitt et al. 2000). Dabei wurde sich zu Nutzen gemacht, dass STAT1-Proteine an Oligonukleotid-Sonden binden und somit deren elektrophoretische Mobilität im Gel verlangsamt wird. Durch den Einsatz von radioaktiv markierten Sonden konnten die Banden anschließend radiographisch detektiert werden. Zur Herstellung von Gesamtzellextrakten bzw. nukleären und zytosolischen wurden U3A-Zellen in 6-Lochplatten in Vollmedium kultiviert und anschließend stimuliert, behandelt und nach Protokoll aufgearbeitet.

Hybridisierungsreaktion Im Rahmen dieser Arbeit wurden zum Nachweis von Protein-DNA-Interaktionen vier verschiedene Sonden verwendet. Dabei handelte es sich um komplementäre Oligonukleotide, die jeweils an ihren überhängenden Enden radioaktiv markiert wurden. Die Sonden enthielten eine singuläre (M67), zweifache (2xGAS), eine singuläre gefolgt von einer degenerierten (GAS-nonGAS) und zwei degenerierte GAS-Bindestellen (2xnonGAS). Für die Herstellung der Sonden wurden je $50 \mathrm{pmol} / \mathrm{mL}$ komplementäre Oligonukleotide bei $95^{\circ} \mathrm{C}$ für 5 min in OligoPuffer $\left(10 \mathrm{mM} \mathrm{MgCl}_{2}, 50 \mathrm{mM} \mathrm{KCl}, 20 \mathrm{mM}\right.$ Tris-HCl, pH 7,5) inkubiert, langsam auf Raumtemperatur abgekühlt und für die weitere Verwendung bei $-20^{\circ} \mathrm{C}$ gelagert.

Radioaktive Markierung Für die radioaktive Markierung wurden die nicht komplementären $5^{\prime}$-überhängenden Enden mit radioaktiven $\alpha$ - $\left.{ }^{32} \mathrm{P}\right]$-Nukleotiden aufgefüllt. Für diesen Zweck wurden aus $0,1 \mathrm{ng}$ Oligonukleotid und $8 \mu \mathrm{L}$ des radioaktiven dATPs ein Ansatz hergestellt und zusammen mit 5 Einheiten des Klenow-Fragments für 25 min bei RT in 5 mL 10x Eco-Pol-Puffer (New England, Biolabs, Frankfurt am Main) inkubiert. Bei dem Klenow-Fragment handelt es sich um ein Fragment der $E$. coli DNA-Polymerase I, das über 5'-3'-Polymerase und $3^{\prime}-5^{\prime}$-Exonuklaseaktivität, jedoch nicht über 5'-3'-Exonuklaseaktivität verfügt. Die Reaktion wurden durch Zugabe von $1 \mu \mathrm{L}$ 0,5 EDTA-Lösung beendet. Durch Zentrifugation bei $700 \mathrm{~g}$ für $3 \mathrm{Mi}$ nuten bei Raumtemperatur wurden freie Nukleotide mithilfe von Illustra MicroSpinG25-Säulen (GE Healthcare, München) chromatographisch entfernt.

Gelretardation Für den DNA-Bindungsversuch wurden $0,2 \quad \mu \mathrm{L}$ radioaktivmarkierte Sonde, $1 \mu \mathrm{L}$ Poly-dI/dC $(2 \mathrm{mg} / \mathrm{mL}), 1,3 \mu \mathrm{L}$ DTT $(100 \mathrm{mM}), 3,5 \mu \mathrm{L}$ $\mathrm{H}_{2} \mathrm{O}, 2,5 \mu \mathrm{L} 5 \mathrm{x}$ Gelshift-Puffer (100 mM Hepes, $200 \mathrm{mM} \mathrm{KCl,} 5 \mathrm{mM} \mathrm{MgCl} 2,2,5$ mM EDTA, 0,5 mM EGTA, $20 \%$ Ficoll, pH 7,9) mit 4,5 $\mu \mathrm{L}$ Zellextrakte bei RT 
inkubiert. Bei geringeren Extraktmengen als 4,5 $\mu \mathrm{L}$, wurden die Proben durch Zugabe von 1x PBS oder untransfizierten U3A-Zellextrakten auf ein Gesamtvolumen von $13 \mu \mathrm{L}$ aufgestockt. Für die Bestätigung der Identität von STAT1 wurden zwei Reaktionsansätze mit je 1,5 $\mu \mathrm{L}$ polyklonalem STAT1 $\alpha$-p91-Antikörper (Santa Cruz) bzw. STAT3-Antikörper im Rahmen einer Supershift-Reaktion inkubiert. Für den Kompetitionsversuch erfolgte eine 20-minütige Inkubation mit je $2 \mu \mathrm{l}$ unmarkierter M67-DNA bei RT bzw. eine 5- und 10-minütige Inkubation mit je $2 \mathrm{~mL}$ unmarkierter M67 bei $4^{\circ} \mathrm{C}$ auf Eis. Dabei wurde die unmarkierte M67-DNA in einem 750-fachen Überschuss eingesetzt. Für je 2 Gele wurden $12 \mathrm{~mL}$ Rotiphorese (Acrylamid/Bisacrylamid (29:1)) mit 4,8 mL 5x TBE und $82 \mathrm{~mL} \mathrm{H}_{2} \mathrm{O}$ gemischt. Zum Start der Polymerisierungsreaktion wurden $2 \mathrm{~mL} 10 \%$ APS und $100 \mu \mathrm{L}$ TEMED hinzugefügt. Die polymerisierten Gele wurden bei $400 \mathrm{~V}$ und $4^{\circ} \mathrm{C}$ für $2,5 \mathrm{~h}$ in 0,25-fachem \% TBE-Laufpuffer präequilibriert. Nach Inkubation mit der entsprechenden Sonde wurden die Proben direkt auf das Gel aufgetragen und bei $4^{\circ} \mathrm{C}$ und $400 \mathrm{~V}$ in 0,25\% TBE-Laufpuffer für $\sim 2,5 \mathrm{~h}$ aufgetrennt. Unmittelbar im Anschluss wurden die Gele auf Whatman-Papier (Albet Lab Science, Dassel) vakuumgetrocknet. Die Gele wurden mindestens über Nacht, gegebenenfalls auch mehrere Tag auf eine Phospho-Imager-Folie exponiert und danach mithilfe des Auslese-Programms TINA v. 2.0 (Raytest, Straubenhardt) ausgelesen. Die weitere Bildbearbeitung erfolgte mit dem Softwareprogramm Aida Image Analyzer v. 4.06 (Raytest) und Corel Draw (Corel, Unterschleißheim).

\subsubsection{Reportergen-Assay}

Die transkriptionelle Aktivität von STAT1-WT und seinen Mutanten wurde unter anderem mithilfe von Reportergen-Assays analysiert. Die Genaktivierung wurde mit verschiedenen IFN $\gamma$-sensitiven Luciferase-Reportergenkonstrukten, wie z.B. dem Promotorelement aus dem Ly6E-Gen, untersucht, welches eine dreifache STAT1Bindestelle im Promotorbereich besitzt (Wen et al. 1995). Hierbei wird durch die Promotorrekrutierung von Phospho-STAT1 das Enzym Luciferase transkribiert. Dieses Enzym katalysiert die Reaktion von $\alpha$-Luciferin zu Oxyluciferin und setzte Lichtquanten frei. Dabei wurde die Anzahl der emittierten Lichtquanten gemessen, die wiederum proportional zur umgesetzten Luciferasemenge war und somit auch zu der Menge an phosphoryliertem STAT1. Zusätzlich wurden die Reportergene pIC-339 und pIC-1352 verwendet. Diese enthielten den trunkierten bzw. den kompletten Promotor des humanen ICAM1-Gens. Dadurch wurde die Luciferaseinduktion mithilfe nativer Promotoren mit singulärer GAS-Bindestelle überprüft. Zusätzlich zu den Luciferase-Reportergenkonstrukten wurde ein $\beta$-GalactosidaseReporterplasmid kotransfiziert, das konstitutiv exprimiert wurde und zur Normierung der Transfektionseffizienz diente. Für dieses Experiment wurden U3A-Zellen in 
48-Lochplatten im zugehörigen Zellkulturmedium kultiviert und je Loch mit $250 \mathrm{ng}$ STAT1-Plasmid, $200 \mathrm{ng} \beta$-Galactosidase-Reporterplasmid und $70 \mathrm{ng}$ des 3xLy6EPlasmids, des pIC-339 Plasmids oder des pIC-1352-Plasmids transfiziert. Je Behandlung und Konstrukt wurde eine Sechsfach-Messung durchgeführt. 16-24 h nach der Transfektion blieben die Zellen entweder unbehandelt oder wurden für $6 \mathrm{~h}$ mit $10 \mathrm{ng} / \mathrm{ml} \mathrm{IFN} \gamma$ in Vollmedium stimuliert. Nach erfolgter Stimulation wurde das Medium von allen Löchern abgenommen und die Zellen 1x mit PBS gewaschen. Die Zellen wurden mit $100 \mu \mathrm{L}$ Triton-Glycylglycin-Lysepuffer (25 mM Glycylglycin, $\mathrm{pH}$ 7,8, 1 \% Triton X-100, $15 \mathrm{mM} \mathrm{MgO}_{4}, 4 \mathrm{mM}$ EGTA) für 15 min bei RT lysiert, zu dem unmittelbar vor der Zelllyse noch $3 \mathrm{mM}$ DTT, 0,4 mM Pefabloc und Complete-Mini-Protease-Inhibitoren hinzugefügt wurden. Nach erfolgter Lyse wurden die Zellen in 1,5 mL Reaktionsgefäße überführt, um bei $4^{\circ} \mathrm{C}$ und 13.000 rpm für 15 min zentrifugiert zu werden. Darauf folgend wurden in jedes Loch je 20 $\mu \mathrm{L}$ des Überstandes in eine 96-Lochplatte (Nunclon Surface, Dänemark) pipettiert. Mit dem Luminometer Centro XS3 LB 960 (Berthold Technologies, Bad Wildbad) wurden je Loch $50 \mu \mathrm{L}$ des Luciferase-Assay-Puffers injiziert und die Luciferaseaktivität gemessen. Die Ergebnisse wurden mithilfe des Softwareprogramms MikroWin, Version 4.41, ausgewertet. Um die $\beta$-Galactosidaseaktivität und somit die Transfektionseffizienz zu bestimmen, wurden zu je $20 \mathrm{~mL}$ des Lysats jeweils 280 mL Substratlösung, bestehend aus 211 mL Natriumphosphat-Puffer (100 mM, pH 7,2), $66 \mathrm{~mL}$ o-Nitrophenyl- $\beta$-D-Galactopyranosid (ONPG, $4 \mathrm{mg} / \mathrm{mL}$ ), in $100 \mathrm{mM}$ Natriumphosphat-Puffer und $3 \mathrm{~mL}$ einer 100x Magnesium-Lösung (100 mM MgCl 2 , 4,5 mM $\beta$-Mercaptoethanol) hinzugefügt. Nach enzymatischem Farbumschlag wurde die Reaktion mit je $500 \mu \mathrm{L}$ einer 0,5 M Natriumcarbonat-Lösung pro Loch gestoppt und im Anschluss wurde die $\beta$-Galactosidaseaktivität bei einer Wellenlänge von $420 \mathrm{~nm}$ photometrisch mit dem Infinite 200 PRO (Tecan, Männedorf, Schweiz) bestimmt. Zur Normierung der Messwerte wurde der Quotient aus der Luciferaseaktivität durch die $\beta$-Galactosidaseaktivität der zugehörigen Probe gebildet und die Standardabweichungen und die Mittelwerte wurden mit den Softwareprogrammen Exel (Microsoft Deutschland, Unterschleißheim) und Sigmablot (Systat Software, Erkrath) berechnet.

\subsubsection{Fluoreszenzmikroskopische Analyse}

Für die fluoreszenzmikroskopische Untersuchung von STAT1-WT und der STAT1Mutanten wurden Zellen auf 8-Kammer-Objektträgern (Lab-Tek Chamber Slides, Thermo-Fisher Scientific, Langenselbold) in Vollmedium kultiviert und mit pEGFPN1-STAT1 transfiziert. 16-20 h nach der Transfektion wurden GFP-markiertes STAT1-exprimierende Zellen nach den angegebenen Zeiten mit $10 \mathrm{ng} / \mathrm{mL}$ IFN $\gamma$ bzw. $1 \mu \mathrm{M}$ Staurosporin jeweils in Vollmedium stimuliert. Die Zellen wurden anschlie- 
ßend 1x mit PBS gewaschen und in $4 \%$ Formaldehyd in PBS für 15 min bei RT auf dem Schüttler fixiert. Darauf folgten zwei Waschschritte mit PBS und ein Waschschritt mit destilliertem $\mathrm{H}_{2} \mathrm{O}$. Die Zellkerne wurden mit $5 \mu \mathrm{g} / \mathrm{mL}$ Hoechst 33258 (Sigma-Aldrich) für 10 min bei RT auf dem Schüttler gefärbt. Nach der Färbung wurden die Zellen zweimal mit PBS und einmal mit destilliertem $\mathrm{H}_{2} \mathrm{O}$ gewaschen, mit Fluoromount-G-Eindeckmedium (Southern Biotech, Birmingham, USA) eingedeckt und lichtgeschützt bei $4^{\circ} \mathrm{C}$ gelagert. Die Zellen wurden mit dem Mikroskop Axiovert 200M (Carl Zeiss Lichtmikroskope, Göttingen) fluoreszenzmikroskopisch analysiert und mithilfe einer CCD-Kamera (Intas, Science Imaging Instruments, Göttingen) unter Verwendung verschiedener Fluoreszenzfilter fotografiert. Für GFPFusionsproteine bei $\lambda=480 \mathrm{~nm}$ und für Hoechst 33258 gefärbte Zellkerne bei $\lambda=$ $280 \mathrm{~nm}$. Die weitere Bearbeitung der Bilder erfolgte mit den Softwareprogrammen ImageJ 1.45s und CorelDraw.

\subsubsection{Immunzytochemie}

Für die immunzytochemische Detektion wurden U3A-Zellen auf 8-KammerObjektträgern in Vollmedium kultiviert und mit pcDNA3.1-STAT1-Konstrukten transfiziert. 16-18 h nach der Transfektion wurden die Zellen einmal mit PBS gewaschen, in der angegebenen Verdünnung und den entsprechenden Zeiten mit IFN $\gamma$ bzw. nachfolgend mit Staurosporin behandelt und anschließend mit bei $-20^{\circ} \mathrm{C}$ vorgekühltem Methanol für 15 min bei $-20^{\circ} \mathrm{C}$ fixiert. Die fixierten Zellen wurden zweimal mit PBS gewaschen und schließlich mit $1 \%$ Triton-X 100 in PBS für 20 min bei RT auf dem Schüttler permeabilisiert. Des Weiteren folgten zwei weitere Waschschritte mit PBS und eine Blockierung von 45 min bei RT mit 25 \% FCS in PBS zur Absättigung von unspezifischen Bindungsstellen. Der Erstantikörper wurde im Verhältnis 1:1000 in 25 \% FCS in PBS verdünnt und für 45 min bei RT auf dem Schüttler inkubiert. Es folgten drei Waschschritte mit PBS. Das Cy3-gekoppelte Anti-KaninchenIgG aus Ziege diente als Zweitantikörper und wurde bei einer Verdünnung von 1:500 ( $25 \%$ FCS in PBS) ebenfalls für 45 min bei RT auf dem Schüttler inkubiert und im Anschluss dreimal mit PBS gewaschen. Nach der Färbung der Zellkerne mit Hoechst 33258 für 10 min bei RT unter Schütteln erfolgte die blasenfreie Eindeckung mithilfe des Fluoromount-G-Eindeckmediums. Zur immunzytochemischen Detektion diente ein Fluoreszenzmikroskop (Axiovert 200M). Die Zellen wurden unter Einsatz verschiedener Fluoreszenzfilter mit einer CCD-Kamera (Intas, Göttingen) fotografiert. Für die mit Hoechst 33258 gefärbten Zellen wurde eine Anregungswellenlänge von $\lambda=280 \mathrm{~nm}$ und für Cy3-gekoppelte Antikörper von $\lambda=550 \mathrm{~nm}$ verwendet. Die weitere Bearbeitung und Quantifizierung der Bilder erfolgte mittels der Softwareprogramme Image J und CorelDraw. 


\subsubsection{RNA-Isolation}

Zur Gewinnung von mRNA wurden U3A-Zellen in 6-Lochplatten in Vollmedium kultiviert. Dafür wurde $24 \mathrm{~h}$ nach dem Umsetzten der Zellen ein Mediumwechsel auf Dulbeccos-modifiziertes Eagle Medium (DMEM) vollzogen, zu dem 1 \% FCS und $1 \%$ Penicillin-Streptomycin hinzugefügt wurden. Direkt im Anschluss wurden die Zellen mit pcDNA3.1-Konstrukten transfiziert. 16-24 h nach der Transfektion wurde ein Teil der Zellen mit $10 \mathrm{ng} / \mathrm{mL}$ IFN $\gamma$ stimuliert, wobei andere Proben unbehandelt blieben. Das Medium wurde abgenommen. Die RNA-Isolation mithilfe des peqGold-Total-RNA-Kits (PEQLAB) erfolgte nach Herstellerangaben und wurde anschließend mit $50 \mu \mathrm{L}$ RNAse-freiem $\mathrm{H}_{2} \mathrm{O}$ eluiert. Die Proben wurden entweder direkt im Anschluss zu cDNA weiterverarbeitet oder für die spätere Nutzung bei $-80^{\circ} \mathrm{C}$ gelagert.

\subsubsection{Synthese von cDNA}

Mithilfe des Verso-cDNA-Kits (Thermo Fisher Scientific) wurde aus der isolierten RNA komplementäre DNA (cDNA) hergestellt, wobei pro $20 \mu \mathrm{L}$ Ansatz je $8 \mu \mathrm{L}$ mRNA eingesetzt wurden. Dabei umfasste das Protokoll der reversen Transkription zwei Zyklen. Der 30-minütigen cDNA-Synthese bei $42^{\circ} \mathrm{C}$ folgte ein zweiter Zyklus, bei dem die Proben für 2 min auf $95^{\circ} \mathrm{C}$ erhitzt wurden. Diese wurden sodann bei $-20^{\circ} \mathrm{C}$ gelagert.

\subsubsection{Real-time-PCR}

Die real-time-PCR wurde zur Analyse der Genexpression durchgeführt. Mithilfe des Absolut-Blue-QPCR-SYBR-Green Mix (Thermo Scientific) wurde ein Reaktionsansatz von $19 \mu \mathrm{L}$ hergestellt, zu dem $1 \mu \mathrm{L}$ cDNA hinzugegeben wurde. Die für den Ansatz verwendeten komplementären Primer stammten von Sigma-Aldrich. Dabei richtete sich die Untersuchung der Genexpression auf bekannte STAT1-Zielgene. Die hergestellten Proben wurden auf eine weiße 96-Lochplatte (Thermo-Fast, Thermo Scientific) aufgetragen und die emittierte Fluoreszenz mithilfe eines real-timeCyclers (Mastercycler ep Realplex, Eppendorf) detektiert. 


\section{Ergebnis}

Durch Sequenzanalysen wurde zunächst gezeigt, in welchem Ausmaß ausgewählte Aminosäuren (AS) im Vergleich zu den anderen Mitgliedern der humanen STATFamilie an homologer Position im STAT1-Protein konserviert sind. Unter Hinzunahme der Kristallstruktur konnte die jeweilige Aminosäure in Position und Ausrichtung im STAT1-Protein beschrieben werden. Anschließend wurden an hoch konservierten Stellen im STAT1-Protein durch Substitution von spezifischen Aminosäureresten Mutanten erstellt und im Anschluss phänotypisiert. Die Ergebnisse der Untersuchungen von STAT1-W504A, -F506A, -W539A und -F554A sind im Folgenden dargestellt.

\subsection{Sequenzvergleich in der Linkerdomäne}

In Position 504 des STAT1-Proteins wurde ein Tryptophanrest identifiziert, welcher der Linker-Domäne (Abb. 3.1) zugehörig ist. Im Vergleich mit den anderen Mitgliedern der bekannten STAT1-Proteinen zeigt sich bei den ersten vier Mitgliedern der humanen STAT-Familie an homologer Stelle ebenfalls ein Tryptophan (Tab. 3.1), bei STAT5a und STAT5b ein Methionin und bei STAT6 ein Leucin. Die Untersuchung der umgebenden Aminosäuren offenbart Sequenzhomologien bei STAT1-STAT4 in vier Positionen carboxyterminal. Lediglich bei STAT4 befindet sich bei Position 499 ein Methionin anstatt eines Leucins. Durch sequenzspezifische Mutagenese wurde die Aminosäure Tryptophan in Position 504 des STAT1-Moleküls nach Alanin mutiert.

Ferner wurde ein Phenylalaninrest in Position 506 der Linker-Domäne identifiziert (Abb. 3.1). Der Sequenzvergleich (Tab. 3.2) zeigt, dass sich sowohl bei allen sieben Mitgliedern der humanen STAT-Familie, bei STAT92E aus D. melanogaster sowie bei dem STAT-Protein aus Dictyostelium discoideum an homologer Stelle einen Phenylalaninrest befindet. Es handelt sich hierbei also um eine hoch konservierte Position der STAT-Primärstruktur. Tab. 3.2 zeigt zusätzlich ein homologes Sequenzmotiv aus drei Aminosäuren N-terminal und zwei Aminosäuren C-terminal bei STAT1, STAT2, STAT3 und STAT4. Um die biologische Rolle dieses konservierten Phenylalaninrestes zu untersuchen, wurde dieser durch sequenzspezifische Mutagenese an Position 506 des STAT1-Proteins nach Alanin mutiert.

Wie zuvor bei W504A gezeigt, handelt es sich auch in Position 539 um einen hoch 


\begin{tabular}{|l|c|c|c|c|c|c|c|c|c|c|c|c|c|c|}
\hline STAT 1 & 499 & S & E & V & L & S & W & Q & F & S & S & V & T & 510 \\
\hline STAT 2 & 497 & G & P & A & L & S & W & Q & F & S & S & Y & V & 508 \\
\hline STAT 3 & 505 & A & E & V & L & S & W & Q & F & S & S & T & T & 516 \\
\hline STAT 4 & 496 & L & E & V & M & S & W & Q & F & S & S & Y & V & 507 \\
\hline STAT 5a & 509 & C & E & A & L & N & M & K & F & K & A & E & V & 520 \\
\hline STAT 5b & 509 & C & E & A & L & N & M & K & F & K & A & E & V & 520 \\
\hline STAT 6 & 452 & C & E & T & L & N & L & K & F & M & A & E & V & 463 \\
\hline
\end{tabular}

Tabelle 3.1: Sequenzvergleich der humanen STAT-Proteine. In der zum STAT1-Protein homologen Stelle 504 befindet sich bei den bekannten Mitgliedern der humanen STATFamilie eine ungeladene Aminosäure.

\begin{tabular}{|c|c|c|c|c|c|c|c|c|c|c|c|c|c|c|}
\hline STAT 1 & 501 & V & L & S & W & Q & F & S & S & V & T & K & - & 511 \\
\hline STAT 2 & 499 & A & L & S & W & Q & F & S & S & Y & V & G & - & 509 \\
\hline STAT 3 & 507 & V & L & S & W & Q & F & S & S & T & T & K & - & 517 \\
\hline STAT 4 & 498 & V & M & S & W & Q & F & S & S & Y & V & G & - & 508 \\
\hline STAT 5a & 511 & A & L & N & M & K & F & K & A & E & V & Q & S & 522 \\
\hline STAT 5b & 511 & A & L & N & M & K & F & K & A & E & V & Q & S & 522 \\
\hline STAT 6 & 454 & T & L & N & L & K & F & M & A & E & V & G & T & 465 \\
\hline 92 E & 524 & A & L & N & I & K & F & G & S & C & T & G & - & 534 \\
\hline Dicty & 515 & T & L & Q & R & H & F & L & I & A & T & K & Q & 516 \\
\hline
\end{tabular}

Tabelle 3.2: Sequenzhomologie von STAT1-F506A. Der Phenylalaninrest an Position 506 des STAT1-Proteins ist bei allen bekannten Mitgliedern der STAT-Familie konserviert.

konservierten Tryptophanrest der Linker-Domäne des STAT1-Proteins (Abb. 3.1). In Position 539 besitzen alle sieben Mitglieder der humanen STAT-Familie als auch das STAT92E aus D. melanogaster einen Tryptophanrest (Tab. 3.3). Lediglich bei dem STAT-Protein aus Dictyostelium befindet sich an homologer Position anstatt des Tryptophans ein Glutamin. Durch sequenzspezifische Mutagenese wurde der Tryptophanrest in Position 539 nach Alanin mutiert.

Durch Sequenzvergleich der Position 554 (Tab. 3.4) des STAT1-Proteins und unter Verwendung der Kristallstruktur (Abb. 3.1) konnte gezeigt werden, dass die neun bekannten Mitglieder der STAT-Familie an homologer Stelle einen Phenylalaninrest besitzen. Somit zeigen sowohl 506 als auch 554 hoch konservierte Phenylalaninreste. In der weiteren Untersuchung der Proteinsequenz zeigen STAT5a, STAT5b und STAT6 homologe Sequenzabschnitte in ihrer Primärstruktur. Um zu weiteren Erkenntnissen zur Funktion des Phenylalanins in Position 554 zu gelangen, wurde dieses durch sequenzspezifische Mutagenese nach Alanin mutiert. 
A

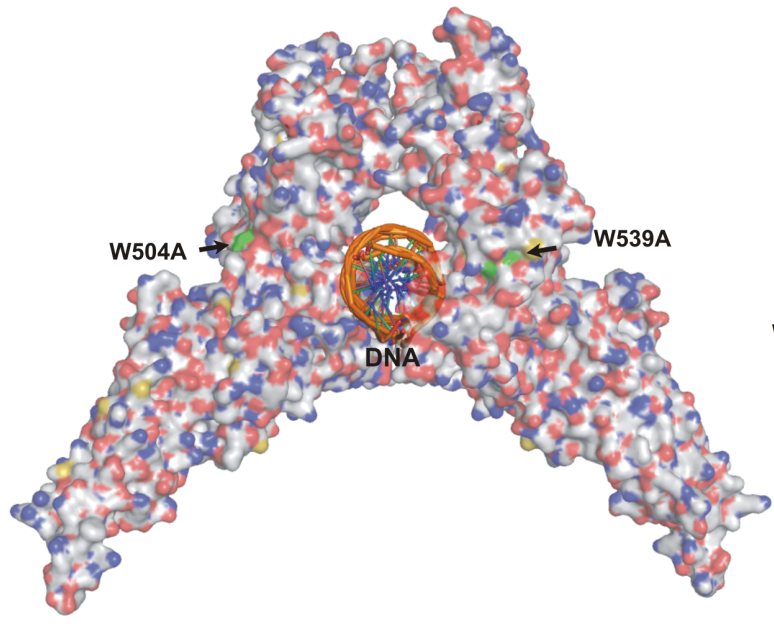

B

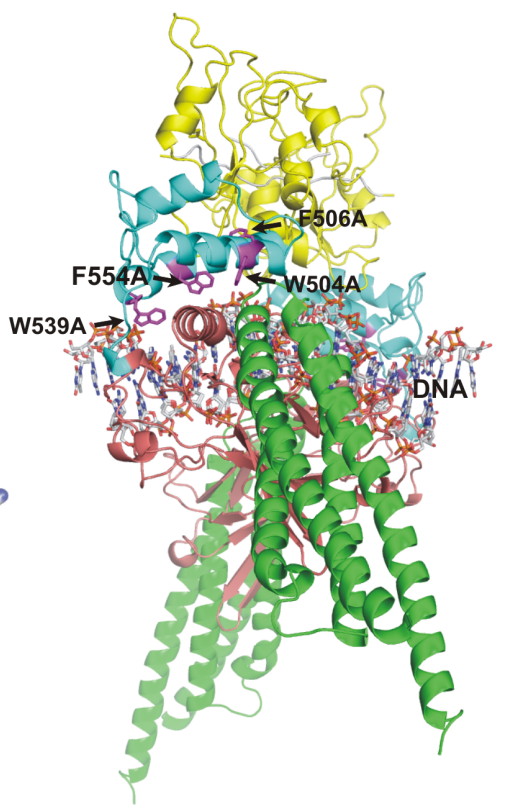

D

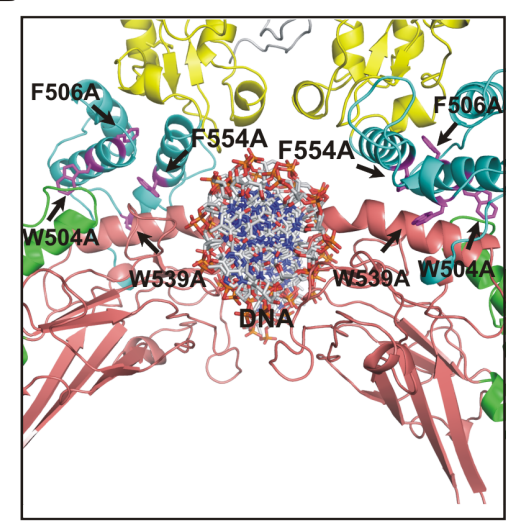

Abbildung 3.1: Kristallstruktur eines DNA-gebundenen STAT1-Dimers mit Lokalisation ausgewählter konservierter Aminosäurereste in der Linker-Domäne. Dargestellt sind die vier Domänen des Kernfragments von STAT1 $\alpha$. Die Coiled-Coil-Domäne (CCD) ist in grün, die DNA-Bindedomäne (DBD) in lachs, die Linker-Domäne (LD) in blau und die SH2-Domäne in gelb illustriert. Die Position der Punktmutationen ist violett hervorgehoben. $\mathrm{Zu}$ sehen ist die Oberflächenstruktur (A) wie auch eine Ribbon-Darstellung des STAT1-Dimers seitlich (B) und axial zur DNA-Doppelhelix (A,C) sowie ein Ausschnitt des DNA-gebundenen STAT1-Dimers (D). 


\begin{tabular}{|c|c|c|c|c|c|c|c|c|c|c|c|c|c|c|}
\hline STAT 1 & 535 & G & - & L & I & P & W & T & R & F & C & K & - & 544 \\
\hline STAT 2 & 532 & D & P & L & L & S & W & A & D & F & T & K & R & 544 \\
\hline STAT 3 & 541 & G & C & Q & I & T & W & A & K & F & C & K & - & 551 \\
\hline STAT 4 & 551 & G & - & H & L & T & W & A & K & F & C & K & - & 541 \\
\hline STAT 5a & 550 & G & L & S & V & S & W & S & Q & F & N & R & - & 560 \\
\hline STAT 5b & 550 & G & L & S & V & S & W & S & Q & F & N & R & - & 560 \\
\hline STAT6 & 494 & H & R & S & V & S & W & S & Q & F & N & K & - & 504 \\
\hline 92 E & 555 & S & E & Y & I & T & W & N & Q & F & C & K & - & 565 \\
\hline Dicty & 551 & R & S & I & I & H & Q & Q & D & F & D & K & - & 561 \\
\hline
\end{tabular}

Tabelle 3.3: Sequenzvergleich der Linker-Domäne von humanen STAT-Proteinen. Bei allen bekannten Mitgliedern der STAT-Familie befindet sich homolog zur Position 539 des STAT1-Proteins ein konservierter Tryptophanrest. Lediglich das STAT-Protein aus Dictyostelium hat an übereinstimmender Position ein Glutamin.

\begin{tabular}{|c|c|c|c|c|c|c|c|c|c|c|c|c|c|c|}
\hline STAT 1 & 549 & D & K & N & F & P & F & W & L & W & I & E & S & 560 \\
\hline STAT 2 & 549 & G & K & - & L & P & F & W & T & W & L & D & K & 559 \\
\hline STAT 3 & 556 & G & K & G & F & S & F & W & V & W & L & D & N & 567 \\
\hline STAT 4 & 546 & G & K & S & F & T & F & W & T & W & L & E & A & 557 \\
\hline STAT 5a & 565 & G & U & N & Y & T & F & W & Q & W & F & D & G & 576 \\
\hline STAT 5b & 565 & G & R & N & Y & T & F & W & Q & W & F & D & G & 576 \\
\hline STAT 6 & 509 & G & R & G & F & T & F & W & Q & W & F & D & G & 520 \\
\hline 92 E & 570 & D & R & S & F & T & F & W & E & W & F & F & A & 581 \\
\hline Dicty & 561 & - & - & - & - & - & F & W & V & W & F & G & K & 568 \\
\hline
\end{tabular}

Tabelle 3.4: Sequenzhomologien in der Linker-Domäne der STAT-Familie. Übereinstimmend zur Position 554 des humanen STAT1-Proteins befindet sich bei allen bekannten Mitgliedern der STAT-Familie ein hoch konservierter Phenylalaninrest.

\subsection{Reduzierte Tyrosinphosphorylierung von STAT1-F554A}

IFN $\gamma$-Stimulation führt zur Tyrosinphosphorylierung an Position 701 von STAT1 und bewirkt eine Dimerisierung mit anschließendem nukleären Import des Transkriptionsfaktors. Um die Effekte von F554A auf die Phosphorylierung an Tyrosin 701 und die daraus resultierende Kernakkumulation von STAT1 zu untersuchen, wurden pSTAT1-GFP-kodierende Plasmide spezifisch mutiert und nach Transfektion in HeLa-S3-Zellen exprimiert. Im gleichen Versuch wurden die Zellen zusätzlich mit dem Kinaseinhibitor Staurosporin behandelt, um die In-vivo-Dephosphorylierung zu überprüfen. Dafür wurden HeLa-S3-Zellen transient mit pSTAT1-F554A-GFP bzw. 
A

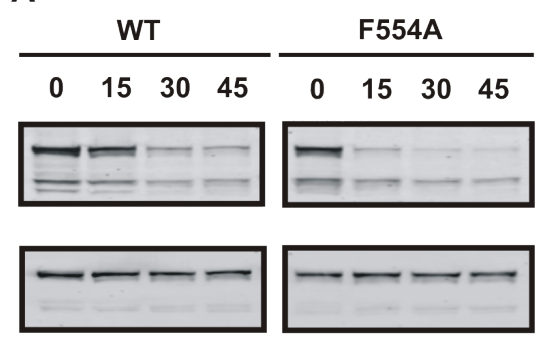

B
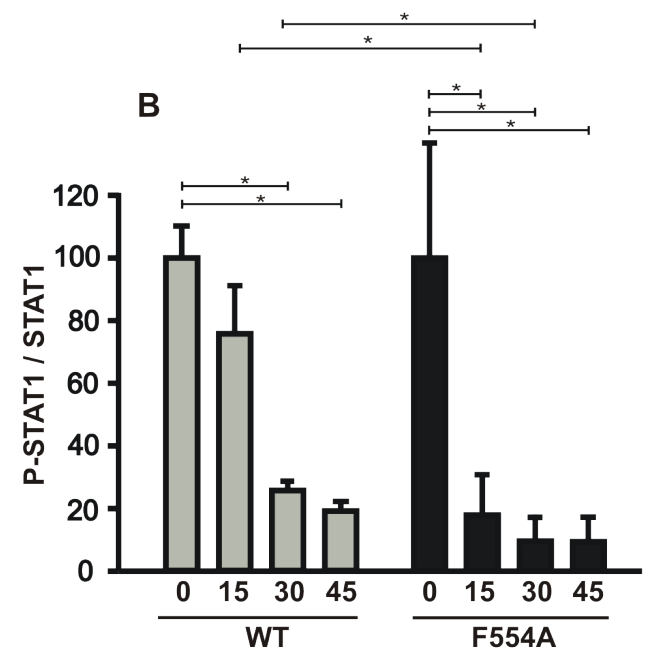

Abbildung 3.2: Verminderte Phosphorylierung bei F554A. HeLa-S3-Zellen wurden mit pSTAT1-WT-GFP bzw. pSTAT1-F554A-GFP transfiziert. Es folgte eine Stimulation mit $10 \mathrm{ng} / \mathrm{mL}$ IFN $\gamma$ und eine Behandlung mit Staurosporin für die angegebenen Zeiten. Die gewonnenen Gesamtzellextrakte wurden anschließend gelelektrophoretisch aufgetrennt und mittels Western-Blot-Analysen untersucht. (A) Dargestellt ist der Blot nach Inkubation mit einem phosphotyrosinspezifischen STAT1-Antikörper (oben) und mit einem Pan-STAT1-Antikörper (unten). (B) Quantifizierung der Phosphorylierungsbanden mit Bestimmung des Verhältnis von p-STAT1 zu STAT-1. Zur Berechnung der statistischen Signifikanz wurden jeweils drei Ergebnisse aus unterschiedlichen Versuchen herangezogen. Statistisch signifikante Ergebnisse sind durch $\left(^{*}\right)$ gekennzeichnet.

pSTAT1-WT-GFP transfiziert und für 45 Minuten mit $10 \mathrm{ng} / \mathrm{mL}$ IFN $\gamma$ stimuliert. Nach unterschiedlichen Inkubationszeiten mit $1 \mu \mathrm{M}$ Staurosporin wurden Gesamtzellextrakte erstellt. Diese wurden anschließend durch Immunoblotting analysiert und die Tyrosinphosphorylierung durch Phospho-STAT1-Antikörper detektiert. Die Quantifizierung der Phosphorylierung erfolgte durch Re-Inkubation mit einem PanSTAT1-Antikörper. Zuvor wurden die Membranen gestrippt und stringent gewaschen.

Wie der Abb. 3.2 zu entnehmen ist, zeigt STAT1-F554A nach IFN $\gamma$-Stimulation ein gleichstarkes Phosphorylierungsniveau im Vergleich zum STAT1-WT. Bereits nach 15-minütiger Staurosporin-Inkubation weist die Mutante ein sichtbar erniedrigtes Phosphorylierungsniveau im Vergleich zum Wildtyp auf, das nach 30-minütiger Behandlung mit Staurosporin weiter abfällt. Dieses Ergebnis wurde durch Quantifizierung der Banden statistisch bestätigt. Bei der anschließenden Untersuchung der Mutanten im Gelshift konnte übereinstimmend ein erniedrigter, jedoch nicht statistisch signifikanter Unterschied in der DNA-Bindung von STAT1-F554A gezeigt werden (Abb. 3.9). 


\subsection{Phosphorylierungsniveau der STAT1-Mutanten W504A, F506A und W539A}

Das Phosphorylierungsniveau von STAT1-W504A, STAT1-F506A und STAT1W539A wurde mithilfe von Western-Blot-Analysen untersucht. Hierfür wurden die oben genannten STAT1-GFP-Plasmide sequenzspezifisch nach Alanin mutiert. Mithilfe dieser rekombinanten Proteine lässt sich die Phosphorylierung unter Verwendung eines Phospho-STAT1-spezifischen Antikörpers in Western-Blot-Experimenten direkt untersuchen. HeLa-S3-Zellen wurden mit dem mutierten STAT1-Plasmid oder dem WT-STAT1-Plasmid transfiziert und am Folgetag für 45 Minuten mit 10 ng/mL IFN $\gamma$ stimuliert. Darauf folgte eine Behandlung mit $1 \mu \mathrm{M}$ des Kinaseinhibtors Staurosporin für unterschiedliche Inkubationszeiten. Dadurch konnte man zusätzlich zur Interferonstimulation den zeitabhängigen Abbruch der Phosphorylierung, die Invivo-Dephosphorylierung der STAT1-Proteine, untersuchen. Nach gelelektrophoretischer Auftrennung der gewonnenen Gesamtzellextrakte wurde die Tyrosinphosphorylierung mittels eines spezifischen Phospho-STAT1-Antikörper detektiert. Um sicherzustellen, dass gleiche Zellextraktmengen aufgetragen worden sind, wurden die Membranen gestrippt und nach mehreren Waschschritten mit einem Pan-STAT1Antikörpers reinkubiert.

Abb. 3.3 zeigt, dass die Tyrosinphosphorylierungsbande von STAT1-WT nach 45minütiger Stimulation mit IFN $\gamma$ klar detektierbar ist. Bereits nach 15-minütiger Inkubation mit dem Kinaseinhibitor Staurosporin zeigten STAT1-WT-exprimierende Zellen eine deutliche Abnahme des Phosphorylierungsniveaus, welches nach 30minütiger Behandlung mit Staurosporin noch weiter abnahm. Die Phosphorylierungsbande von STAT1-WT war nach 45-minütiger Staurosporinbehandlung kaum noch nachweisbar. Bei der Mutante STAT1-W506A konnte nach 45-minütiger IFN $\gamma$-Stimulation ein deutliches Phosphorylierungssignal nachgewiesen werden. Nach 15-minütiger Behandlung der Zellen mit Staurosporin zeigte sich eine Abnahme der Bandenintensität, die nach weiterer Behandlung der Zellen mit dem Kinaseinhibitor eine zeitabhängige Abklingkinetik aufwies. Dies zeigte sich auch für die Mutante STAT1-F539A, die eine deutliche Tyrosinphosphorylierungsbande nach 45-minütiger IFN $\gamma$-Stimulation erkennen ließ. Mit zunehmender Dauer der Staurosporin-Inkubation zeigte sich eine kontinuierliche Abnahme des Signals. Dieses Experiment deutet darauf hin, dass sich die Mutanten STAT1-F506A und STAT1-W539A weder in ihrem Phosphorylierungsniveau nach IFN $\gamma$-Stimulation noch in ihrer Dephosphorylierungskinetik nach Staurosporinbehandlung signifikant vom STAT1-WT unterscheiden.

Bei der Phänotypisierung der Mutante STAT1-W504A im Western Blot zeigte sich nach initialer Stimulation mit IFN $\gamma$ und anschließender Behandlung mit dem 
A

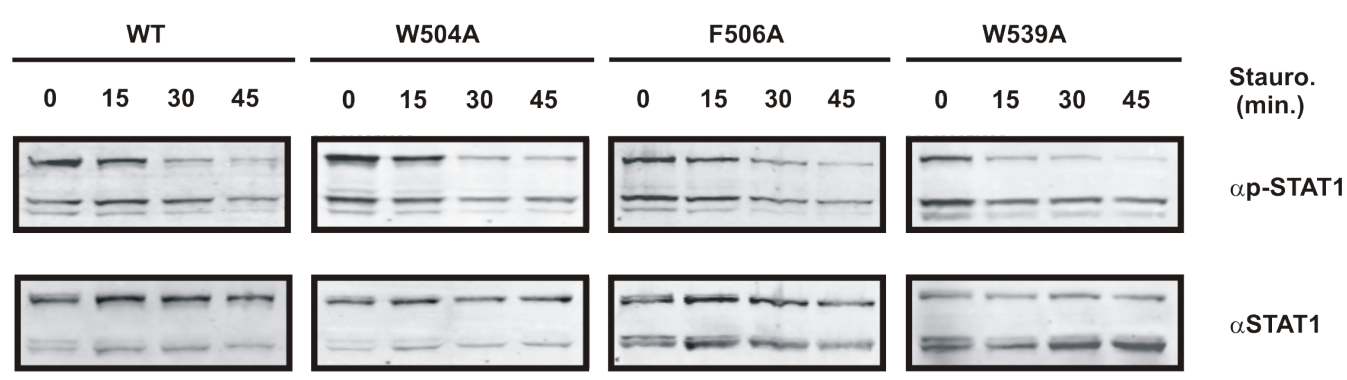

B

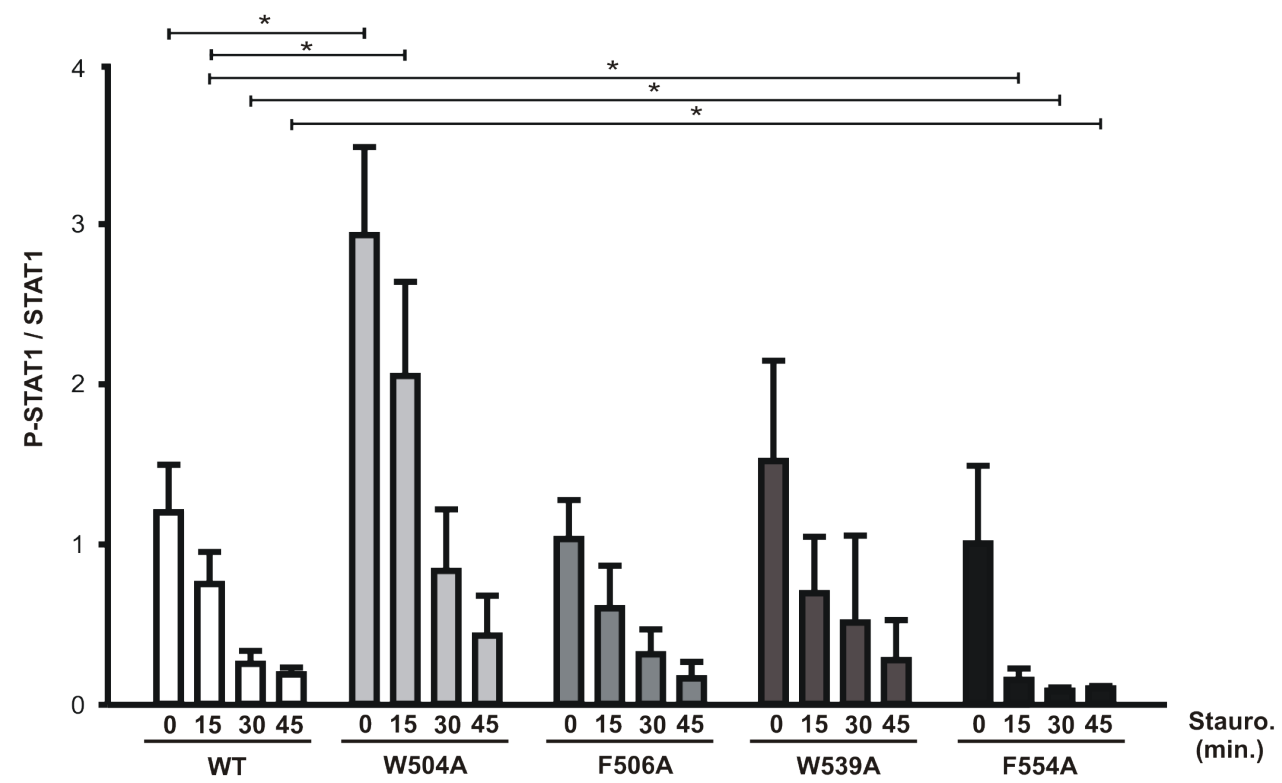

Abbildung 3.3: Tyrosinphosphorylierung und In-vivo-Dephosphorylierung von STAT1W504A, -F506A und -F539A. STAT1-W504A zeigt im Vergleich zum STAT1-WT ein erhöhtes Phosphorylierungsniveau nach IFN $\gamma$-Stimulation der Zellen. (A) HeLa-S3-Zellen wurden transient mit Expressionsplasmiden kodierend für STAT1-WT, STAT1-W504A, STAT1-F506A oder STAT1-W539A transfiziert. Anschließend wurden die Zellen für 45 Minuten mit $10 \mathrm{ng} / \mathrm{mL}$ IFN $\gamma$ stimuliert und für die angegebenen Zeiten mit $1 \mu \mathrm{M}$ Staurosporin behandelt. Hergestellte Gesamtextrakte wurden im Western-Blot-Experiment analysiert. Die obere Reihe zeigt das Ergebnis nach Inkubation mit einem PhosphoSTAT1-Antikörper, die untere Reihe das Ergebnis nach Re-Exposition mit einem PanSTAT1-Antikörper. (B) Dargestellt ist die Quantifizierung der Phosphorylierungsbanden wobei das Verhältnis p-STAT1 zu STAT1 aufgetragen wurde. Zur Berechnung von Gruppenunterschieden wurden jeweils drei Ergebnisse aus unterschiedlichen Versuchstagen herangezogen. Statistisch signifikante Ergebnisse sind durch das Symbol $\left(^{*}\right)$ gekennzeichnet. 
Kinaseinhibitor Staurosporin für die angegebenen Zeiten im Vergleich zum STAT1WT ein erhöhtes Phosphorylierungsniveau (Abb. 3.3 A,B). Die Quantifizierung und statistische Auswertung der Western Blots zeigte einen statistisch signifikanten Unterschied zwischen dem ersten Zeitpunkt (45-minütige IFN $\gamma$-Stimulation, 0-minütige Staurosporinbehandlung $(\mathrm{p}=0,009))$ und dem zweiten Zeitpunkt (15-minütige Staurosporinbehandlung $(\mathrm{p}=0,022))$.

\subsection{Kernakkumulation der Linker-Domäne-Mutanten}

Die Kinetik der Kernakkumulation nach IFN $\gamma$-Stimulation wurde zusätzlich direkt unter Verwendung von STAT1-GFP-kodierenden Plasmiden fluoreszenzmikroskopisch untersucht. Der folgende Versuch diente dem Vergleich der Kernakkumulation der Mutanten STAT1-W504A, STAT1-F506A, STAT1-W539A und STAT1-F554A mit der des Wildtyp-Moleküls nach IFN $\gamma$-Stimulation sowie dem Zusammenbruch nach Staurosporinbehandlung. Zur Generierung der Mutanten wurde ein pEGFPN1-Plasmid mit Insertion humaner STAT1-cDNA verwendet, in welches durch sequenzspezifische Mutagenese die zu untersuchende Punktmutation eingefügt wurde. Zur Beurteilung des zellulären Verteilungsmusters des STAT1-GFP-Proteins wurden HeLa-S3-Zellen transient mit den genannten Konstrukten transfiziert. Nachfolgend wurden die Zellen entweder unbehandelt belassen, für 45 Minuten mit $10 \mathrm{ng} / \mathrm{mL}$ IFN $\gamma$ stimuliert oder zusätzlich zeitabhängig mit $1 \mu \mathrm{M}$ Staurosporin inkubiert. Nach Fixierung der Zellen mit 3,7 \% Formaldehyd in PBS folgte die Färbung der Zellkerne mit Hoechst 33258. Bei den unstimulierten Zellen zeigte sich eine panzelluläre Verteilung sowohl bei STAT1-WT als auch bei den vier oben genannten Punktmutanten. Abb. 3.4 zeigt die zugehörigen fluoreszenzmikroskopischen Aufnahmen. Nach 45-minütiger Stimulation mit IFN $\gamma$ zeigte sich sowohl bei den rekombinanten GFP-markierten Proteinen STAT1-W504A, STAT1-F506A, STAT1-W539A und STAT1-F554A als auch bei STAT1-WT eine nahezu vollständige Kernakkumulation des phosphorylierten STAT1. Durch Inhibition der Tyrosin-Kinasen-Aktivität mittels Staurosporin war nach einstündiger Inkubation bereits eine verminderte Kernlokalisation des phosphorylierten STAT1 erkennbar, nach zweistündiger Staurosporininkubation entsprach die Verteilung des STAT1 wieder nahezu dem panzellulären Verteilungsmuster unstimulierter Zellen. Dies demonstrierte, dass bei den Mutanten STAT1-W504A, -F506A, -W539A und -F554A kein Unterschied in der zytokinabhängigen Kernakkumulation im Vergleich zum STAT1-Wildtyp gefunden werden konnte.

In vorherigen Versuchen zeigten STAT1-F506A und -W539A zusätzlich eine dem Wildtyp ähnliche zytokinabhängige Phosphorylierung sowie Dephosphorylierungskinetik nach Behandlung mit Staurosporin (Abb. 3.3). Die nukleäre Exportrate 
von STAT1-GFP-Fusionsproteinen ist im Vergleich zur Exportrate von endogenem STAT1 verringert (Meyer et al. 2007). Um sicherzustellen, dass die beobachtete Kinetik der Kernakkumulation unbeeinflusst vom GFP-Anteil des Fusionsproteins der generierten Punktmutanten auch für nicht-markierte STAT1-Proteine gilt, wurden Zellen nach Transfektion von pcDNA3.1-STAT1-Plasmiden untersucht. Hierfür wurden U3A-Zellen mit pcDNA3.1-Expressionsvektoren der jeweilig generierten STAT1Mutante transfiziert, nach angegebenen Zeiten mit $10 \mathrm{ng} / \mathrm{mL} \mathrm{IFN} \gamma$ stimuliert und zeitabhängig mit Staurosporin behandelt. Die fluoreszenzmikroskopischen Aufnahmen erfolgten nach Inkubation mit einem spezifischen STAT1-Antikörper. Abb. 3.5 demonstriert die IFN $\gamma$-abhängige Kernakkumulation von STAT1-WT und den Mutanten STAT1-W504A, STAT1-F506A und STAT1-W539A. STAT1 weist nach Interferonstimulation eine präferenziell nukleäre Lokalisation auf. Nach ein- und zweistündiger Staurosporinbehandlung zeigte sich ein panzelluläres Verteilungsmuster des phosphorylierten STAT1-Proteins wobei sich in der Kinetik der Kernakkumulation von Wildtyp und den Mutanten kein Unterschied nachweisen ließ.

Zusätzlich wurde die Kernakkumulation und DNA-Bindung von STAT1-F506A mittels des Fusionsproteins STAT1-F506A-NES untersucht. NES-Fusionsproteine beinhalten ein ektopes hyperaktives nukleäres Exportsignal (NES). Dieses bewirkt, dass phosphoryliertes STAT1-Protein trotz IFN $\gamma$-Stimulation nicht im Zellkern akkumuliert, sondern weiterhin ein zytoplasmatisches Verteilungsmuster unter Zytokinstimulation aufweist (Abb. 3.6). Durch Hinzugabe von Leptomycin B (LMB) kann dieses hyperaktive Exportsignal inhibiert werden und eine adäquate InterferonAntwort wieder hergestellt werden (Hüntelmann et al. 2014). Aus Abb. 3.6 ist ersichtlich, dass NES-F506A und NES-WT sowohl unter IFN $\gamma$-Stimulation als auch unter zusätzlicher Behandlung mit LMB eine gleiche Kinetik der Kernakkumulation aufweisen.

\subsection{Erhaltene kooperative DNA-Bindung und Dissoziationskinetik der Mutanten}

Phosphorylierte STAT1-Proteine bilden Dimere, die im Zellkern spezifisch an sogenannte GAS-Bindestellen (gamma-activated sites) binden. Bei GAS-Bindestellen handelt es sich um palindromische DNA-Sequenzen. Die Fähigkeit zur kooperativen DNA-Bindung wurde im Folgenden untersucht. Diese resultiert aus der Eigenschaft der STAT1-Proteine, aus zwei DNA-gebundenen Dimeren stabile Tetramere an Tandem-GAS-Bindestellen zu bilden. Zu diesem Zweck wurde eine $\left[{ }^{32} \mathrm{P}\right]$-markierteDNA-Sonde mit doppelter GAS-Bindestelle (2xGAS) in Tandem-Stellung eingesetzt und mit stimulierten, STAT1-exprimierenden U3A-Gesamtzellextrakten für $15 \mathrm{Mi}$ nuten inkubiert. Hierfür wurden STAT1-W504A-, STAT1-F506A-, STAT1-W539A- 

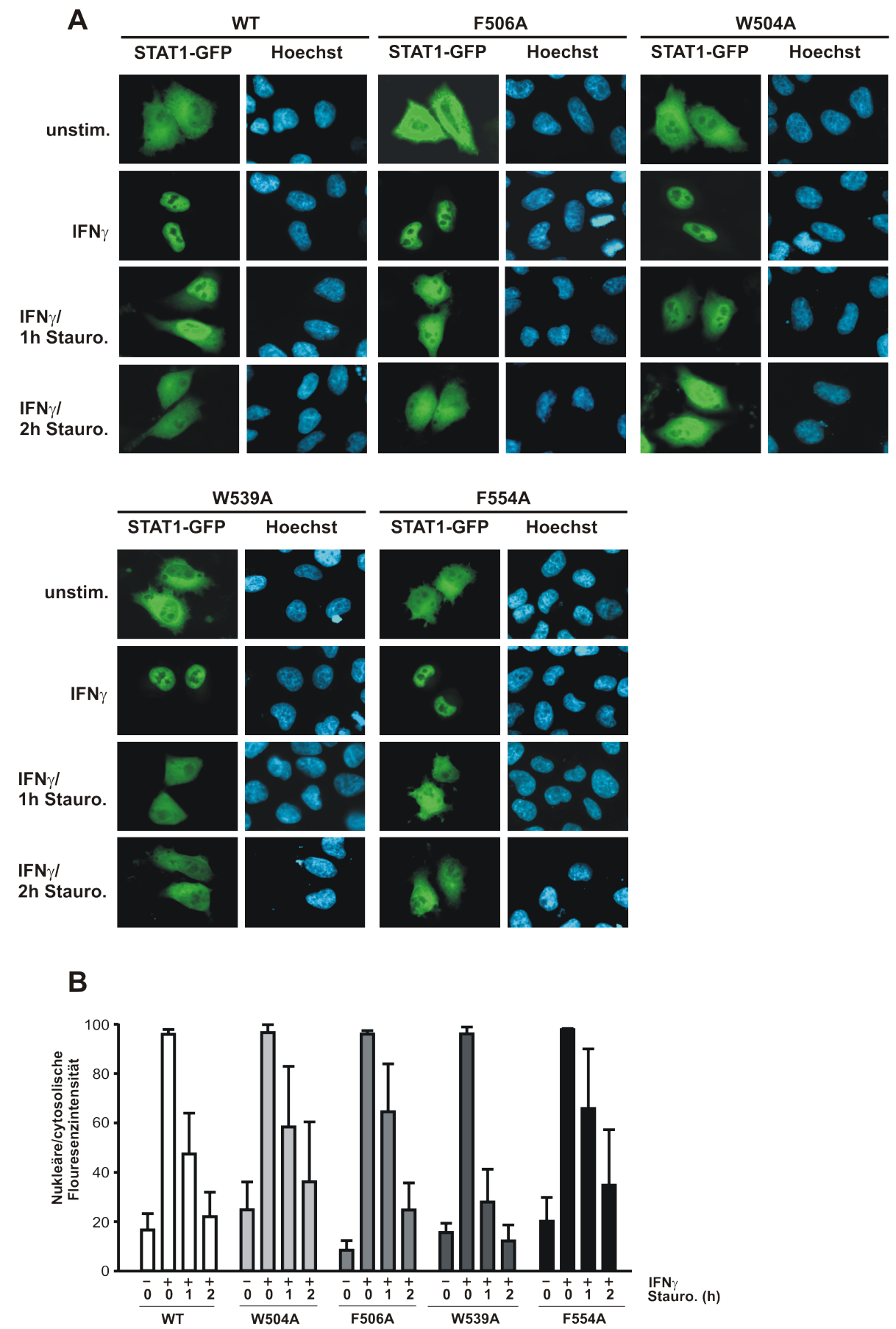

Abbildung 3.4: Vergleichbare Kinetik der IFN $\gamma$-abhängigen Kernakkumulation von STAT1-WT und STAT1-W504, STAT1-F506, STAT1-W539A und STAT1-F554A. (A) Transfizierte HeLa-S3-Zellen wurden unbehandelt belassen (1. Reihe) oder mit $10 \mathrm{ng} / \mathrm{mL}$ IFN $\gamma$ stimuliert (2. Reihe). Ferner folgte eine 60-minütige (3. Reihe) bzw. 120-minütige (4. Reihe) Behandlung mit $1 \mu \mathrm{M}$ Staurosporin nach vorheriger IFN $\gamma$-Stimulation. Nach Fixierung der Zellen und Färbung der Zellkerne mit Hoechst 33258 wurden fluoreszenzmikroskopische Aufnahmen erstellt. (B) Diese wurden anschließend quantifiziert. Dargestellt ist das Verhältnis der Fluoreszenzintensität von nukleärem STAT1 zu cytosolischem STAT1. Es wurde kein statistisch signifikanter Unterschied erhoben. 

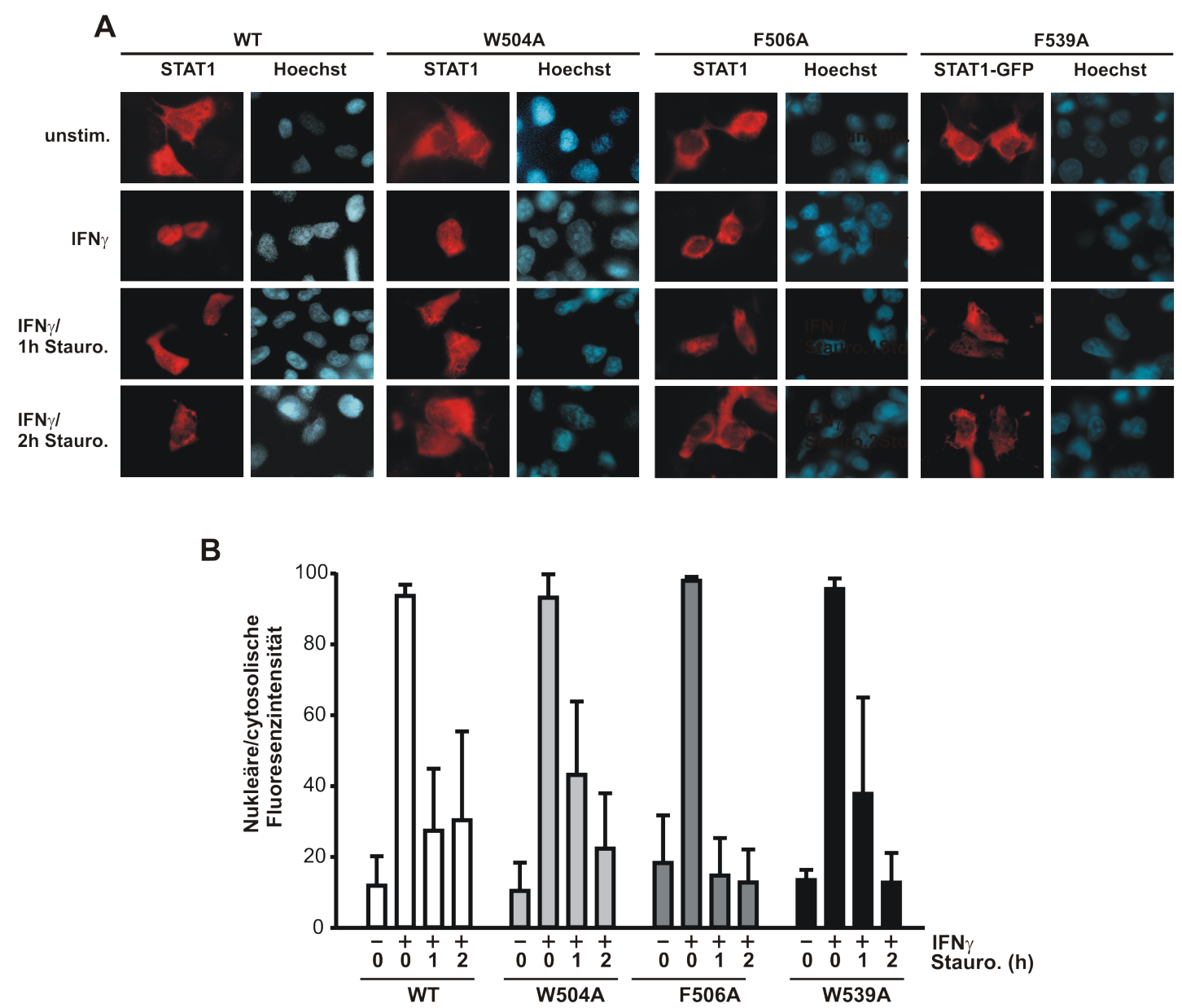

Abbildung 3.5: Die immuncytochemische Untersuchung der Kernakkumulation von STAT1-W504A, -F506A und -W539A zeigte keinen signifikanten Unterschied zum Wildtyp-Molekül. (A) STAT1-WT und die entsprechenden Mutanten exprimierenden U3A-Zellen wurden unbehandelt belassen, für $45 \mathrm{~min}$ mit $10 \mathrm{ng} / \mathrm{mL} \mathrm{IFN} \gamma$ stimuliert und für die angegebenen Zeiten mit Staurosporin inkubiert. Nach Fixierung in Methanol erfolgte die Detektion der STAT1-Lokalisation durch einen spezifischen STAT1-Antikörper und Cy3-gekoppeltes Anti-Kaninchen-IgG aus Ziege. Zur Darstellung der Zellkerne wurden diese mit Hoechst-Farbstoff angefärbt. (B) Die Quantifizierung der Kernakkumulation offenbarte eine vergleichbare Kinetik von STAT1-WT, STAT1-W504A, STAT1F506A und STAT1-W539A. Es wurde kein statistisch signifikanter Unterschied nachgewiesen. 
A

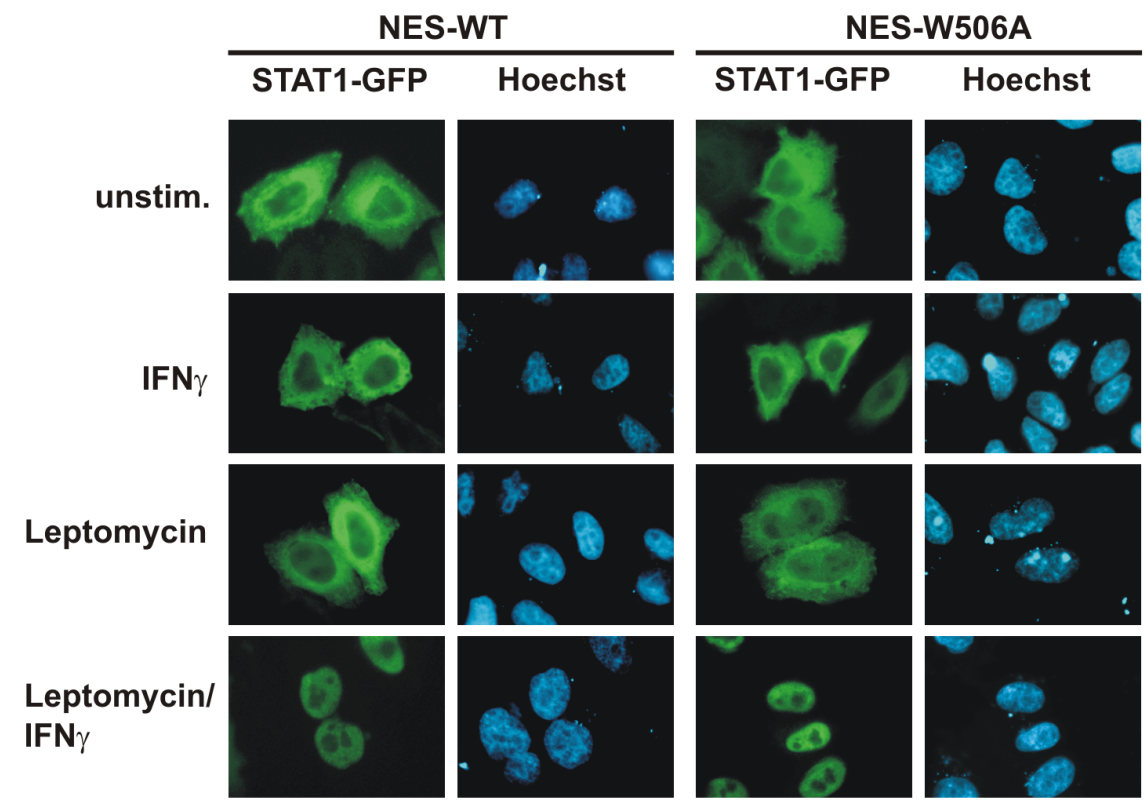

B

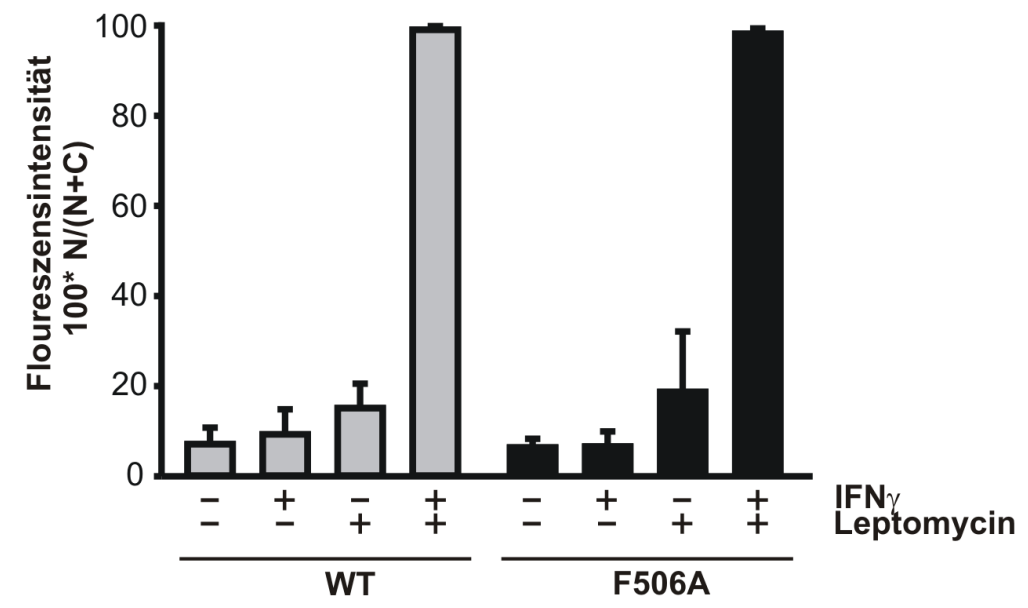

Abbildung 3.6: NES-F506A zeigt nach Behandlung mit Leptomycin B (LMB) und IFN $\gamma$ eine dem Wildtyp vergleichbare Kernakkumulation. HeLa-S3-Zellen wurden mit pSTAT1-WT-NES-GFP und pSTAT1-F506A-NES-GFP transfiziert. Anschließend wurden die Zellen entweder unstimuliert belassen (1.Reihe), für 45 Minuten mit $10 \mathrm{ng} / \mathrm{mL}$ IFN $\gamma$ stimuliert (2.Reihe), für 45 Minuten mit LMB behandelt (3.Reihe) oder für $45 \mathrm{Mi}$ nuten mit IFN $\gamma$ und LMB behandelt (4.Reihe). Die Zellen wurden im direkten Anschluss mit $4 \%$ Formalin fixiert und die Zellkerne mit Hoechst angefärbt. (B) Dargestellt ist das Verhältnis von nukleärer zur gesamtzellulären (d.h. Summe aus nukleärer und cytoplasmatischer) Fluoreszenzintensität. Dabei war kein statistisch signifikanter Unterschied nachweisbar. 
und STAT1-F554A-exprimierende U3A-Zellen für 45 Minuten mit $10 \mathrm{ng} / \mathrm{mL}$ IFN $\gamma$ stimuliert. Es folgte eine Kompetition mit unmarkierter M67-DNA im 750-fachen molaren Überschuss und die anschließende gelelektrophoretische Auftrennung. Das nicht denaturierte Polyacrylamidgel wurde anschließend autoradiographisch ausgewertet.

Wie aus Abb. $3.7 \mathrm{zu}$ entnehmen, banden im nicht-kompetierten Zustand zunächst alle Mutanten sowohl als Dimer an eine singuläre GAS-Bindestelle als auch als Tetramer an eine 2xGAS-Bindestelle (durch Pfeile markiert). Nach der Zugabe der unmarkierten M67-DNA und einer 20-minütigen Inkubation verschwand beim STAT1Wildtyp als auch bei STAT1-W504, STAT1-F506A, STAT1-W539A und STAT1F554A der nicht-stabilisierte Dimer-Komplex. Der durch die kooperative DNABindung stabilisierte tetramere Komplex blieb bestehen und war nach 20-minütiger Inkubation autoradiographisch weiterhin detektierbar. Dieses Ergebnis demonstrierte eine erhaltene kooperative Bindung der oben aufgeführten STAT1-Derivate. Die Supershift-Reaktion mit Einsatz spezifischer $\alpha$ STAT1- und $\alpha$ STAT3 Antikörper belegte das Vorhandensein von STAT1-DNA-Komplexen. Abb. 3.7 B zeigt, dass nach Kompetition mit unmarkierter M67-DNA weniger als $2 \%$ der Dimer-Komplexe in Bindung mit der DNA verbleiben.

Wie aus diesen EMSA-Experimenten ersichtlich (Abb. 3.7) zeigten STAT1W504A, STAT1-F506A, STAT1-W539A und STAT1-F554A eine intakte kooperative DNA-Bindung. Im folgenden Experiment sollte untersucht werden, wie sich die generierten Punktmutationen nach Alanin auf die Off-Rate der STAT1-Derivate von DNA auswirken. Hierfür wurden STAT1-W504A-, F506A-, W539A- und F554Aexprimierende U3A-Zellen für 45 Minuten mit IFN $\gamma$ stimuliert. Die gewonnenen Gesamtzellextrakte wurden anschließend für 15 Minuten mit markierter M67-DNA inkubiert (Abb. 3.8). Zusätzlich erfolgte eine Inkubation mit unmarkierter M67-DNA im 750-fachen molaren Überschuss für die angegebenen Zeiten. Nach gelelektrophoretischer Auftrennung der Proben wurden die vakuumgetrockneten Polyacrylamidgele autoradiographisch analysiert.

Abb. 3.8 zeigt, dass alle in dieser Arbeit untersuchten STAT1-Punktmutanten eine dem STAT1-Wildtyp vergleichbare Dissoziationskinetik aufwiesen. Es ergab sich im Vergleich zum Wildtyp-Molekül zu keinem Zeitpunkt ein statistisch relevanter Unterschied. Abb. 3.9 präsentiert die DNA-Bindung aller hier untersuchten Mutanten zeitabhängig nach entsprechender Behandlung der Zellen. U3A-Gesamtzellextrakte wurden zuvor mit IFN $\gamma$ stimuliert und im Anschluss für angegebene Zeiträume mit Staurosporin behandelt. Es zeigte sich kein statistisch signifikanter Unterschied in der DNA-Bindefähigkeit der Mutanten zum Wildtyp-Protein. 
A

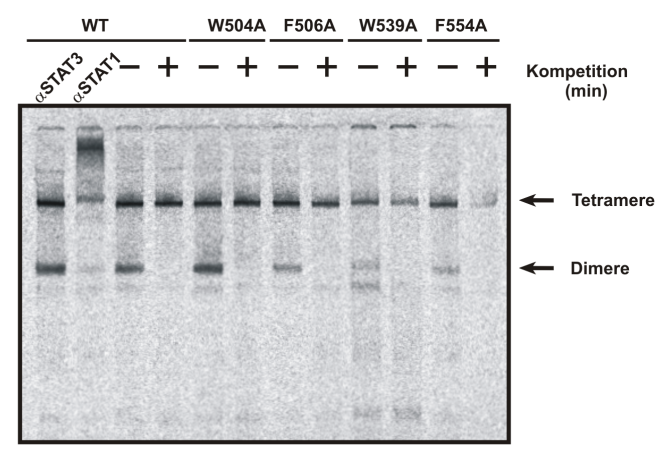

B

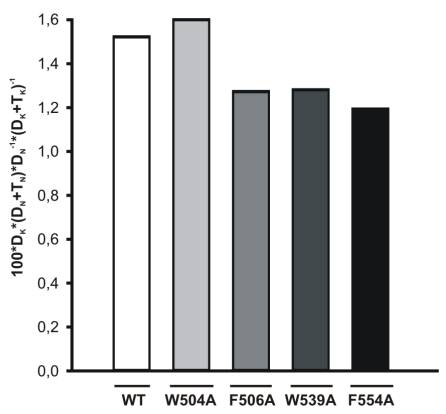

\begin{abstract}
Abbildung 3.7: Die STAT1 Punktmutanten W504A, F506A, W539A und F554A sind zur kooperativen DNA-Bindung fähig. (A) STAT1-WT-, STAT1-W504A-, STAT1-F506A-, STAT1-W539A- oder STAT1-F554A-exprimierende U3A-Zellen wurden für 45 Minuten mit IFN $\gamma$ stimuliert, die gewonnenen Gesamtzellextrakte für 15 Minuten mit radioaktiv markierter 2xGAS Sonde bei RT inkubiert und anschließend zusätzlich für $20 \mathrm{Minu-}$ ten mit einem 750-fachen molaren Überschuss an unmarkierter M67-DNA kompetiert. Gleiche Zellextraktmengen wurden gelelektrophoretisch aufgetrennt. Nach autoradiographischer Detektion lassen sich tetramergebundene (oberer Pfeil) und dimergebundene (unterer Pfeil) STAT1-DNA-Komplexe unterscheiden. $\alpha$ STAT1 bezeichnet die Supershiftreaktion mit einem STAT1-spezifischen Antikörper, $\alpha$ STAT3 den Kontroll-Supershift mit STAT3-spezifischem Antikörper. Der Stern $\left(^{*}\right)$ markiert unspezifische Banden. (B) Dargestellt ist das Verhältnis der kompetierten Dimer-Komplexe $\left(\mathrm{D}_{K}\right)$ zum Anteil der nicht kompetierten Dimer-Komplexe $\left(\mathrm{D}_{N}\right)$ zur jeweiligen gesamten STAT1-DNABindeaktivität im kompetierten $\left(\mathrm{D}_{K}+\mathrm{T}_{K}\right)$ bzw. nicht kompetierten Zustand $\left(\mathrm{D}_{N}+\mathrm{T}_{N}\right)$.
\end{abstract}

\title{
3.6 Vergleichbare DNA-Bindeaffinität von STAT1-WT, STAT1-W504A und STAT1-F506A
}

Bei der Untersuchung der Bindeaffinität zu verschiedenen DNA-Sonden fand zusammenfassend sich kein Unterschied zwischen den Mutanten und dem WildtypMolekül. Für diesen Versuch wurden U3A-Zellen im Vorfeld mit pSTAT1-WT-GFP, pSTAT1-W504A-GFP und pSTAT1-F506A-GFP transfiziert und anschließend für 45 Minuten mit $10 \mathrm{ng} / \mathrm{mL} \mathrm{IFN} \gamma$ stimuliert. Im Anschluss wurden nukleäre Extrakte gewonnen und, wie in Abb. 3.10 dargestellt, mit drei verschiedenen Sonden inkubiert (2xGAS mit doppelter GAS-Bindestelle, GAS-nonGAS mit einfacher GAS-Bindestelle und 2xnonGAS ohne GAS-Bindestelle). Diese wurden auf ein Polyacrylamidgel aufgetragen und gelelektrophoretisch aufgetrennt. Abb. 3.10 zeigt ein dem STAT1-Wildtyp entsprechendes DNA-Bindeverhalten von STAT1-W504A und STAT1-F506A. 


\section{A}
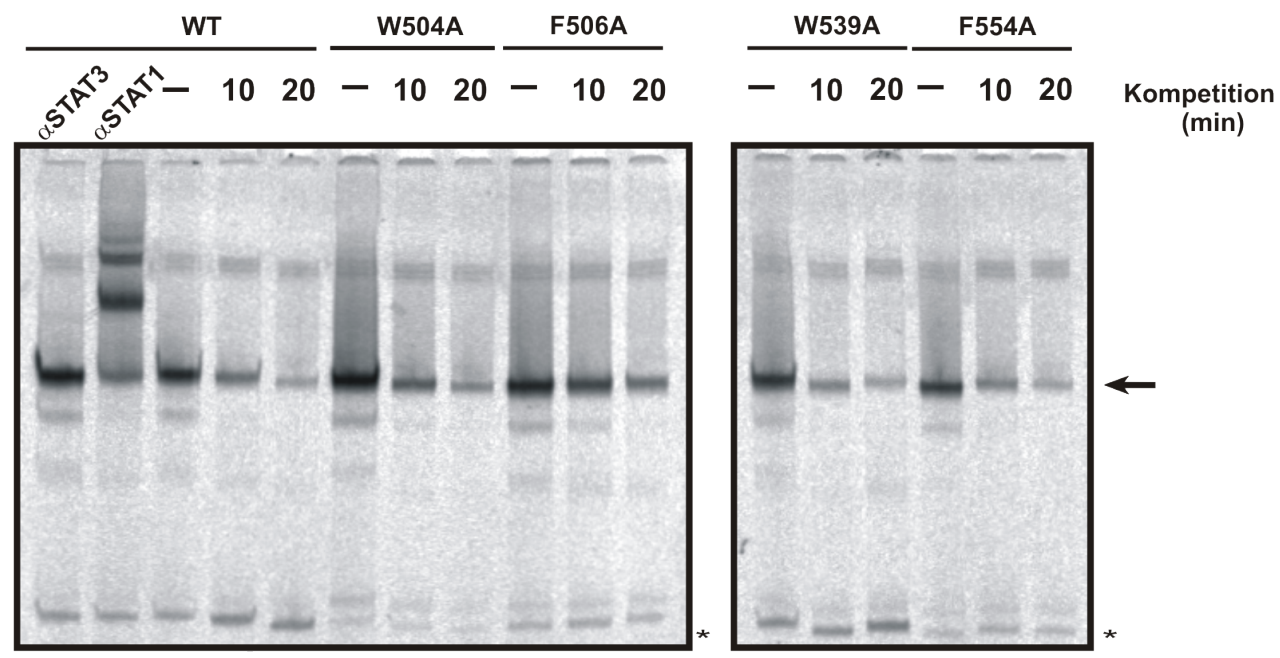

B

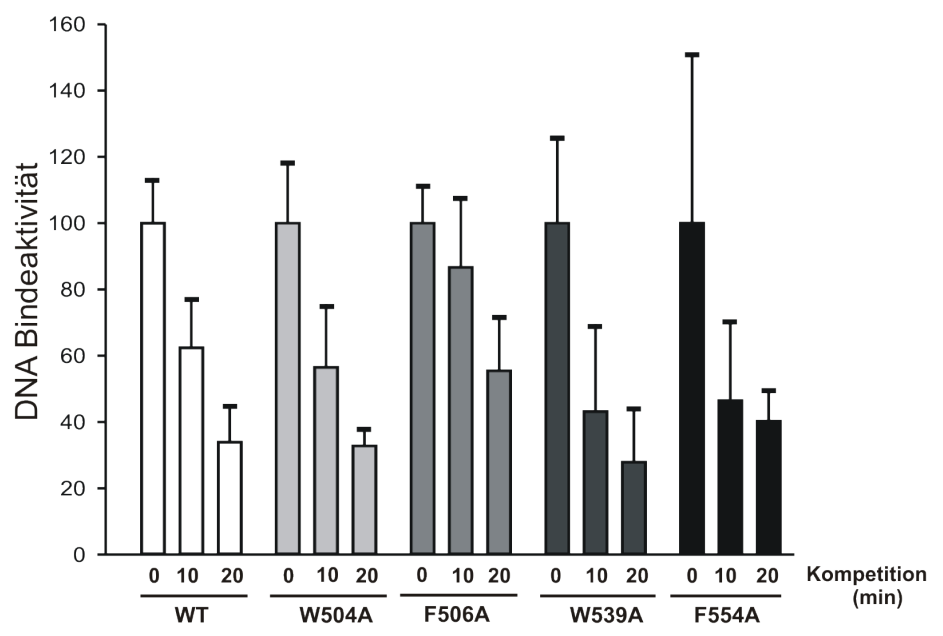

Abbildung 3.8: STAT1-W504A, STAT1-F506A und STAT1-W539A zeigen eine dem Wildtyp-Molekül ähnliche Dissoziationsrate von DNA. (A) Mit pSTAT1-WT, pSTAT1W504A, pSTAT1-F506A, pSTAT1-W539A oder pSTAT1-F554A transfizierte U3AZellen wurden für 45 Minuten mit $10 \mathrm{ng} / \mathrm{mL}$ IFN $\gamma$ stimuliert. Ferner wurden Gesamtzellextrakte erstellt. Diese wurden für 15 min mit radioaktiv markierter M67-Sonde inkubiert und im Anschluss mit einer unmarkierten M67-DNA im 750-fachen molaren Überschuss für die angegebenen Zeiten auf Eis inkubiert. Die Proben wurden auf native Polyacrylamidgele aufgetragen und gelelektrophoretisch aufgetrennt. Die vakuumgetrockneten Gele wurde sodann autoradiographisch ausgewertet. Spezifische STAT1Banden sind mit einem Pfeil markiert. Für den Nachweis der STAT1-Identität erfolgte eine Supershift-Reaktion mit einem spezifischen STAT1-Antikörper ( $\alpha$ STAT1) und einem Kontroll-Supershift mit spezifischem STAT3-Antikörper ( $\alpha$ STAT3). (B) Die Abbildung zeigt die Quantifizierung der detektierten STAT1-DNA-Komplexe zu den beschriebenen Zeitpunkten nach Zugabe des Kompetitors. 

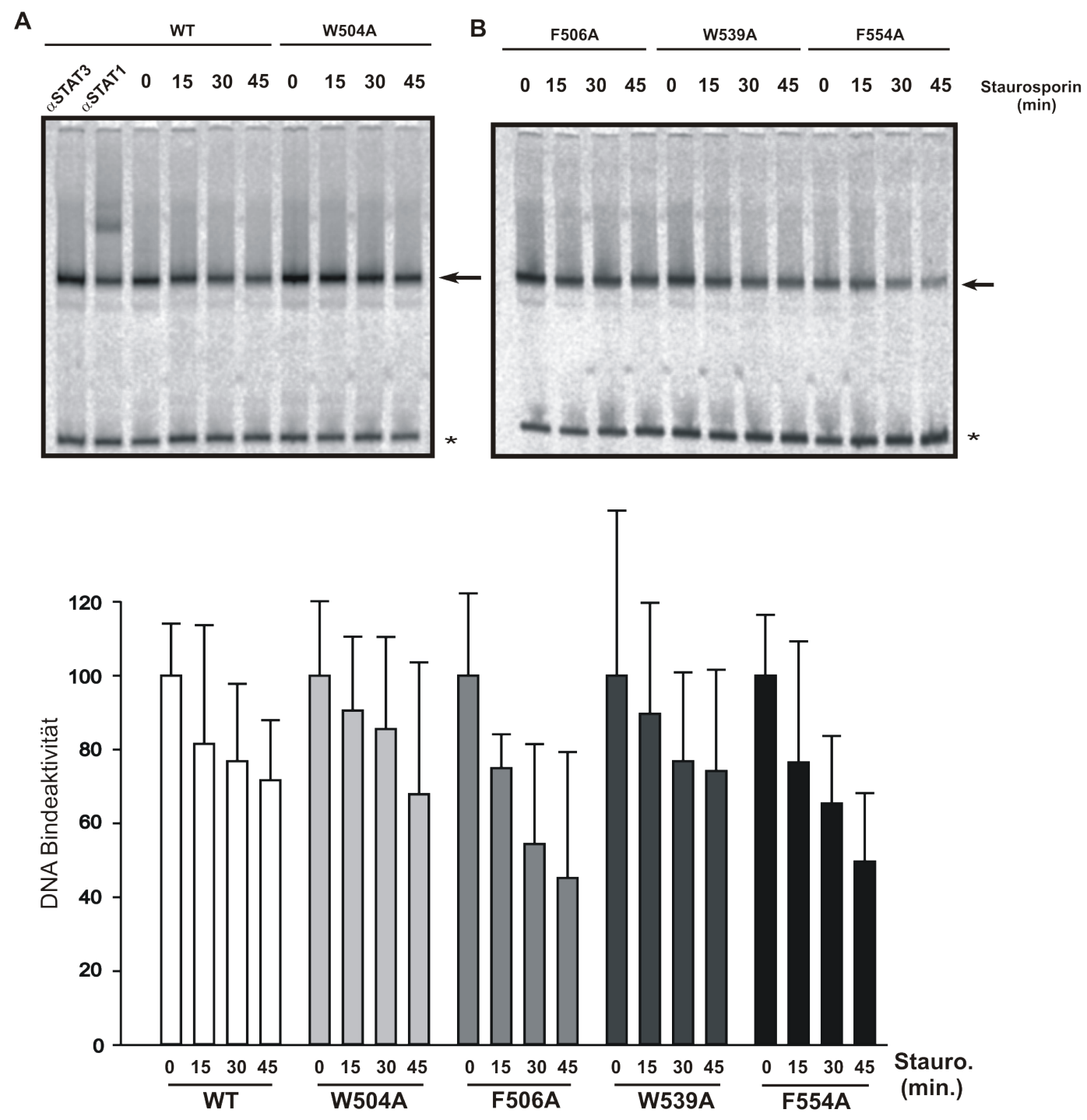

Abbildung 3.9: Nachweis der erhaltenen GAS-Bindung aller Mutanten. STAT-WTGFP- bzw. STAT1-W504A-GFP-, STAT1-F506A-GFP-, STAT1-W539A-GFP-, STAT1F554A-GFP-exprimierende U3A-Zellen wurden für $45 \mathrm{~min}$ mit $10 \mathrm{ng} / \mathrm{mL} \mathrm{IFN \gamma}$ stimuliert und anschließend für die angegebenen Zeiten mit Staurosporin behandelt. Die gewonnenen Gesamtzellextrakte wurden für 15 Minuten mit radioaktiv markierter M67Sonde bei RT inkubiert und im Anschluss gelelektrophoretisch aufgetrennt. DNASTAT1-Komplexe sind mit einem Pfeil, unspezifische Banden mit einem Stern $\left(^{*}\right)$ gekennzeichnet. Der Nachweis der STAT1-Identität erfolgte über eine Supershift-Reaktion mit einem spezifischen STAT1-Antikörper $(\alpha$ STAT1) und ein Kontroll-Supershift mit unspezifischem STAT3-Antikörper ( $\alpha$ STAT3). 


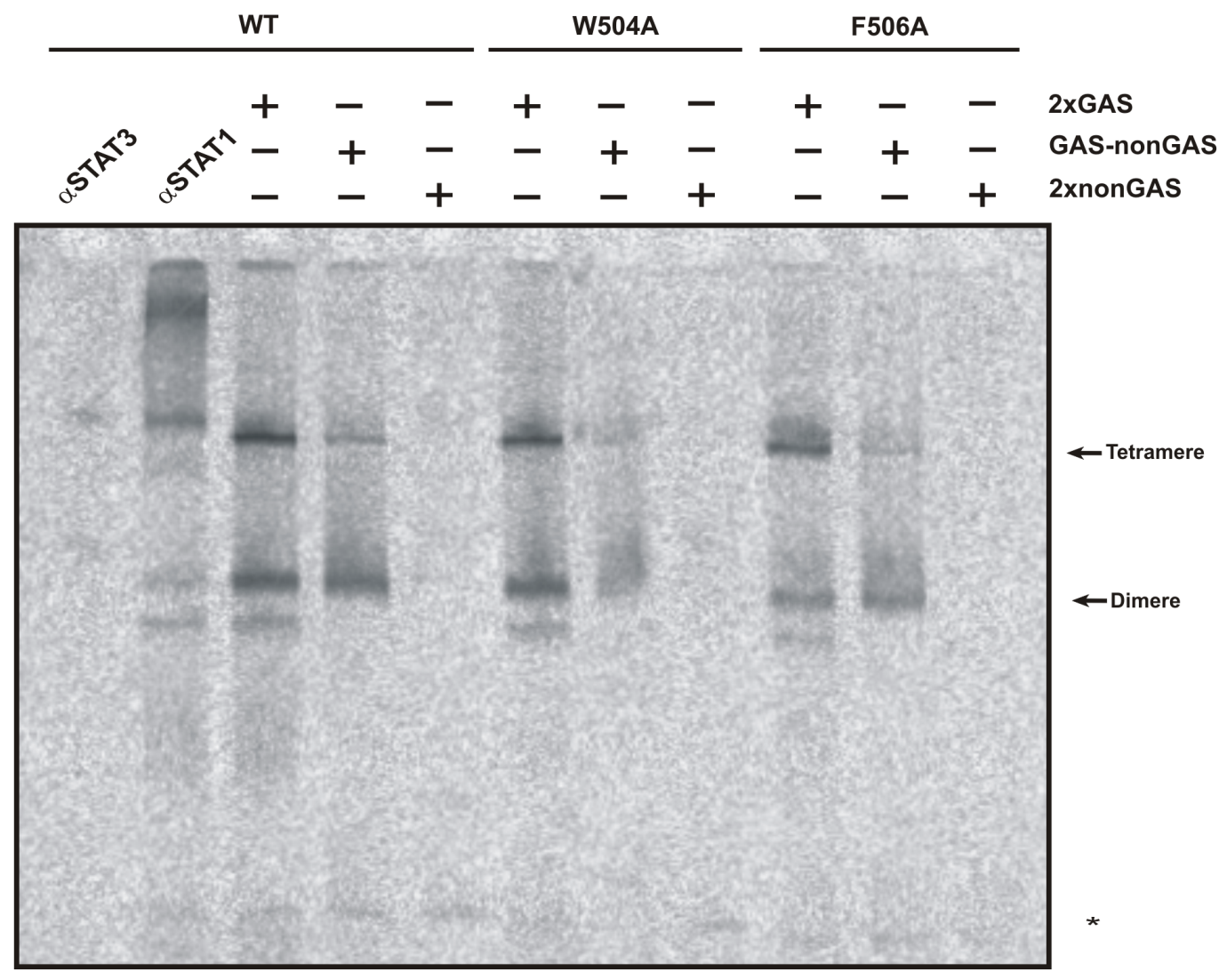

Abbildung 3.10: Gleiche DNA-Bindeaffinität von STAT1-W504A und STAT1-F506A im Vergleich zum Wildtyp-Protein. Für dieses Experiment wurden U3A-Zellen mit pSTAT1-WT-GFP, pSTAT1-W504A-GFP oder pSTAT1-F506A-GFP transfiziert und anschließend jeweils mit $10 \mathrm{ng} / \mathrm{mL} \mathrm{IFN} \gamma$ stimuliert. Die erhaltenen nukleären Extrakte wurden im Anschluss wie in der Abbildung beschrieben mit verschiedenen DNA-Sonden inkubiert. Anschließend wurden die Proben auf ein Polyacrylamidgel aufgetragen und gelelektrophoretisch aufgetrennt. Dieses wurde autoradiographisch ausgewertet. Spezifische STAT1-Banden sind mit einem Pfeil, unspezifische Banden mit einem Stern markiert. Für den Nachweis der STAT1-Spezifität erfolgte eine Supershift-Reaktion mit spezifischem STAT1-Antikörper ( $\alpha$ STAT1) und ein Kontroll-Supershift mit STAT3Antikörper ( $\alpha$ STAT3).

\subsection{Reportergenaktivierung von STAT1-W539A und STAT1-F554A}

Zur Untersuchung der transkriptionellen Aktivität der Punktmutanten STAT1W539A und STAT1-F554A wurden Reportergen-Assays durchgeführt. Hierbei kamen sowohl zwei native als auch ein synthetischer Promotor in LuciferaseReportern zum Einsatz. Beide nativen Promotoren beinhalteten eine singuläre GASBindestelle, wobei das Reportergen pIC-339 einen trunkierten Promotor des ICAM1-Gens enthielt und pIC-1352 den Volle-Länge-Promotor, welcher für das humane 
intrazelluläre Adhäsionsmolekül 1 (ICAM-1) kodiert. Der synthetische LuciferaseReporter (3xLy6E) enthielt drei Konsensus-GAS-Bindestellen. Die U3A-Zellen wurden mit den Plasmiden pSTAT1-WT-GFP, pSTAT1-W539A-GFP oder pSTAT1F554A-GFP und den Reportern pIC-339, pIC-1352 oder pGAS3xLy6E sowie p $\beta$ Galaktosidase transfiziert. Nach 16-24 h wurden die Zellen unbehandelt gelassen oder für $6 \mathrm{~h}$ mit $10 \mathrm{ng} / \mathrm{mL}$ IFN $\gamma$ stimuliert. Anschließend wurde die LuciferaseAktivität mithilfe eines spektrometrischen Verfahrens bestimmt und auf die $\beta$ Galaktosidaseaktivität normiert. Aus Abb. 3.11 ist zu entnehmen, dass die transkriptionelle Aktivität von STAT1-W539A und STAT1-F554A sowohl bei der Verwendung nativer Promotoren als auch des synthetischen Promotors signifikant vermindert ist. Bei vorausgegangenen Western-Blot-Analysen konnte für STAT1-F554A wie erwähnt ein diskret vermindertes Phosphorylierungsniveau gezeigt werden (Abb. $3.2)$.

\subsection{Genaktivierung von W504A und F506A}

Weiterhin wurde die transkriptionelle Aktivität der STAT1-Derivate W504A und F506A im Vergleich zum STAT1-Wildtyp im Reportergen-Experiment untersucht. Zu diesem Zweck wurde, wie bereits für STAT1-W539A und STAT1-F554A, ein synthetischer Luciferase-Reporter mit dreifacher GAS-Bindestelle verwendet. Die mit pSTAT1-W504A-GFP bzw. pSTAT1-F506A-GFP, pGAS3xLy6E und p $\beta$ Galaktosidase transfizierten U3A-Zellen wurden 16-24 h nach Transfektion im unstimulierten Zustand belassen oder über $6 \mathrm{~h}$ mit $10 \mathrm{ng} / \mathrm{mL} \mathrm{IFN} \gamma$ behandelt. Die Luciferase-Aktivität wurde anschließend spektrometrisch ermittelt und auf die $\beta$ Galaktosidaseaktivität normiert. Mittelwerte und Standardabweichungen wurden bestimmt. In Abb. 3.12 wird demonstriert, dass für die STAT1-Mutanten W504A und F506A an dem synthetischen Promotor eine höhere transkriptionelle Aktivität als in STAT1-WT-exprimierenden Zellen gefunden wurde.

Zur weiteren Überprüfung der In-vitro-Genaktivierung der Punktmutanten STAT1-W504A und STAT1-F506A wurden zusätzliche Reportergen-Assays durchgeführt in diesem Fall unter der Verwendung von nativen Promotoren mit singulärer GAS-Bindestelle: pIC-339, bestehend aus einer trunkierten Form des Promotors des ICAM-1-Gens, und pIC-1352, welches für den Volle-Länge-Promotor des Gens für das humane intrazelluläre Adhäsionsmoleküls 1 kodiert. Die transkriptionelle Aktivität von STAT1-W504A und STAT1-F506A ist unter Verwendung nativer Promotoren vermindert (Abb. 3.13). Somit konnten für die Mutanten STAT1-W504A und STAT1-F506A widersprüchliche Ergebnisse hinsichtlich der Genaktivierung in Abhängigkeit von der Art des Promotors im Vergleich zum Wildtyp-Protein gefunden werden (Abb. 3.12 und Abb. 3.13). 
A

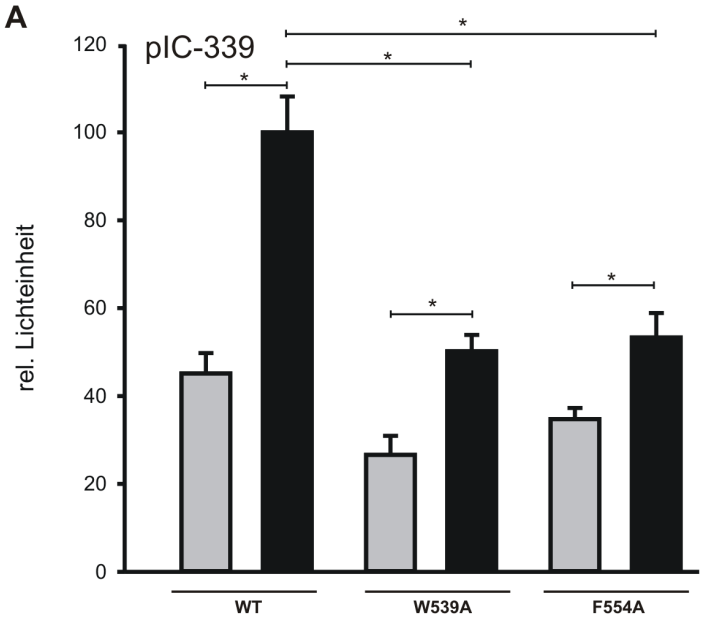

C

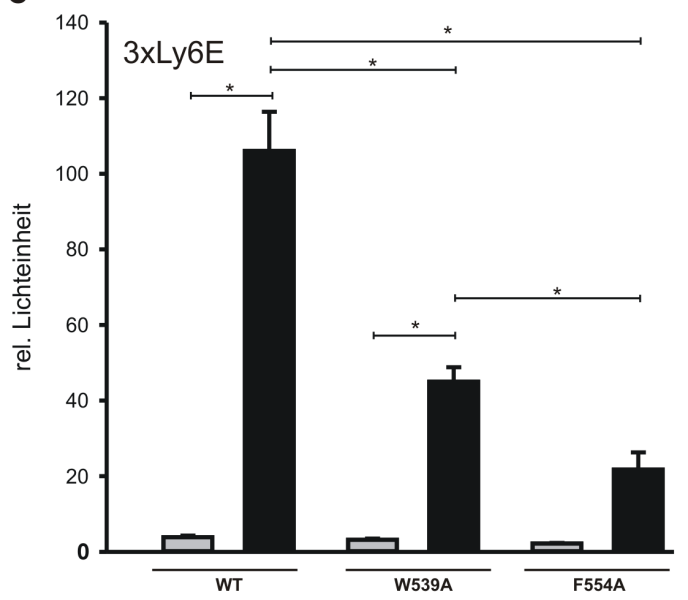

B

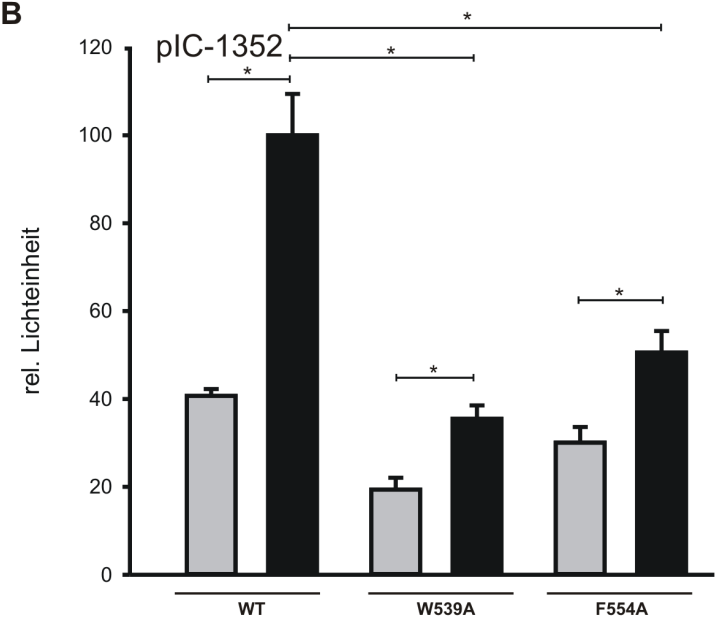

Abbildung 3.11: Die transkriptionelle Aktivität von STAT1-W539A und STAT1-F554A ist im Reportergen-Assay vermindert. U3A-Zellen wurden mit pSTAT1-WT, pSTAT1W539A-GFP bzw. pSTAT1-F554A-GFP sowie mit p $\beta$ Gal und entweder pIC-339 (A), pIC-1352 (B) oder p3xLy6E (C) transfiziert und nach 16-24 h entweder unbehandelt belassen (grauer Balken) oder $6 \mathrm{~h} \mathrm{mit} 10 \mathrm{ng} / \mathrm{mL}$ IFN $\gamma$ stimuliert (schwarzer Balken). Nach erfolgter Zelllyse wurde die Luciferaseaktivität gemessen und auf die $\beta$ Galaktosidaseaktivität der jeweiligen Probe normiert. Dargestellt sind die Mittelwerte und Standardabweichungen der vorgenommenen Sechsfachmessung. Statistisch signifikante Unterschiede sind mit einem Stern $\left(^{*}\right)$ gekennzeichnet.

\subsection{Endogene Zielgenaktivierung von STAT1-W504A, -F506A, -W539A und -F554A}

In den vorausgegangenen Experimenten Reportergen-Assays wurde gezeigt, dass die STAT1-Derivate W539A und F554A sowohl an synthetischen sowie an nativen Promotoren eine geringere transkriptionelle Aktivität aufweisen (Abb. 3.11). Bei den STAT1-Mutanten STAT1-W504A und STAT1-F506A bestand hingegen eine Diskrepanz zwischen dem Promotor 3xLy6E und den beiden Promotorbestandteilen aus 


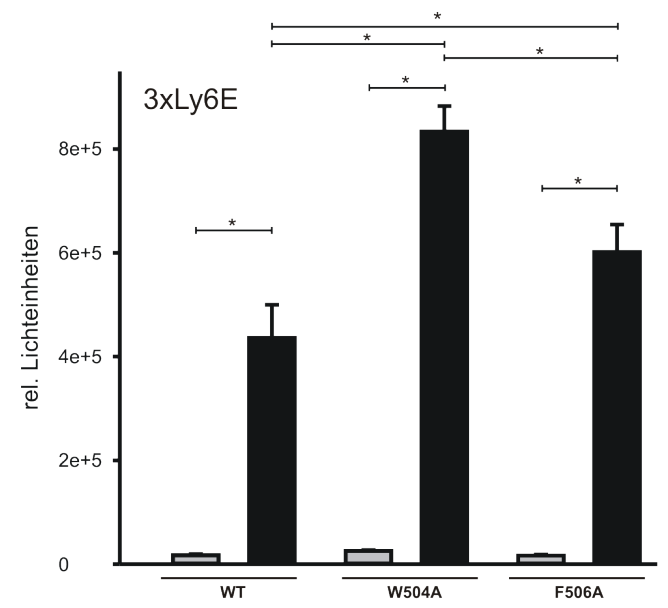

Abbildung 3.12: Die transkriptionelle Aktivität von STAT1-W504A und STAT1-F506A ist im Reportergen-Assay mit einem 3xLy6E-Promotor höher als beim STAT1-WT. U3A-Zellen wurden mit den Plasmiden pSTAT1-WT-GFP, -W504A-GFP bzw. -F506AGFP sowie mit $\mathrm{p} \beta$-Gal und pGAS3xLy6E transfiziert. Nach 16-24 h wurden die Zellen unbehandelt belassen (grauer Balken) oder $6 \mathrm{~h}$ mit $10 \mathrm{ng} / \mathrm{mL} \mathrm{IFN} \gamma$ stimuliert (schwarzer Balken). Aus den anschließend gewonnenen Gesamtzellextrakten wurde spektrometrisch die Luciferase-Aktivität gemessen und auf die $\beta$-Galaktosidase-Aktivität der jeweiligen Probe normiert. Aus den sechs unabhängigen Transfektionen wurden Standardabweichungen und Mittelwerte berechnet. Der Stern $\left(^{*}\right)$ kennzeichnet statistisch signifikante Abweichungen.

dem humanen ICAM-1-Gen. Die transkriptionelle Aktivität zeigte sich am synthetischen Promotor vermehrt und an den nativen Promotoren statistisch signifikant vermindert (Abb. 3.12 und Abb. 3.13). Zur weiteren Untersuchung der Genexpression wurde die Induktion von fünf bekannten endogenen STAT1-Zielgenen mittels real-time-PCR in vivo untersucht. Dabei handelte es ich um die Zielgene mig1, gbp1, mcp1, cxcl10 und irf1, deren Aktivierung IFN $\gamma$-abhängig induziert wird. U3A-Zellen wurden transient mit pcDNA3.1-STAT1-WT, -W504A, -F506, -W539A und -F554A transfiziert. 16-24 h nach Transfektion wurde ein Mediumwechsel gegen ein serumverarmtes $1 \%$ FCS-haltiges Kulturmedium vorgenommen und die rekonstituierten U3A-Zellen für $6 \mathrm{~h}$ mit $10 \mathrm{ng} / \mathrm{mL}$ IFN $\gamma$ stimuliert oder unbehandelt belassen. Anschließend erfolgte die Isolation der RNA, die mittels reverser Transkriptase in cDNA ungeschrieben wurde. Die Genexpression wurde mithilfe der real-time-PCR detektiert und die Werte auf die zugehörigen Ergebnisse des Haushaltsgens gapdh normiert. 
A

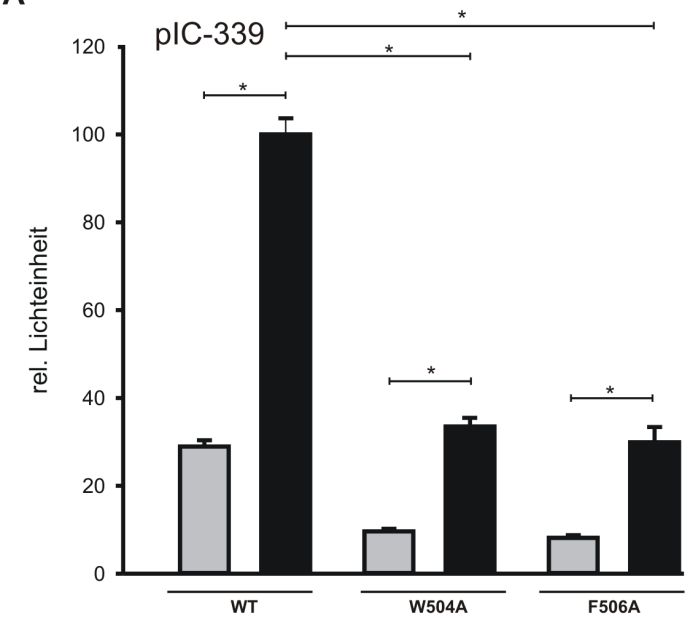

B

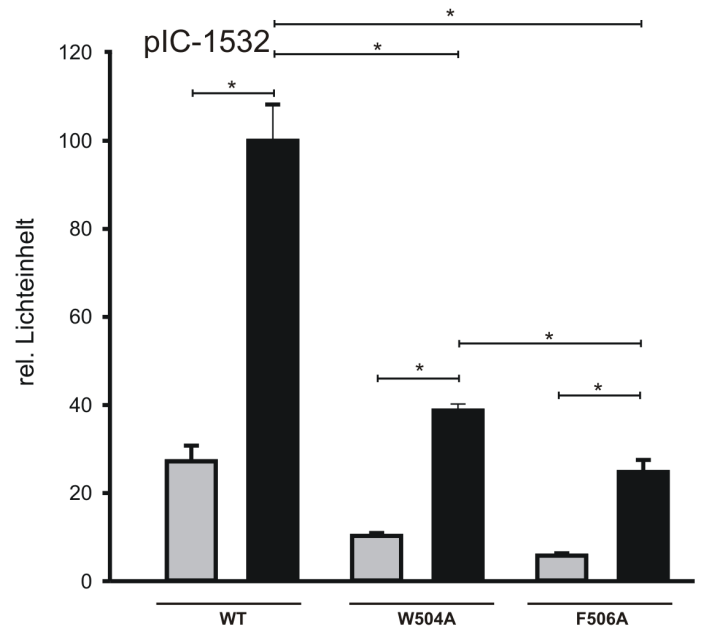

Abbildung 3.13: Unter Verwendung nativer Promotoren im Reportergen-Assay ist die transkriptionelle Aktivität von STAT1-W504A und STAT1-F506A im Vergleich zum STAT1-Wildtyp vermindert. U3A-Zellen wurden mit den Plasmiden pSTAT1-WT-GFP, pSTAT1-W504A-GFP, pSTAT1-F506A-GFP, ferner mit pIC-339 (A) bzw. pIC-1352 (B) und $\mathrm{p} \beta$ Gal transfiziert. Nach $16-24 \mathrm{~h}$ erfolgte eine Stimulation mit $10 \mathrm{ng} / \mathrm{mL}$ IFN $\gamma$ (schwarzer Balken) oder die Zellen wurden unbehandelt belassen (grauer Balken). Aus den isolierten Zellextrakten wurde die Luciferase- sowie die $\beta$-Galaktosidaseaktivität gemessen. Die Normierung erfolgte auf die $\beta$-Galaktosidaseaktivität. Die Berechnung von Mittelwerten und Standardabweichungen erfolgte aus den Werten von sechs unterschiedlichen Transfektionen. Statistisch signifikante Unterschiede sind durch einen Stern $\left(^{*}\right)$ markiert.

\subsection{Differentielle Genaktivierung von STAT1-W504A}

Zur Untersuchung der Interferon-abhängigen Induktion von STAT1-Zielgenen durch die Mutante STAT1-W504A wurden real-time-PCR-Experimente durchgeführt. Obwohl die STAT1-Menge bei der Mutante im Vergleich zum Wildtyp signifikant vermindert war, zeigte sich bei mcp1 und cxcl1 eine erhöhte Geninduktion (Abb. 3.14 D,E). Die Genexpression von mig1 und gbp1 zeigte keine signifikante Abweichung zum STAT1-Wildtyp und die Genexpression von irf1 war diskret vermindert (Abb. 3.14 D,E). Bei vorausgegangenen Versuchen zur Genaktivierung von STAT1-W504A zeigte sich für die Mutante eine erhöhte transkriptionelle Aktivität am synthetischen 3xLy6E-Promotor; bei den nativen Promotoren pIC-339 und pIC-1352 hingegen war diese vermindert (Abb. 3.12 und Abb. 3.13). 

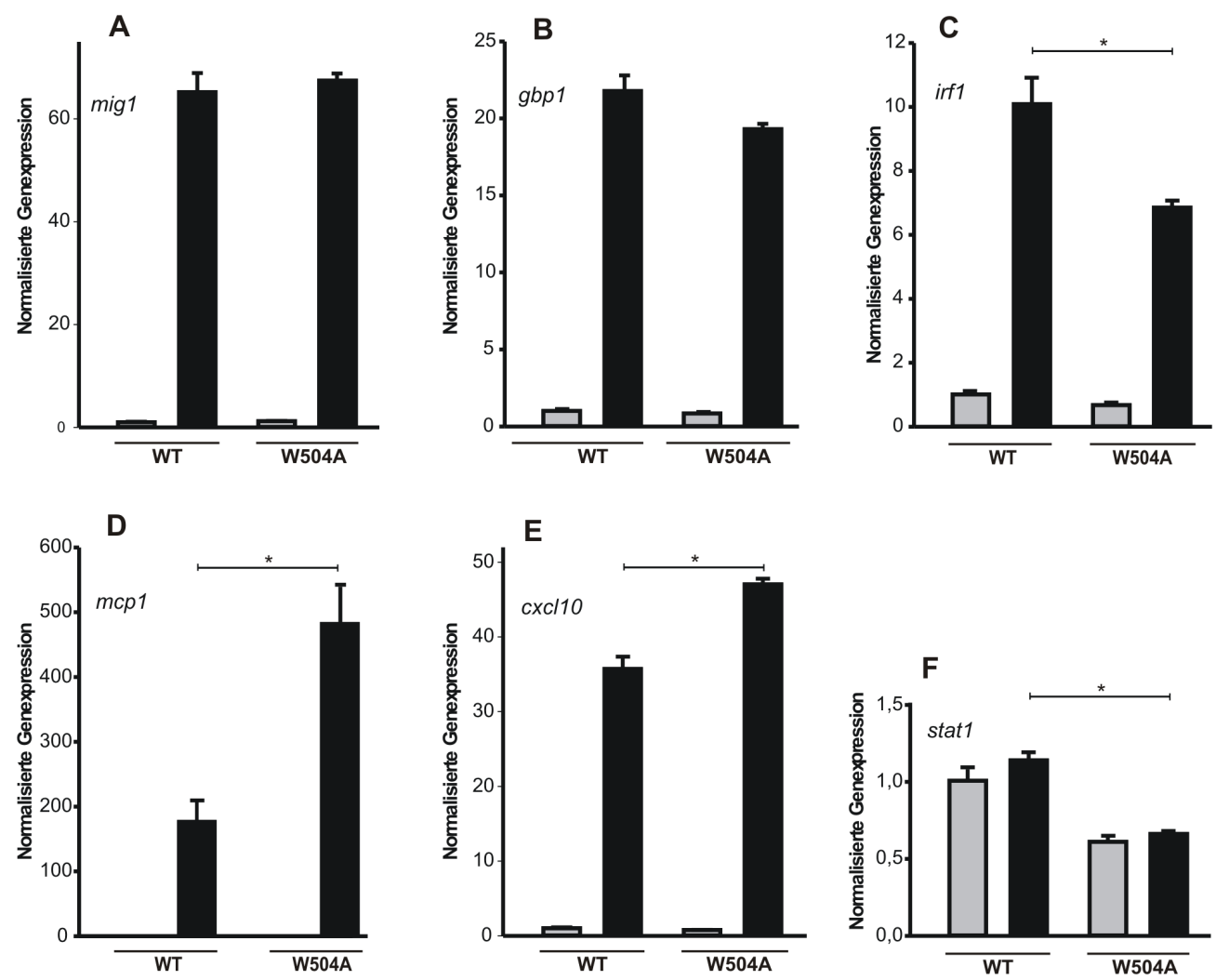

Abbildung 3.14: STAT1-W504A zeigt eine differentiell unterschiedliche Genexpression zum Wildtyp-Molekül. Nach Transfektion mit pcDNA3.1-Plasmiden kodierend für STAT1-W504A und STAT1-WT wurden die rekonstituierten U3A-Zellen in serumverarmtem Kulturmedium mit $1 \%$ FCS kultiviert. Am Folgetag wurden die Zellen unbehandelt belassen (grauer Balken) oder für $6 \mathrm{~h}$ mit $10 \mathrm{ng} / \mathrm{mL} \mathrm{IFN} \gamma$ stimuliert (schwarzer Balken). Aus den Zellysaten wurde die RNA extrahiert und anschließend cDNA hergestellt. Die Genexpression der oben genannten Zielgene wurde mittels real-time-PCR überprüft und auf die entsprechenden Werte von gapdh normiert. Aus den Doppelmessungen wurden Standardabweichungen und Mittelwerte berechnet. Statistisch signifikante Unterschiede sind mit einem Stern $\left(^{*}\right)$ gekennzeichnet. 


\subsection{Zielgenaktivierung von STAT1-F506A und STAT1-W539A}

Abb. 3.15 zeigt die Aktivierung endogener Zielgene durch die Mutanten STAT1F506A und -W539A nach 6-stündiger Stimulation mit IFN $\gamma$ im Vergleich zum STAT1-WT. Das Wildtyp-Molekül weist eine deutliche Zunahme aller untersuchten STAT1-Zielgene auf. Trotz vergleichbarer STAT1-Expression (Abb. 3.15 D) bei Wildtyp und den STAT1-Derivaten wurde bei beiden Mutanten ein signifikant erniedrigtes Genexpressionsniveau für die Zielgene mig1, gbp1, irf1 und mcp1 detektiert. Dieses zeigte sich bei mig1 besonders ausgeprägt (Abb. 3.15 A). Des Weiteren fand sich auch für STAT1-F506A im Vergleich zu STAT1-WT für die Gesamtheit der oben genannten Zielgene ein signifikant niedrigeres Aktivitätsniveau.

\subsection{Verminderte Zielgenaktivierung von STAT1-F554A}

Wie zuvor bei der Untersuchung der Genaktivierung im Reportergen-Assay konnte für die STAT1-Punktmutante STAT1-F554A ebenfalls eine verminderte Genaktivierung von endogenen STAT1-Zielgenen aufgezeigt werden. Wie Abb. 3.16 zu entnehmen, fand sich für STAT1-F554A eine signifikant erniedrigte transkriptionelle Aktivität für die Gene cxcl10, gbp1 und irf1. Dies bestätigt, dass der Austausch des Phenylalanins an Position 554 des STAT1-Proteins sowohl zu einem erniedrigten Phosphorylierungsniveau (Abb. 3.2) als auch zu einer verminderten IFN $\gamma$ induzierten Genexpression führt. 

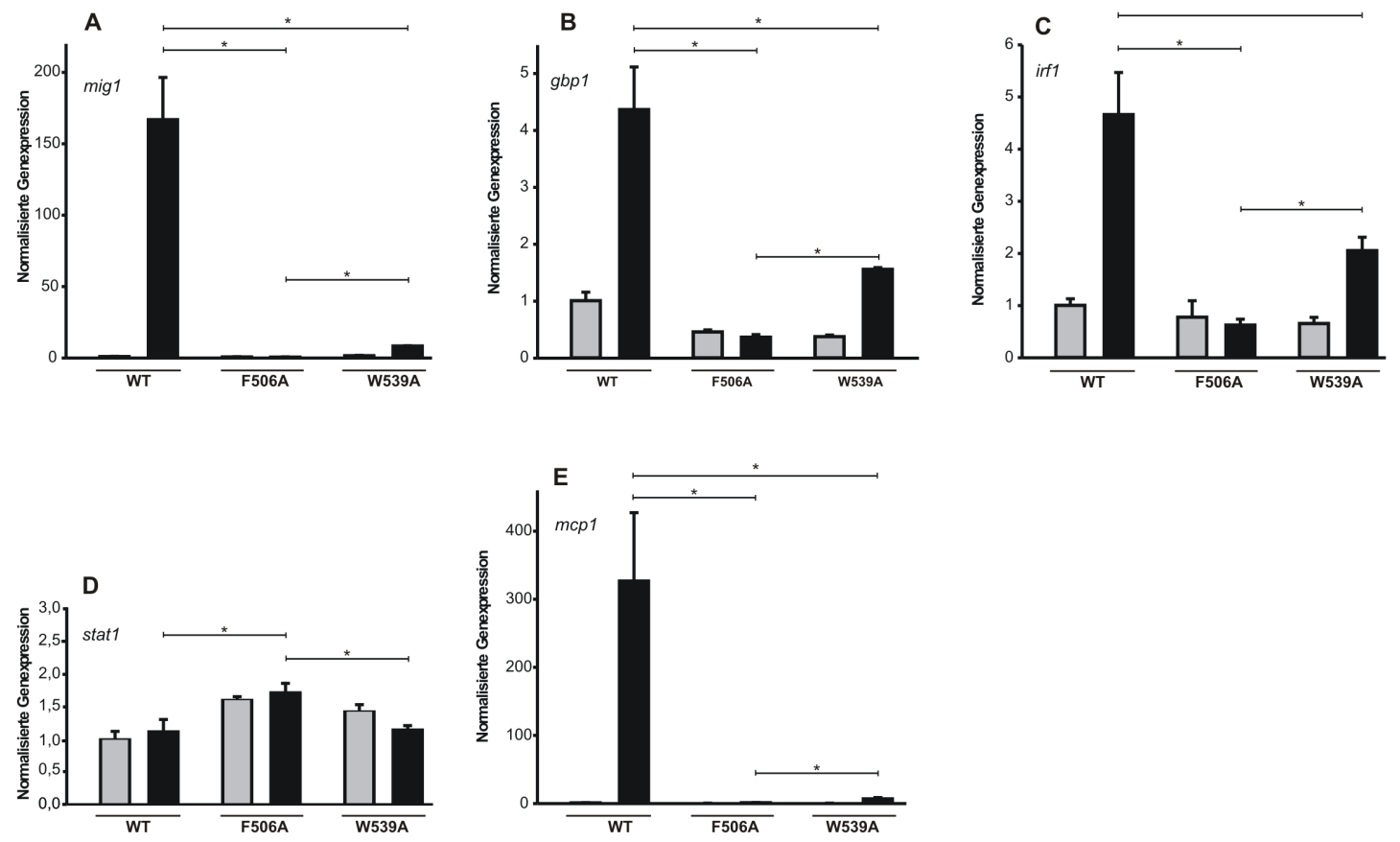

Abbildung 3.15: Verminderte Zielgenaktivierung von STAT1-F506A und -W539A. Die aufgeführten STAT1-rekonstituierten U3A-Zellen wurden nach Transfektion in Nährmedium mit $1 \%$ FCS kultiviert. Am Folgetag wurden die Zellen unbehandelt belassen (grauer Balken) oder $6 \mathrm{~h}$ mit $10 \mathrm{ng} / \mathrm{mL}$ IFN $\gamma$ stimuliert (schwarzer Balken). Aus den gewonnenen Zelllysaten wurde die RNA extrahiert und in cDNA umgeschrieben. Die Genexpression von (A) mig1, (B) gbp1, (C) irf1, (D) stat1 und (E) mcp1 wurde mittels real-time-PCR überprüft und auf das Haushaltsgens gapdh normiert. Aus Doppelmessungen wurden Mittelwerte und Standardabweichungen berechnet. Statistisch signifikante Abweichungen sind mit einem Stern $\left(^{*}\right)$ markiert. 

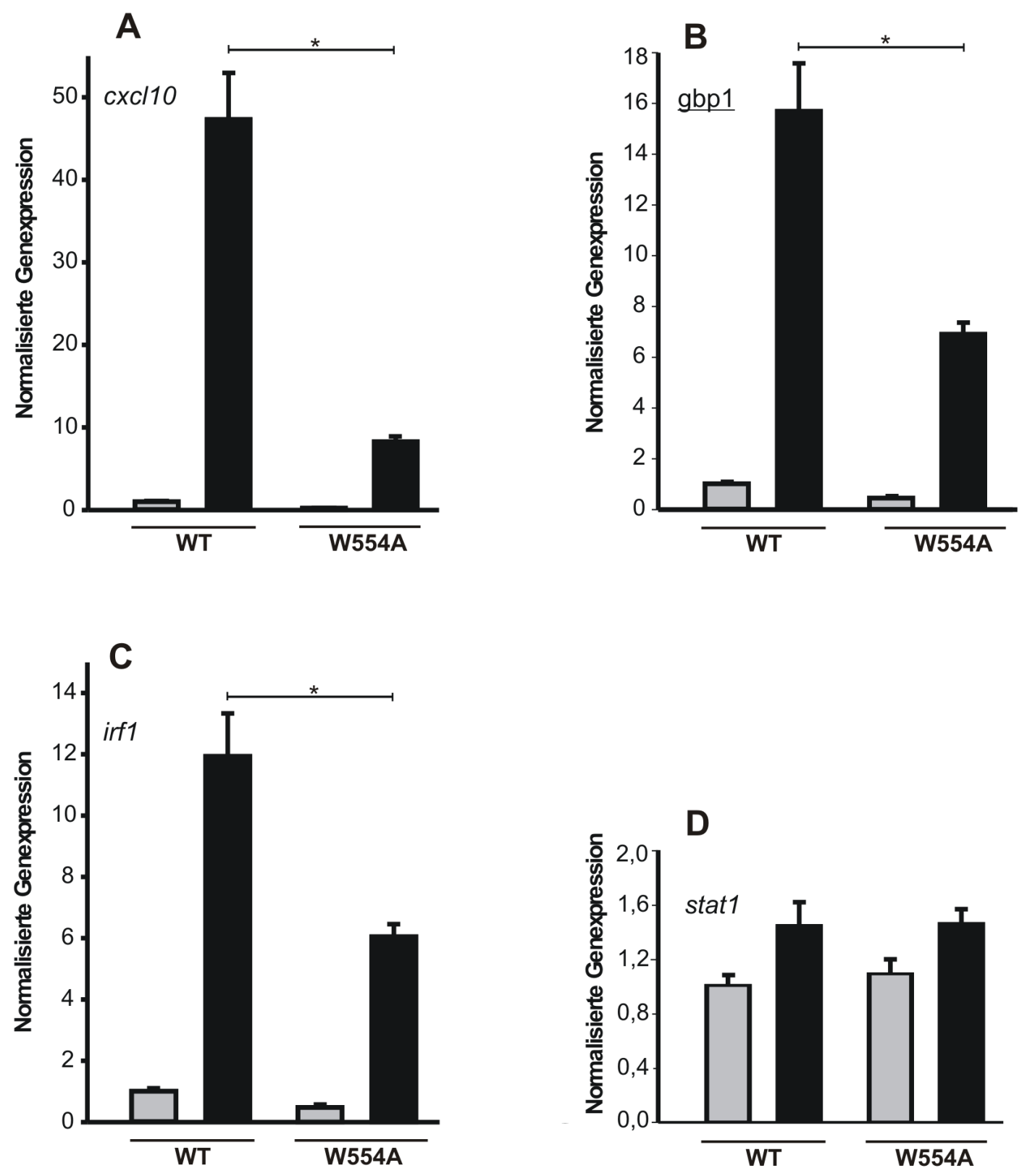

Abbildung 3.16: Die Punktmutante W554A zeigt eine verminderte Genaktivierung. U3A-Zellen wurden mit pcDNA3.1-STAT1-F554A transfiziert und im Anschluss in einem Nährmedium mit 1 \% FCS kultiviert. Am Folgetag wurden die Zellen unbehandelt belassen (grauer Balken) oder $6 \mathrm{~h}$ mit $10 \mathrm{ng} / \mathrm{mL}$ IFN $\gamma$ stimuliert. Anschließend wurde die RNA aus den Zellen extrahiert, cDNA hergestellt und die Expression von (A) cxcl10, (B) $g b p 1$, (C) irf1 und (D) stat1 mittels real-time-PCR überprüft. Die Expressionsrate des jeweiligen Gens wurde auf die entsprechenden Werte der gapdh-Messung normiert. Es wurden Doppelmessungen vorgenommen und Mittelwerte und Standardabweichungen berechnet. Statistisch signifikante Unterschiede sind mit einem Stern $\left(^{*}\right)$ gekennzeichnet. 


\section{Diskussion}

Der JAK-STAT-Weg ist ein hoch konservierter und intensiv untersuchter Signaltransduktionsweg, nicht zuletzt aufgrund seiner entscheidenden Mitwirkung an lebensnotwendigen Prozessen bei der Immunabwehr. Mehrere Arbeitsgruppen beschrieben Mutationen in der Sequenz von STAT1, welche zu Immundefekten und assoziierten Krankheiten prädisponieren (Liu et al. 2011; Boisson-Dupuis et al. 2012). So wurden eine Reihe von Gain-of-function-Mutationen identifiziert, welche unter anderem zu chronisch vaginalen und kutanen Candidainfektionen führen (Van de Veerdonk et al. 2011).

Die vorliegende Arbeit untersucht den Phänotyp von vier in der Linker-Domäne des STAT1-Proteins generierten Substitutionsmutanten. Hierzu wurden hoch konservierte Aminosäurereste (je zwei Phenylalanine und Tryptophane) durch die Einführung von Punktmutationen an Position 504, 506, 539 und 554 der Linker-Domäne des STAT1-Proteins jeweils nach Alanin mutiert (Tab. 3.1-3.4). Bei den Mutanten wurde das Phosphorylierungsniveau, die Kernakkumulation, die Fähigkeit zur DNABindung sowie die Genaktivierung untersucht. Als Referenz diente dabei stets der STAT1-WT, dessen Eigenschaften mit denen der Mutanten verglichen wurden.

In der Literatur sind bisher nur wenige Arbeiten über den Einfluss von Mutationen der Linker-Domäne auf die Aktivität von STAT1 veröffentlicht worden. Allen voran hatten Yang et al. in den Jahren 1999 und 2002 Arbeiten zur Charakterisierung der Doppelmutante STAT1-(KE544-545AA) publiziert. Zu Beginn wurde von der Linker-Domäne als SH3-Domäne gesprochen (Fu 1992). Eine Hypothese zur Mitwirkung der Linker-Domäne in der Transkriptionsmaschinerie des STAT1-Moleküls war, dass die Linker-Domäne eine Rolle in der Rekrutierung von Koaktivatoren der Transkription spielt (Yang et al. 1999). Für andere Domänen des STAT1-Proteins wurde die Interaktion mit diversen Koaktivatoren bereits untersucht. Es konnte gezeigt werden, dass die transkriptionelle Aktivierung durch STAT1 unter anderem von der Bindung und Mitwirkung der Kofaktoren CBP, p300, MCM5 und Nmi abhängt (Zhang et al. 1996; Zhang et al. 1998; Zhu et al. 1999).

Unsere Arbeitsgruppe hat sich im Rahmen von zwei bisher veröffentlichten Dissertationsschriften (Staab 2011; Bolten 2013) und einer Veröffentlichung (Hüntelmann et al. 2014) mit den Eigenschaften von Substitutionsmutanten in der Linker-Domäne auseinandergesetzt. Dabei zeigen die Punktmutanten der Linker-Domäne (STAT1- 
E500A, -K525A, -K550A, -K550E, -E559, -E563, -E605A ) unter anderem Veränderungen der Genaktivierung, eine Beeinträchtigung der DNA-Bindung sowie eine verbesserte transkriptionelle Aktivität. Ob die Linker-Domäne auch Interaktionsfläche für Kofaktoren bietet, bleibt ein interessantes Feld für weitere Experimente.

\subsection{Struktur und Funktion der Domänen}

Erste Erkenntnisse über die dreidimensionale Struktur ergaben sich durch kristallographische Untersuchungen phosphorylierter DNA-gebundener STAT1- und STAT3Homodimere (Becker et al. 1998; Chen et al. 1998). Dabei konnte jedoch nur die Struktur des Kernfragments ohne den Aminoterminus dargestellt werden (Vinkemeier et al. 1998). Bei kristallographischen Untersuchungen des isolierten Aminoterminus von STAT4 konnte dieser erstmalig dargestellt werden. Nachfolgend wurde auch der STAT1-Aminoterminus im Kontext des unphosphorylierten Moleküls beschrieben (Mao et al. 2005). Die Untersuchung der initialen Kristallstruktur des isolierten Aminoterminus ergab ein alternatives Erklärungsmodell für die Interaktion der STAT1-Dimere und ihrer N-Termini (Vinkemeier et al. 1998; Chen et al. 2003). Abhängig vom Grad der Phosphorylierung ergeben sich zwei mögliche Konformationen. Bei dem phosphorylierten Dimer zeigen die beiden Protomere in die gleiche Richtung, sind also parallel zueinander ausgerichtet. In dieser Konformation ist das STAT-Dimer zur DNA-Bindung befähigt. Der Stabilisierung des parallelen Dimers dienen reziproke SH2-Phosphotyrosin-Wechselwirkungen.

Das unphosphorylierte STAT-Dimer wird durch N-terminale Wechselwirkungen sowie die Interaktion zwischen der Coiled-Coil-Domäne und der DNA-Bindedomäne stabilisiert. Möglicherweise kann das STAT-Dimer zwischen der parallelen und der antiparallelen Konformation wechseln, bei Letzterer sind die beiden SH2-Domänen in entgegengesetzter Richtung lokalisiert (Mao et al. 2005; Mertens et al. 2006; Wenta et al. 2008). Um von der TC-45 Phosphatase dephosphoryliert zu werden, muss das STAT-Dimer in antiparalleler Konformation vorliegen. Es wurde postuliert, dass die reziproke aminoterminale Interaktion bei der Lösung der SH2-PhosphotyrosinBindung assistiert und das Dimer somit für die Phosphatase zugänglich macht. Eine weitere möglich Annahme wäre, dass dafür zuvor eine Dissoziation des Dimers in seine beiden Monomere notwendig ist (Zhong et al. 2005; Mertens et al. 2006; Wenta et al. 2008). Im Folgenden werden die spezifischen Eigenschaften der verschiedenen STAT1-Domänen beleuchtet (Abb. 1.1). Experimente zur Untersuchung von STAT1Punktmutanten umfassen in dieser Arbeit ausschließlich die Linker-Domäne.

Die aminoterminale Domäne von STAT1 umfasst 135 Aminosäurereste, mit der höchsten Sequenzhomologie unter den ersten 100 Aminosäureresten. Die am höchsten konservierte Domäne des STAT1-Proteins ist die SH2-Domäne (Schindler, Dar- 
nell 1995; Shuai et al. 1996; Strehlow, Schindler 1998). Der Aminoterminus spielt eine Schlüsselrolle in der Vermittlung von Protein-Protein-Wechselwirkungen und ermöglicht die Tetramerisierung von STAT1-Dimeren, die kooperative DNA-Bindung auf GAS-Elementen (Xu et al. 1996; John et al. 1999). Mutationsexperimente im Aminoterminus mit Austausch eines konservierten Phenylalaninrests (STAT1: F77; STAT5: F81) nach Alanin ergaben, dass die transkriptionelle Aktivität durch die aufgehobene Fähigkeit zur Oligomerisierung bzw. der kooperativen DNA-Bindung signifikant vermindert war (Begitt et al. 2014). STAT1-F77A zeigte zusätzlich eine verminderte Abnahme des Phosphorylierungsniveaus, was damit erklärt wurde, dass die Punktmutation Einfluss auf den Shift der parallelen in die antiparallele Konformation hat und die antiparallele Konformation zur Interaktion mit der TC45-Phosphatase notwendig ist (Meyer et al. 2004; Mao et al. 2005; Mertens et al. 2006). Eine Punktmutation an der Position 37 von STAT1 (STAT1: W37A) führt $\mathrm{zu}$ einer verminderten Oligomerisierung in vitro und zu einer reduzierten transkriptionellen Aktivität in vivo, wahrscheinlich als Folge einer aminoterminalen Deletion (Vinkemeier et al. 1998). Der Aminoterminus ist ebenfalls an der Regulierung der Tyrosinphosphorylierung und Dephosphorylierung beteiligt (Shuai et al. 1996; Meyer et al. 2004). Neben der Interaktion mit Koaktivatoren wie dem CREB-bindenden Protein (CBP/p300), welches sowohl mit dem Aminoterminus als auch mit der carboxyterminalen Domäne von STAT1 kommuniziert (Zhang et al. 1996; Horvath 2000; Shuai 2000), ist die aminoterminale Domäne zusätzlich in der Interaktion von STAT1 und PIAS1 beteiligt. Die COOH-terminale Region von PIAS1 tritt direkt mit der $\mathrm{NH}_{2}$-terminalen Region von STAT1 in Verbindung (Liao et al. 2000; Shuai 2000).

Die Coiled-Coil-Domäne befindet sich im direkten Anschluss an den Aminoterminus mit dem sie über eine flexible, etwa 20 AS-Reste enthaltende Region verbunden ist (Mertens et al. 2006). Sie besteht aus vier langen $\alpha$-Helices. Die CoiledCoil-Domäne umfasst die Aminosäurereste 136-317 des STAT1-Proteins und ist Teil des STAT1-Kernfragments (Chen et al. 1998) (Abb. 1.1). Weitere Funktionen der Coiled-Coil-Domäne sind die intensive Interaktion mit Proteinen und Transkriptionsfaktoren (Chen et al. 1998; Shuai 2000) sowie der nukleäre Export. Es wurde eine leucinreiche helikale Region in der Coiled-Coil-Domäne von STAT1 als nukleäres Exportsignal (NES) identifiziert (Begitt et al. 2000).

Die DNA-Bindedomäne von STAT1, welche mit der SH2-Domäne die LinkerDomäne umgibt, befindet sich im Bereich der Aminosäuren 300-500 des STAT1Proteins. Der Aufbau der DNA-Bindedomäne ist strukturell dem Aufbau von Immunglobulinen ähnlich, ebenso wie die DNA-Bindedomäne der Transkriptionsfaktoren p50 und NF $\kappa$ B. Die DNA-Bindedomäne enthält in ihrer Sekundärstruktur 170 Aminosäuren, die in $\beta$-Faltblätter und Schleifen angeordnet sind (Bork et al. 1994; Chen et al. 1998). In STAT1-Dimeren tritt sie über DNA-Protein-Wechselwirkungen 
mit palindromischen DNA-Sequenzen in Kontakt. Dies bewirkt, dass je ein phosphoryliertes STAT1-Monomer eine halbe palindromische GAS-Stelle bindet. Sowohl die große als auch die kleine Furche der DNA sind an der Bindung beteiligt (Chen et al. 1998). Durch Mutationsexperimente im Bereich der DNA-Bindedomäne wurde gezeigt, dass diese Mutationen eine Veränderung der spezifischen DNA-Bindung bewirken (Darnell 1997; Meyer et al. 2003). Im Bereich der DNA-Bindedomäne befindet sich das nukleäre Lokalisationssignal (NLS), welches am nukleären Import aktivierter STAT1-Dimere beteiligt ist (Melen et al. 2001; Meyer et al. 2002).

In dieser Arbeit wurden Mutationsexperimente im Bereich der Linker-Domäne von STAT1 durchgeführt. Die Linker-Domäne umfasst die Aminosäuren 480-580 (Yang et al. 1999). Sie liegt zwischen der DNA-Bindedomäne und SH2-Domäne und beinhaltet mehrere $\alpha$-Helices sowie stark konservierte Aminosäurereste (Chen et al. 1998). Aus der Literatur ist bekannt, dass die bislang generierten Punktmutanten der Linker-Domäne zwar ein normales Phosphorylierungsniveau, einen unauffälligen nukleären Transport und normale DNA-Bindung zeigten, jedoch eine verminderte transkriptionelle Antwort auf IFN $\gamma$ besaßen. Die untersuchten Mutanten K544A und E545A zeigten eine erhöhte Off-Rate von der DNA, wodurch die verminderte transkriptionelle Aktivität erklärt wurde (Yang et al. 1999; Yang et al. 2002). Die Linker-Domäne ist am nukleozytoplasmatischen Transport von unphosphoryliertem STAT1 beteiligt. Unphosphoryliertes STAT1 bindet in vitro zytokinunabhängig an Nukleoporine des nukleären Porenkomplexes (Marg et al. 2004).

Die SH2-Domäne (AS-Reste: 575-680) ist die am stärksten konservierte Domäne des STAT-Proteins (Schindler, Darnell 1995). Sie nimmt eine zentrale Rolle in der zytokinabhängigen Signalweiterleitung im STAT-Signalweg ein. Über die SH2Domäne werden STAT1-Proteine an die phosphorylierten Rezeptoren rekrutiert, wo diese entweder vom Rezeptor selbst oder von rezeptor-assoziierten JAK-Kinasen an einem carboxyterminalen Tyrosin phosphoryliert werden (Darnell 1997). Im Anschluss bilden die phosphorylierten STAT-Monomere Homo- oder Heterodimere. Die Dimerbildung erfolgt durch die SH2-Phosphotyrosin-Interaktion der beiden STATProtomere (Shuai et al. 1994; Wenta et al. 2008). 


\subsection{Hypophosphorylierung von STAT1-F554A bewirkt verminderte Genaktivierung}

Die Mutante STAT1-F554A befindet sich wie alle im Rahmen dieser Arbeit untersuchten Mutanten in der Linker-Domäne des STAT1-Proteins. STAT1-F554A wird an dieser Stelle zum ersten Mal in einer Veröffentlichung beschrieben. An dieser Position des STAT1-Proteins wurde ein Phenylalanin nach Alanin mutiert. Die im Rahmen dieser Arbeit durchgeführten Experimente zur Untersuchung von F554A demonstrierten, dass diese Mutation zu einem statistisch signifikant erniedrigten Phosphorylierungsniveau (Abb. 3.2) sowie zu einer reduzierten Genaktivierung in Reporter- und real-time-PCR-Assays führt (Abb. 3.11 und Abb. 3.16). Die im Western Blot gezeigte Hypophosphorylierung konnte in den darauf folgenden EMSAExperimenten statistisch jedoch nicht bestätigt werden (Abb. 3.9). Die Quantifizierung und statistische Auswertung der EMSA-Experimente erreichte kein Signifikanzniveau. Bei näherer Betrachtung der Abb. 3.9 ist jedoch ein klarer Trend in Sinne einer Verminderung der DNA-Bindung der Mutante F554A anzunehmen. Im Rahmen der EMSA-Experimente wurde ebenso die Fähigkeit zur kooperativen DNA-Bindung als auch die Dissoziationskinetik der F554A-Mutante von spezifischen GAS-Bindestellen im Vergleich zum Wildtyp untersucht (Abb. 3.7 und Abb. 3.8). Beide Experimente ergaben ein dem Wildtyp ähnliches Niveau der DNA-Bindung und der Dissoziationskinetik. Experimente zur Untersuchung der Kernakkumulation ergaben ebenfalls keinen signifikanten Unterschied zum Wildtyp-Protein (Abb. 3.4).

Sowohl das erniedrigte Phosphorylierungsniveau als auch die verminderte Genexpression lassen einen Defekt in der SH2-Phosphotyrosin-Interaktion bei STAT1F554A annehmen und somit eine verminderte Stabilität des Dimers in paralleler zu Gunsten der antiparallelen Konformation vermuten. Eine Mutante mit einem ähnlichen Phänotyp sowie ähnlicher Position im STAT1-Protein wie STAT1-F554A ist STAT1-K550A, welche sich über die Hypophosphorylierung und die verminderte Genexpression hinaus als Dephosphorylierungsmutante gezeigt hat (Bolten 2013). Zusätzlich zeigte STAT1-K550A eine verkürzte Kernakkumulationszeit. Als möglichen Grund des ausgeprägten Phänotyps von STAT1-K550A wurde eine Instabilität des STAT1-Dimers in paralleler Konformation diskutiert (Bolten 2013). Liegt ein Dimer bevorzugt in der antiparallelen Konformation vor, wird es zu einem bevorzugten Substrat für die TC-45 Phosphatase. Diese Phosphatase kann Dimere nur in antiparalleler Dimer-Konformation dephosphorylieren (ten Hoeve et al. 2002; Zhong et al. 2005). Ob es sich bei STAT1-F554A ebenfalls um eine Dephosphorylierungsmutante handelt, sollte im Rahmen von zum Beispiel Dephosphorylierungs-Assays geklärt werden. Ebenso sollte im Rahmen von weiteren Gelshift-Experimenten die DNA-Bindeaffinität tiefergehend untersucht werden. 
Die SH2-Domäne spielt eine entscheidende Rolle bei der Dimerbildung der STATProteine. Ein Argeninrest in Position 602 des einen STAT-Protomers tritt dabei in Kontakt mit dem Phosphotyrosin des anderen Protomers (Chen et al. 1998). Für die reziproke SH2-Phosphotyrosin-Interaktion ist eine strukturelle Umorientierung der beiden SH2-Domänen essentiell. Dieser Prozess wird von der $\alpha$-Helix 10 der LinkerDomäne stabilisiert. Die $\alpha$-Helix 10 der Linker-Domäne beinhaltet hoch konservierte hydrophobe Seitenketten, welche mit dem hydrophoben Kern der SH2-Domäne interagieren. Dies geschieht über eine Interaktion zwischen der Phosphat-bindenden Schleife mit der Linker-Domäne (Chen et al. 1998). Auf der $\alpha$-Helix 10 befinden sich die hoch konservierten Aminosäurereste STAT1-W555 und STAT1-W557. Es wurde gezeigt, dass STAT1-W555 mit Segment 4 der DNA-Bindedomäne und STAT1-W557 mit der Phosphat-bindenden Schleife interagiert. Dieses dient der Stabilisierung des STAT1-Dimers in paralleler Form. Die Mutation an Position 557 führt folglich zu einer Destabilisierung des Dimers in paralleler Ausrichtung und zur verminderten Genaktivierung (Chen et al. 1998).

Experimente zur Charakterisierung dieser Mutante demonstrierten, dass die Mutante STAT1-W557A ähnlich der hier charakterisierten Mutante STAT1-F554A eine verminderte Genaktivierung aufweist. STAT1-F554A zeigt wie STAT1-W557A wohl keinen Unterschied in der DNA-Dissoziationsrate im Vergleich zum STAT1Wildtyp (Yang et al. 2002). STAT1-F554A ist wie STAT1-W557A ebenfalls auf der $\alpha$-Helix 10 des STAT1-Proteins positioniert und beide STAT1-Mutanten zeigen ein deutlich erniedrigtes Niveau der Aktivierung im Luciferase-Assay sowie eine Hypophosphorylierung im Western-Blot-Experiment, wohingegen STAT1-W555A eine dem Wildtyp ähnliche Aktivierung aufzeigt (Yang et al. 2002). STAT1-W557A befindet sich auf der Oberfläche des STAT1-Proteins und STAT1-F554A liegt partiell verdeckt in einer hydrophoben Tasche. Beide Aminosäurereste zeigen sich von ihrer Position im Molekül gen Phosphat-bindende Schleife ausgerichtet (Abb. 4.1). Eine weitere Mutante der Linker-Domäne (KE544-545AA) zeigte ebenfalls eine erniedrigte transkriptionelle Aktivität. Diese Mutante zeigte jedoch zusätzlich eine höhere Dissoziationsrate von der DNA, womit sich die reduzierte transkriptionelle Aktivität erklären ließ (Yang et al. 1999; Yang et al. 2002).

Folglich kann davon ausgegangen werden, dass die Linker-Domäne eine entscheidende Rolle in der Stabilisierung des STAT1-Dimers in paralleler Konformation inne hat, unter anderem durch direkte Interaktion mit der Phosphat-bindenden Schleife der SH2-Domäne. Durch Punktmutationen an stark konservierten Aminosäureresten wird die parallele zu Gunsten der antiparallelen Ausrichtung der STAT1-Dimers hin destabilisiert. Dies führt zur verminderten Genaktivierung, wie am Beispiel von STAT1-F554A, STAT1-W557A und STAT1-K550A gezeigt werden konnte. Zusätzlich wird das STAT1-Dimer in antiparalleler Konformation als besseres Substrat für 


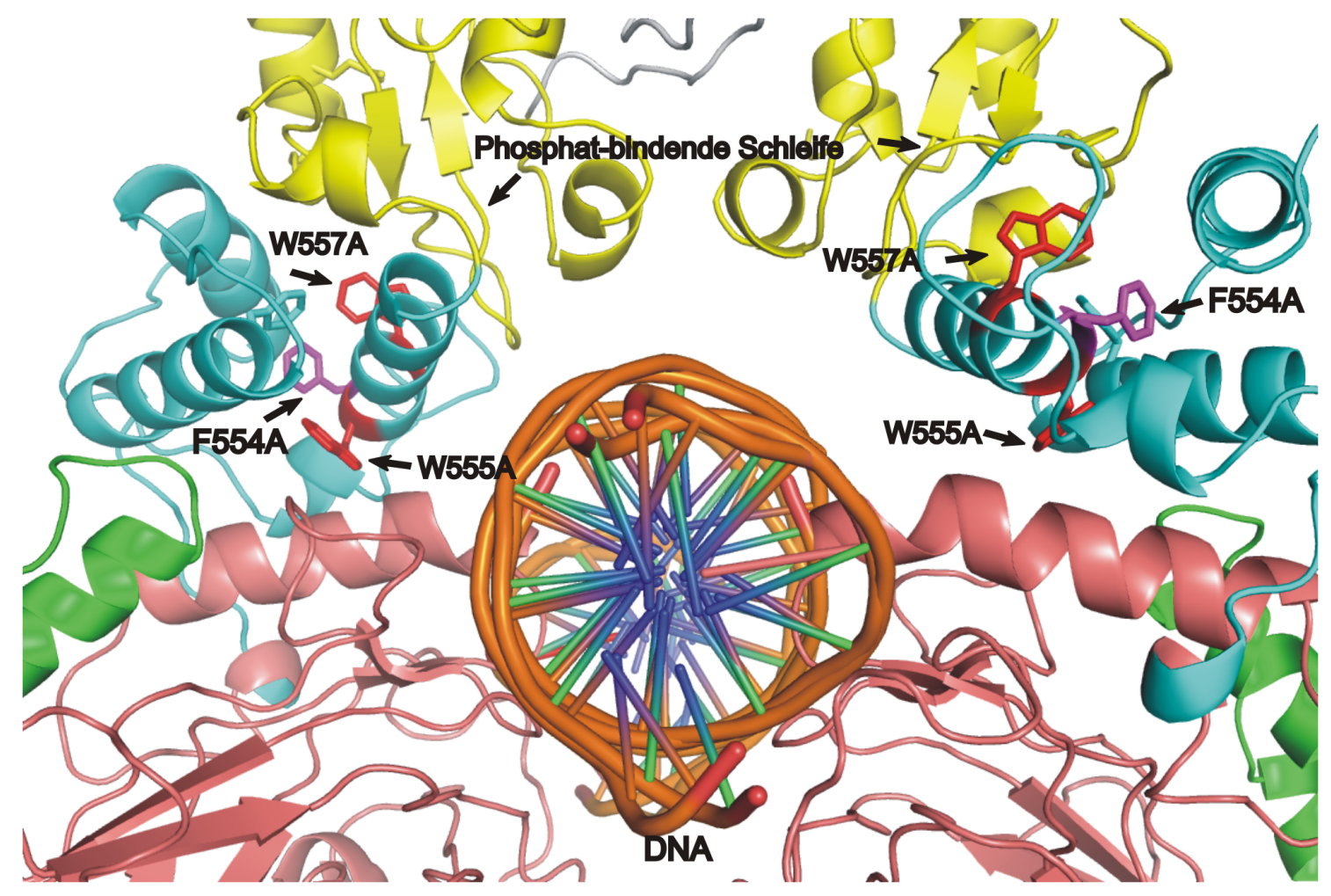

Abbildung 4.1: Ausschnitt des DNA-gebundenen STAT1-Dimers. Dargestellt sind die vier Domänen des Kernfragments von STAT1- $\alpha$. Die Coiled-Coil-Domäne ist in grün, die DNA-Bindedomäne in lachs, die Linker-Domäne in blau und die SH2-Domäne in gelb markiert. Die Mutanten der Linker-Domäne sind in rot (STAT1-W555A und STAT1W557A) und violett (STAT1-F554A) und die Phosphat-bindende Schleife mit einem Pfeil gekennzeichnet.

die TC-45 Phosphatase diskutiert (Staab 2011; Bolten 2013). 


\subsection{Genaktivierung von STAT1-F506A und STAT1-W539A}

Yang et al veröffentlichten Ergebnisse zur transkriptionellen Aktivität von STAT1F506A und STAT1-W539A am 3xLy6E-Promotor (Yang et al. 1999). Weiterführende Untersuchungen zur Phänotypisierung wurden in ihren Arbeiten nicht veröffentlicht. Aufbauend auf diesen Ergebnissen führten wir noch eine Reihe weiterer Experimente zur eingehenderen Charakterisierung dieser beiden STAT1-Mutanten durch.

Wie zuvor beschrieben zeigt STAT1-F506A eine diskret erhöhte transkriptionelle Aktivität im Reportergen-Assay mit dem 3xLy6E-Promotor (Abb. 3.12). Bei weiterer Prüfung der Genaktivierung durch Reportergene mit den nativen Promotoren pIC-339 und pIC-1352 konnte die erhöhte Rate der Genaktivierung von STAT1-F506A jedoch nicht bestätigt werden (Abb. 3.13). In real-time-PCRExperimenten war die Genaktivierung von STAT1-F506A ebenfalls kompromittiert (Abb. 3.15). Interessanterweise zeigt STAT1-F506A unter Verwendung des synthetischen 3xLy6E Promotors ein gegensätzliches Ergebnis zu den vorherigen Untersuchungen. Der 3xLy6E-Promotor besteht aus drei in Tandem-Position angeordneten GAS-Bindestellen. Diese Beschaffenheit macht den Promotor sensibler für die Menge des vorhandenen Phospho-STAT1. Phosphorylierungsniveau und DNA-Bindung von STAT1-F506A wiesen keine Abweichung zum Wildtyp-Protein auf. Ein Grund für diesen Phänotyp könnte die Lage des substituierten Phenylalanins in Position 506 des STAT1-Proteins sein (Abb. 4.3). Dieses liegt in zentraler Lage partiell verdeckt in der Linker-Domäne (Yang et al. 1999). Möglich ist, dass STAT1-F506A somit in einer nur schwachen Wechselwirkung mit einer benachbarten funktionellen Domäne im STAT1-Protein steht. Eine geringere DNA-Bindung von STAT1-F506A könnte eine verminderte Genaktivierung erklären. Abb. 3.10 zeigt jedoch, dass die Affinität von STAT1-F506A an die verschiedenen GAS-Sonden sich statistisch nicht von der Affinität des Wildtyps unterscheidet. Die verminderte transkriptionelle Aktivität ließe sich auch durch ein vermindertes Niveau der Tyrosin-Phosphorylierung oder durch eine veränderte Kernakkumulationszeit erklären. STAT1-F506A weist allerdings bei den Western-Blot-Analysen statistisch keinen Unterschied zum STAT1-Wildtyp auf (Abb. 3.3). Unterschiede im Phosphorylierungsniveau sind nach Zusammenschau der Ergebnisse nicht der Grund für den unterschiedlichen Grad der Genaktivierung. Abb. 3.4 zeigt ebenfalls, dass weder eine verkürzte noch verlängerte Kernakkumulationszeit der phosphorylierten STAT1-F506A-Proteine eine Begründung für die Ergebnisse der Reportergen-Assays liefern kann. Es konnte bislang anhand mehrerer Beispiele gezeigt werden, dass Veränderungen in der Linker-Domäne Einfluss auf die Transkription nehmen (Yang et al. 1999; Yang et al. 2002; Staab 2011; Bolten 
2013; Hüntelmann et al. 2014).

Es bleibt jedoch kritisch zu betrachten, dass sich die erhöhte Genexpressionsrate von STAT1-F506A allein in den Ergebnissen des Reportergen-Assays mit dem 3xLy6E-Promoter zeigen ließen. Als mögliche Gründe dafür sind dabei sowohl die Empfindlichkeit des Experiments auf die Transfektionsrate der Zellen mit dem jeweilig eingesetzten Plasmid als auch das Ansprechen des Promoters auf die vorhandene Phospho-STAT Menge nach Zytokin-Stimulation in Betracht zu ziehen. Somit stehen potentielle Fehlerquellen zur Diskussion, welche bei der Beurteilung der Ergebnisse mit bedacht werden müssen.

STAT1-W539A zeigt nach IFN $\gamma$-Stimulation eine erniedrigte transkriptionelle Aktivität in Reportergen-Assays, unabhängig davon, ob ein nativer oder synthetischer Promotor verwendet wurde (Abb. 3.11). Auch konnte eine verminderte Aktivierung von endogenen STAT1-Zielgenen in den real-time-Experimenten gezeigt werden (Abb. 3.15). Grund für die verminderte transkriptionelle Aktivität kann unter anderem eine Veränderung in der Dissoziationskinetik von der DNA, der Grad der Tyrosin-Phosphorylierung oder eine verminderte Kernakkumulation sein. Bis auf die Genaktivierung zeigte STAT1-W539A bei den im Rahmen dieser Arbeit durchgeführten Verfahren jedoch keinen weiteren Unterschied zum Wildtyp-Protein. Aus Abb. 4.3 ist ersichtlich, dass die aromatische Seitenkette des Tryptophans an Position 539 des STAT1-Moleküls zur DNA-Bindedomäne ausgerichtet ist. Diesem Tryptophan-Rest liegt ein hoch konservierter Serinrest in der Position 470 auf der $\alpha$-Helix 6 der DNA-Bindedomäne gegenüber. Dieser Serin-Rest liegt bei STAT1, STAT2, STAT3 und STAT4 der humanen STAT-Familie konserviert vor (Abb. 4.2 B). Eine Interaktion mit der DNA-Bindedomäne kann wegen der engen räumlichen Nähe der beiden Domänen mit ihrem jeweiligen Aminosäureresten in Betracht gezogen werden und kann einen möglichen Grund für die verminderte transkriptionelle Aktivität von STAT1-W539A darstellen.

In der DNA-Bindedomäne des STAT-Proteins befindet sich ein Lysin- und Argininreiches Cluster, welches den nukleären Import von phosphoryliertem STAT1 reguliert (Melen et al. 2001; Meyer et al. 2002). Veränderungen in der intramolekularen Struktur der DNA-Bindedomäne können zu Hinderungen des Imports führen und somit Einfluss auf die Genaktivierung haben. Eine veränderte Kernakkumulation von STAT1-W539A konnte jedoch nicht nachgewiesen werden (Abb. 3.4). Die beobachtete Veränderung der Genaktivierung könnte demnach in einer strukturellen Alteration zwischen der Linker-Domäne und der DNA-Bindedomäne begründet liegen. 
A

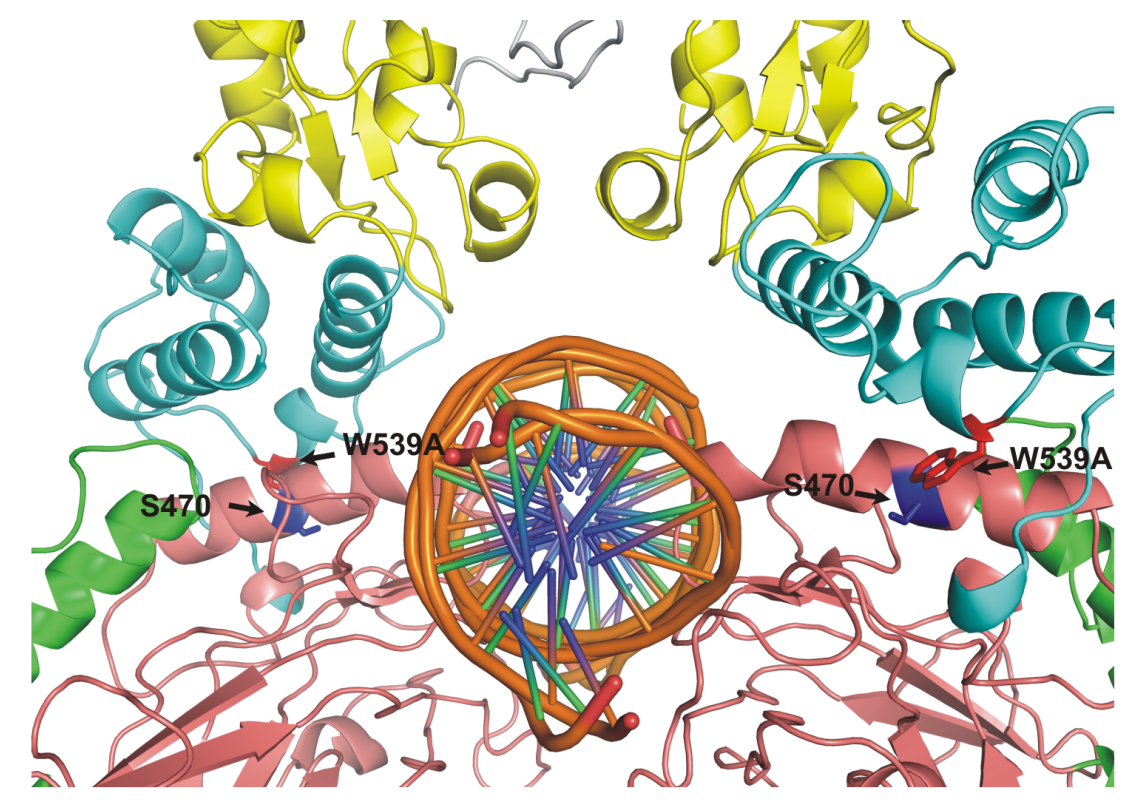

B

STAT1 LCQPG - -LV IDLETTSLPVVV ISNVSQLPSGWAS I LWYNMLVAE

STAT2 YTYQG - - LKQELKTDTLPVV I ISN MNQLSI AWAS VLWFNL LSPN

STAT3 VYHQG - -LK I DLETHSLSVVV ISNI CQMPNAWASILWYNMLTNN

STAT4 I CLYG - - L T I DLETS SLPVVMISNVSQ L PNAWASI IWYNVSTNC

STAT5a F SV GSNELVFQVKTLSLPVVV IVHGSQDHNAT ATV LW DNAFAEP

STAT6 FTLG PGKLPIQ LQALSLPLVV IVHGNQDNNAKATI LWDNAFSEM

Abbildung 4.2: Kristallstruktur eines DNA-gebundenen STAT1-Dimers mit zwei konservierten Aminosäureresten. (A) Dargestellt sind die vier Domänen des Kernfragments von STAT1- $\alpha$. Die Coiled-Coil-Domäne ist in grün, die DNA-Bindedomäne in lachs, die Linker-Domäne in blau und die SH2-Domäne in gelb dargestellt. Die Mutante der LinkerDomäne ist in rot und ein hoch konservierter Aminosäurerest der DNA-Bindedomäne in blau dargestellt. (B) Ausschnitt aus dem Sequenzvergleich der Position 439-480 von STAT1 mit anderen Mitgliedern der humanen STAT-Proteinfamilie.

\subsection{STAT1-W504A zeigt eine vom Phosphorylierungsniveau-abhängige Genaktivierung}

STAT1-W504A wurde im Vergleich zu den beiden zuletzt genannten Mutanten in der Literatur noch nicht beschrieben. Kernakkumulation, Dissoziationskinetik und DNA-Bindung entsprechen dem STAT1-Wildtyp (Abb. 3.4, Abb. 3.8 und Abb. 3.7). Im Luciferase-Assay zeigt sich zunächst eine diskret erhöhte transkriptionelle Aktivität (Abb. 3.12). Bei Untersuchungen mit zwei nativen Promotoren (pIC-339 und 


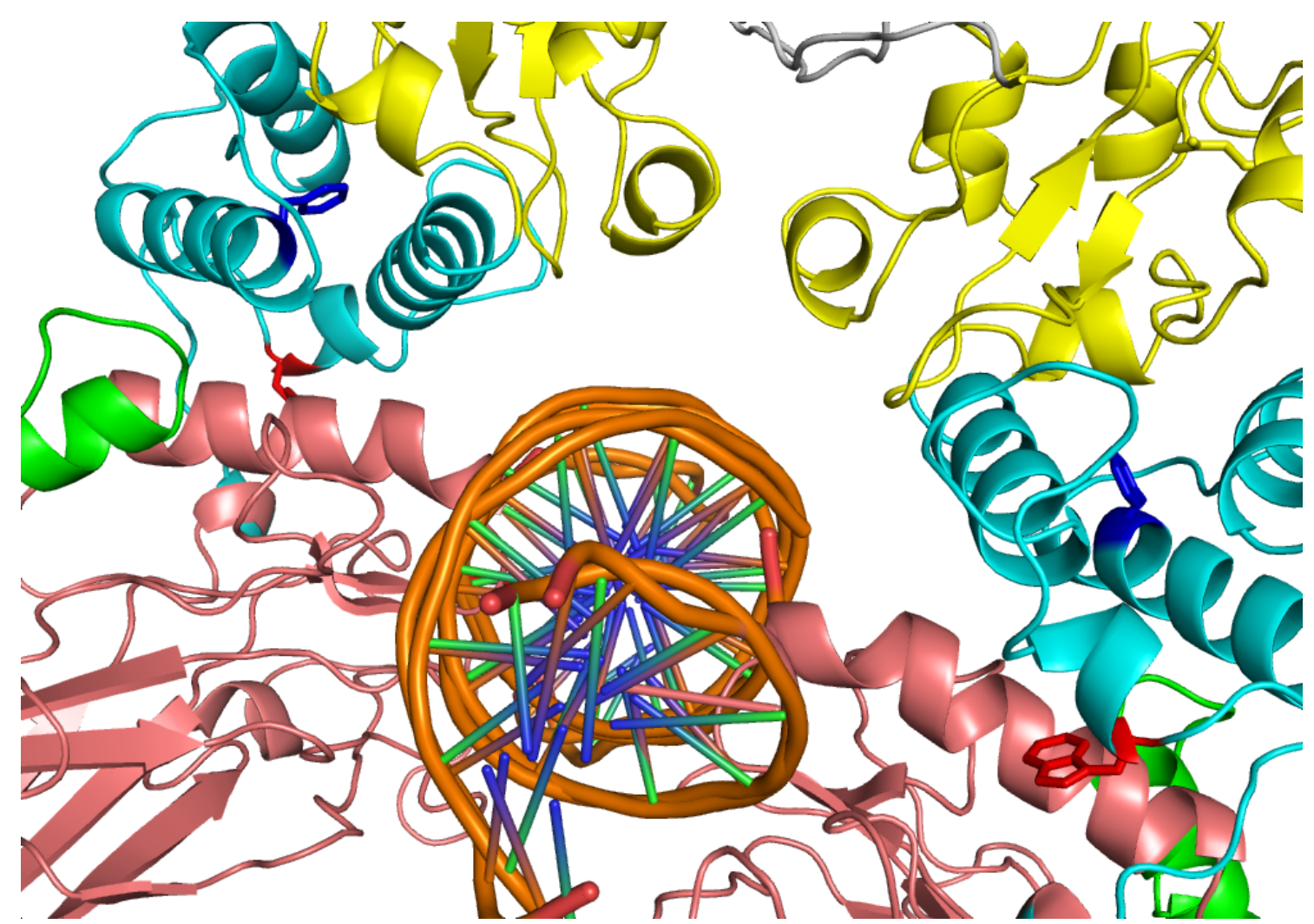

Abbildung 4.3: Ausschnitt aus der Kristallstruktur eines DNA-gebundenen STAT1Dimers. Dargestellt sind Teile der vier Domänen des Kernfragments von STAT1- $\alpha$. Die Coiled-Coil-Domäne ist in grün, die DNA-Bindedomäne in lachs, die Linker-Domäne in blau und die SH2-Domäne in gelb dargestellt. Die Mutanten der Linker-Domäne sind in rot (STAT1-W539A) und blau (STAT1-F506A) markiert.

pIC-1532) wurde die Genaktivierung jedoch als signifikant vermindert gemessen (Abb. 3.13). Western-Blot-Analysen ergaben ein signifikant erhöhtes Phosphorylierungsniveau im Vergleich zum STAT1-Wildtyp (Abb. 3.3). Die Aktivierung von endogenen STAT1-Zielgenen im Rahmen von real-time-Experimenten zeigte ein inhomogenes Bild der Genaktivierung. Obwohl die exprimierte Stat1-Menge von STAT1W504A im Vergleich zum STAT1-Wildtyp statistisch signifikant vermindert war, zeigten sich signifikant erhöhte nachweisbare Level der endogenen STAT1-Zielgene cxcl10 und mcp1. Die Expression von mig1 und gbp1 zeigte ein gleiches Niveau, während irf1 vermindert transkribiert wurde (Abb. 3.14).

In einer vorausgegangenen Arbeit wurde die Punktmutante STAT1-T385A beschrieben (Staab et al. 2013). Diese zeigt, ähnlich STAT1-W504A, ein erhöhtes Niveau der Tyrosin-Phosphorylierung im Western-Blot-Experiment. Im ReportergenAssay mit dem 3xLy6E-Promotor zeigten STAT1-T385A und STAT1-W504A ein erhöhtes transkriptionelles Niveau. Beide STAT1-Derivate zeigten ein sehr ähnliches Ergebnis in den real-time-Experimenten. Die STAT1-Expressionsrate war gleich oder im Vergleich zum Wildtyp vermindert. Allerdings wurde auch bei STAT1-T385A nach IFN $\gamma$-Stimulation eine erhöhte Expressionsrate von cxcl10 und mcp1 gemes- 
sen (Abb. 3.14). Beide zuletzt genannten Gene haben zur regulären GAS-Bindestelle ein zusätzliches TCC/GAA-Bindemotiv, welches 10 Basenpaare von der eigentlichen GAS-Bindestelle entfernt liegt. Somit besitzen cxcl10 und mcp1 eine „anderthalbfache" GAS-Bindestelle, welche zu einem erhöhten transkriptionellen Aktivitätsniveau dieser STAT1-Zielgene nach IFN $\gamma$-Stimulation führt (Staab et al. 2013). Die Gene $g b p 1$, irf1 und mig1 besitzen dahingegen je nur eine einfache reguläre GASBindestelle. Bei der Untersuchung von STAT1-T385A konnte gezeigt werden, dass die Mutante eine veränderte kooperative DNA-Bindung aufweist. Die Dissoziationsrate von DNA blieb durch die Mutation an Position 385 des STAT1-Proteins unbeeinträchtigt. STAT1-W504A zeigt ebenfalls eine dem STAT1-Wildtyp vergleichbare Dissoziationsrate von DNA (Abb. 3.8). STAT1-W504A ist an der Oberfläche des Proteins lokalisiert und zusätzlich nach außen ausgerichtet (Abb. 3.1). Somit könnte die Position 504 im STAT1-Molekül einen Angriffspunkt der TC-45 Phosphatase darstellen bzw. Konformationsänderungen durch eine Mutation nach Alanin könnten STAT1-W504A zu einem weniger bevorzugten Substrat dieser Phosphatase machen.

Zum Abschluss lässt sich bestätigen, dass die Linker-Domäne eine wichtige Rolle in der Genaktivierung der STAT1-Proteine spielt. Diese ist wahrscheinlich an die Stabilität der Dimerbildung geknüpft. 


\section{Zusammenfassung}

Signaltransduktoren und Aktivatoren der Transkription (STATs) sind Teil eines phylogenetisch alten und hoch konservierten Signaltransduktionsweges. Als essentielle Komponenten des JAK-STAT-Signalwegs sind sie an der Vermittlung von Prozessen wie der Immunantwort, Zellwachstum und Homöostase beteiligt. Auf externe Stimuli hin werden die latent im Zytoplasma befindlichen STAT-Proteine an einem kritischen Tyrosinrest phosphoryliert, wandern dann als tyrosinphosphorylierte Dimere in den Zellkern und bewirken dort eine Modulation der Genexpression. In dieser Arbeit wurden durch gerichtete Mutagenese nach Alanin vier Punktmutanten in der Linker-Domäne des STAT1-Proteins generiert (W504, F506, W539 und F554). Die Mutation eines hoch konservierten Phenylalanins in der Position 554 des STAT1-Proteins führte zu einer verminderten Tyrosinphosphorylierung nach der Stimulation STAT1-exprimierender Zellen mit Interferon- $\gamma$. Ebenso zeigte sich eine verminderte Genaktivierung von STAT1-regulierten Reportergenen und endogenen Zielgenen durch diese Mutante. Diese phänotypischen Eigenschaften wurden mit der verminderten Stabilität des STAT1-Dimers in der parallelen Konformation zu Gunsten einer Verlagerung in die antiparallele Konformation erklärt, wodurch das Dimer mutmaßlich zu einem präferenziellen Substrat für die inaktivierende TC-45 Phosphatase wird. Im Gegensatz dazu zeigten STAT1-W504A-exprimierende Zellen im Vergleich zum Wildtyp-Protein nach Interferon- $\gamma$-Stimulation eine leicht erhöhte Tyrosinphosphorylierung. Ebenso wurde ein erhöhtes transkriptionelles Niveau in Reportergenexperimenten sowie bei endogenen STAT1-Zielgenen registriert. Die Ergebnisse bestätigen, dass die Linker-Domäne eine wichtige Rolle in der Tyrosinphosphorylierung und Genexpression spielt. Weitere Untersuchungen sollten die physiologischen Funktionen der Linker-Domäne in einem organismischen Kontext klären.

\subsection{Summary}

Signal transducers and activators of transcription (STATs) are components of an old phylogenetic and highly conserved signal transduction pathway in metazoans. As key elements of the JAK-STAT signal pathway, members of this protein family are involved in immune processes, cell growth and homeostasis. Upon external sti- 
muli, cytoplasmatic STAT proteins are phosphorylated on a single tyrosine residue in their carboxy-termini and are then transported in the nucleus as dimeric transcription factors to drive STAT-dependent gene expression. In the present study, four point mutants were generated in the linker domain of the STAT1 molecules (W504, F506, W539 and F554). The exchange of a highly conserved phenylalanine to alanine in position 554 resulted in reduced levels of tyrosine phosphorylation. The STAT1-F554A mutant also showed decreased transcriptional activation of STAT1driven reporter genes and endogenous target genes. The phenotype of this mutant is explained by decreased stability of the parallel conformer of STAT1 dimers in favor of the antiparallel conformation. The altered conformational equilibrium results in enhanced dephosphorylation by the inactivating TC-45 tyrosine phosphatase. In contrast, STAT1-W504A was slightly hyperphosphorylated on the critical tyrosine residue 701 and consequently showed a higher level of transcriptional activation in reporter gene assays and reverse-transcriptase PCR assays. In summary, these data confirm that the linker domain of the STAT1 molecule plays an important role in tyrosine phosphorylation and gene expression. Further research should address the physiological functions of the linker domain in an organismic context. 


\section{Literaturverzeichnis}

Bach E, Aguet M, Schreiber R (1997): The IFN-gamma receptor: a paradigm for cytokine receptor signaling. Annu Rev Immunol 15, 563-591

Barillas-Mury C, Han YS, Seeley D, Kafatos FC (1999): Anopheles gambiae AgSTAT, a new insect member of the STAT family, is activated in response to bacterial infection. EMBO J 18, 959-967

Becker S, Groner B, Müller CW (1998): Three-dimensional structure of the Stat3 $\beta$ homodimer bound to DNA. Nature 394, 145-151

Begitt A, Meyer T, van Rossum M, Vinkemeier U (2000): Nucleocytoplasmic translocation of Stat1 is regulated by a leucine-rich export signal in the coiled-coil domain. Proc Natl Acad Sci USA 97, 10418-10423

Begitt A, Droescher M, Meyer T, Schmid CD, Baker M, Antunes F, Knobeloch KP, Owen MR, Naumann R, Decker T, Vinkemeier U (2014): STAT1-cooperative DNA binding distinguishes type 1 from type 2 interferon signaling. Nat Immunol $15,168-176$

Bluyssen H (1996): ISGF3ץ p48, a specificity switch for interferon activated transcription factors. Cytokine Growth Factor Rev $\underline{7}, 11-17$

Boehm U, Klamp T, Groot M, Howard JC (1997): Cellular responses to interferongamma. Annu Rev Immunol 15, 749-795

Boisson-Dupuis S, Kong XF, Okada S, Cypowyj S, Puel A, Abel L, Casanova JL (2012): Inborn errors of human STAT1: allelic heterogeneity governs the diversity of immunological and infectious phenotypes. Curr Opin Immunol 24, 364-378

Bolten JC (2013): Die Rolle der Linker-Domäne von STAT1 bei der Regulation transkriptioneller Antworten im Interferon-Signalweg. Med. Diss. Göttingen 2013 Bork P, Holm L, Sander C (1994): The immunoglobulin fold. Structural classification, sequence patterns and common core. J Mol Biol 242, 309-320

Bowman T, Garcia R, Turkson J, Jove R (2000): STATs in oncogenesis. Oncogene $\underline{19}, 2474-2488$

Chang CH, Hammer J, Loh JE, Fodor WL, Flavell R (1992): The activation of major histocompatibility complex class I genes by interferon regulatory factor-1 (IRF-1). Immunogenetics 35, 378-384 
Chapgier A, Boisson-Dupuis S, Jouanguy E, Vogt G, Feinberg J, ProchnickaChalufour A, Casrouge A, Yang K, Soudais C, Fieschi C (2006): Novel STAT1 alleles in otherwise healthy patients with mycobacterial disease. PLoS Genetics 2 , e131

Chen X, Vinkemeier U, Zhao Y, Jeruzalmi D, Darnell JE, Kuriyan J (1998): Crystal Structure of a tyrosine phosphorylated STAT-1 dimer bound to DNA. Cell 93, 827839

Chen X, Bhandari R, Vinkemeier U, Van Den Akker, F., Darnell JE, Kuriyan J (2003): A reinterpretation of the dimerization interface of the N-terminal domains of STATs. Protein Sci 12, 361-365

Chung CD (1997): Specific inhibition of Stat3 signal transduction by PIAS3. Science 278, 1803-1805

Cohen SN, Chang ACY, Hsu L (1972): nonchromosomal antibiotic resistance in bacteria: genetic transformation of Escherichia coli by R-Factor DNA. Proc Natl Acad Sci USA 69, 2110-2114

Cook JR, Jung V, Schwartz B, Wang P, Pestka S (1992): Structural analysis of the human interferon gamma receptor: a small segment of the intracellular domain is specifically required for class I major histocompatibility complex antigen induction and antiviral activity. Proc Natl Acad Sci USA 89, 11317-11321

Copeland NG, Gilbert DJ, Schindler C, Zhong Z, Wen Z, Darnell JE, Mui ALF, Miyajima A, Quelle FW, Ihle JN (1995): Distribution of the mammalian Stat gene family in mouse chromosomes. Genomics 29, 225-228

Darnell J (1997): STATs and gene regulation. Science 277, 1630-1635

Darnell J, Kerr I, Stark G (1994): Jak-STAT pathways and transcriptional activation in response to IFNs and other extracellular signaling proteins. Science $\underline{264}, 1415-1421$

Drozina G, Kohoutek J, Jabrane-Ferrat N, Peterlin BM (2005): Expression of MHC II Genes. Curr Top Microbiol Immunol 290, 147-170

Dupuis S (2001): Impairment of mycobacterial but not viral immunity by a germline human STAT1 mutation. Science 293, 300-303

Dupuis S, Jouanguy E, Al-Hajjar S, Fieschi C, Al-Mohsen IZ, Al-Jumaah S, Yang K, Chapgier A, Eidenschenk C, Eid P, Ghonaium AA, Tufenkeji H, Frayha H, Al-Gazlan S, Al-Rayes H, Schreiber RD, Gresser I, Casanova JL (2003): Impaired response to interferon $\alpha / \beta$ and lethal viral disease in human STAT1 deficiency. Nat Genet 33, 388-391 
Durbin JE, Hackenmiller R, Simon M, Levy DE (1996): Targeted tisruption of the mouse Stat1 gene results in compromised innate immunity to viral disease. Cell 84, 443-450

Ealick S, Cook W, Vijay-Kumar S, Carson M, Nagabhushan T, Trotta P, Bugg C (1991): Three-dimensional structure of recombinant human interferon-gamma. Science 252, 698-702

Fagerlund R, Mélen K, Kinnunen L, Julkunen I (2002): Arginine/lysine-rich nuclear localization signals mediate interactions between dimeric STATs and importin alpha 5. J Bio Chem 277, 30072-30078

Fahrenkrog B, Köser J, Aebi U (2004): The nuclear pore complex: a jack of all trades? Trends Biochem Sci 29, 175-182

Fu X (1992): A transcription factor with SH2 and SH3 domains is directly activated by an interferon $\alpha$-induced cytoplasmic protein tyrosine kinase(s). Cell 70, 323-335

Fu X, Kessler D, Veals S, Levy D, Darnell J (1990): ISGF3, the transcriptional activator induced by interferon alpha, consists of multiple interacting polypeptide chains. Proc Natl Acad Sci USA 87, 8555-8559

Gao B (2005): Cytokines, STATs and liver disease. Cell Mol Immunol 2, 92-100

Ginger RS, Dalton EC, Ryves WJ, Fukuzawa M, Williams JG, Harwood AJ (2000): Glycogen synthase kinase-3 enhances nuclear export of a Dictyostelium STAT protein. EMBO J $\underline{19}, 5483-5491$

Görlich D, Kutay U (1999): Transport between the cell nucleus and the cytoplasm. Annu Rev Cell Dev Biol 15, 607-660

Görlich D, Kostka S, Kraft R, Dingwall C, Laskey RA, Hartmann E, Prehn S (1995): Two different subunits of importin cooperate to recognize nuclear localization signals and bind them to the nuclear envelope. Curr Biol 5, 383-392

Greenlund A (1995): Stat recruitment by tyrosine-phosphorylated cytokine receptors: An ordered reversible affinity-driven process. Immunity 2, 677-687

Grimley P (1999): Stat5a and Stat5b: fraternal twins of signal transduction and transcriptional activation. Cytokine Growth Factor Rev 10, 131-157

Haspel RL, Salditt-Georgieff M, Darnell JE (1996): The rapid inactivation of nuclear tyrosine phosphorylated Stat1 depends upon a protein tyrosine phosphatase. EMBO J 15, 6262-6268

Horvath CM (2000): STAT proteins and transcriptional responses to extracellular signals. Trends Biochem Sci 25, 496-502

Hou S, Zheng Z, Chen X, Perrimon N (2002): The JAK/STAT pathway in model organisms emerging roles in cell movement. Dev Cell $\underline{3}, 765-778$ 
Hüntelmann B, Staab J, Herrmann-Lingen C, Meyer T (2014): A conserved motif in the linker domain of STAT1 transcription factor is required for both recognition and release from high-affinity DNA-binding sites. PloS one 9, e97633

Ihle JN (2001): The Stat family in cytokine signaling. Curr Opin Cell Biol 13, 211217

Imada K, Leonard WJ (2000): The Jak-STAT pathway. Mol Immunol 37, 1-11

Isaacs A, Lindenmann J (1957): Virus interference. I. The Interferon. Proc R Soc Lond B Biol Sci 147, 258-267

Ivashkiv LB, Hu X (2004): Signaling by STATs. Arthritis Res Ther 6, 159-168

John S, Vinkemeier U, Soldaini E, Darnell JE, Leonard WJ (1999): The significance of tetramerization in promoter recruitment by Stat5. Moll Cell Biol 19, 1910-1918

Kaplan MH, Sun YL, Hoey T, Grusby MJ (1996 a): Impaired IL-12 responses and enhanced development of Th2 cells in Stat4-deficient mice. Nature 382, 174-177

Kaplan MH, Schindler U, Smiley ST, Grusby MJ (1996 b): Stat6 is required for mediating responses to IL-4 and for the development of Th2 Cells. Immunity 4, 313-319

Krebs DL, Hilton DJ (2001): SOCS proteins: negative regulators of cytokine signaling. Stem cells 19, 378-387

Larsen L, Ropke C (2002): Suppressors of cytokine signalling: SOCS. APMIS $\underline{110}, 833-844$

Leonard WJ, Lin JX (2000): Cytokine receptor signaling pathways. J Allergy Clin Immunol $\underline{105}, 877-888$

Levy DE, Darnell JE (2002): Stats: transcriptional control and biological impact. Nat Rev Mol Cell Biol 3, 651-662

Liao J, Fu Y, Shuai K (2000): Distinct roles of the NH2- and COOH-terminal domains of the protein inhibitor of activated signal transducer and activator of transcription (STAT) 1 (PIAS1) in cytokine-induced PIAS1-Stat1 interaction. Proc Natl Acad Sci USA 97, 5267-5272

Liu B, Jiayu L (1998): Inhibition of Stat1-mediated gene activation by PIAS1. Proc Natl Acad Sci USA 95, 10626-10631

Liu L, Okada S, Kong XF, Kreins AY, Cypowyj S, Abhyankar A, Toubiana J, Itan Y, Audry M, Nitschke P (2011): Gain-of-function human STAT1 mutations impair IL-17 immunity and underlie chronic mucocutaneous candidiasis. J Exp Med 208, 1635-1648

Liu X (1999): STAT genes found in C.elegans. Science 285, 167a-167

Liu X, Robinson G, Gouilleux F, Groner B, Hennighausen L (1995): Cloning and expression of Stat5 and an additional homologue (Stat5b) involved in prolactin 
signal transduction in mouse mammary tissue. Proc Natl Acad Sci USA 92, 88318835

Liu X, Robinson GW, Wagner KU, Garrett L, Wynshaw-Boris A, Hennighausen L (1997): Stat5a is mandatory for adult mammary gland development and lactogenesis. Genes Dev 11, 179-186

Macara IG (2001): Transport into and out of the nucleus. Microbiol Mol Biol Rev 65, 570-94, table of contents

Mao X, Ren Z, Parker GN, Sondermann H, Pastorello MA, Wang W, McMurray JS, Demeler B, Darnell JE, Chen X (2005): Structural bases of unphosphorylated STAT1 association and receptor binding. Mol Cell 17, 761-771

Marg A, Shan Y, Meyer T, Meissner T, Brandenburg M, Vinkemeier U (2004): Nucleocytoplasmic shuttling by nucleoporins Nup153 and Nup214 and CRM1dependent nuclear export control the subcellular distribution of latent Stat1. J Cell Biol 165, 823-833

Mattaj IW, Englmeier L (1998): Nucleocytoplasmic transport: the soluble phase. Annu Rev Biochem 67, 265-306

McBride KM, Reich NC (2003): The ins and outs of STAT1 nuclear transport. Sci STKE 2003, RE13

McBride KM, McDonald C, Reich NC (2000): Nuclear export signal located within the DNA-binding domain of the STAT1 transcription factor. EMBO J $\underline{19}$, 61966206

McBride KM, Banninger G, McDonald C, Reich NC (2002): Regulated nuclear import of the STAT1 transcription factor by direct binding of importin-alpha. EMBO J 21, 1754-1763

Melen K, Kinnunen L, Julkunen I (2001): Arginine/lysine-rich structural element is involved in interferon-induced nuclear import of STATs. J Bio Chem 276, 1644716455

Meraz MA, White J, Sheehan KC, Bach EA, Rodig SJ, Dighe AS, Kaplan DH, Riley JK, Greenlund AC, Campbell D (1996): Targeted disruption of the Stat1 gene in mice reveals unexpected physiologic specificity in the JAK-STAT signaling pathway. Cell 84, 431-442

Mertens C, Zhong M, Krishnaraj R, Zou W, Chen X, Darnell JE (2006): Dephosphorylation of phosphotyrosine on STAT1 dimers requires extensive spatial reorientation of the monomers facilitated by the N-terminal domain. Genes Dev 20, 3372-3381

Meyer T, Vinkemeier U (2004): Nucleocytoplasmic shuttling of STAT transcription factors. Eur J Biochem 271, 4606-4612 
Meyer T, Begitt A, Lödige I, van Rossum M, Vinkemeier U (2002): Constitutive and IFN-gamma-induced nuclear import of STAT1 proceed through independent pathways. EMBO J $\underline{21}, 344-354$

Meyer T, Marg A, Lemke P, Wiesner B, Vinkemeier U (2003): DNA binding controls inactivation and nuclear accumulation of the transcription factor Stat1. Genes Dev 17, 1992-2005

Meyer T, Hendry L, Begitt A, John S, Vinkemeier U (2004): A single residue modulates tyrosine dephosphorylation, oligomerization, and nuclear accumulation of stat transcription factors. J Bio Chem 279, 18998-19007

Meyer T, Begitt A, Vinkemeier U (2007): Green fluorescent protein-tagging reduces the nucleocytoplasmic shuttling specifically of unphosphorylated STAT1. FEBS J 274, 815-826

Mowen K, David M (1998): Role of the STAT1-SH2 domain and STAT2 in the activation and nuclear translocation of STAT1. J Bio Chem 273, 30073-30076

Müller M, Briscoe J, Laxton C, Guschin D, Ziemiecki A, Silvennoinen O, Harpur A, Barbieri G, Witthuhn B, Schindler C (1993): The protein tyrosine kinase JAK1 complements defects in interferon-alpha/beta and -gamma signal transduction. Nature $\underline{366}, 129-135$

Nguyen KB, Watford WT, Salomon R, Hofmann SR, Pien GC, Morinobu A, Gadina M, O'Shea JJ, Biron CA (2002): Critical role for STAT4 activation by type 1 interferons in the interferon-gamma response to viral infection. Science 297, 20632066

Nigg E (1997): Nucleocytoplasmic transport: signals, mechanisms and regulation. Nature 386, 779-787

Novick D (1994): The human interferon alpha/beta receptor: Characterization and molecular cloning. Cell 구, 391-400

Oritani K, Tomiyama Y (2004): Interferon-3/limitin: novel type I Interferon that displays a narrow range of biological activity. Int J Hematol 80, 325-331

O'Shea JJ (1997): Jaks, STATs, cytokine signal transduction, and immunoregulation: are we there yet? Immunity $\underline{7}, 1-11$

Park C, Li S, Cha E, Schindler C (2000): Immune response in Stat2 knockout mice. Immunity $\underline{13}$, 795-804

Pestka S (2007): The interferons: 50 years after their discovery, there is much more to learn. J Bio Chem 282, 20047-20051

Rane S, Reddy E (2000): Janus kinases: components of multiple signaling pathways. Oncogene $\underline{19}, 5662-5679$ 
Rout MP, Wente SR (1994): Pores for thought: nuclear pore complex proteins. Trends Cell Biol 4, 357-365

Rytinki MM, Kaikkonen S, Pehkonen P, Jääskeläinen T, Palvimo JJ (2009): PIAS proteins: pleiotropic interactors associated with SUMO. Cell Mol Life Sci 66, 30293041

Schindler C, Darnell J (1995): Transcriptional responses to polypeptide ligands: the JAK-STAT pathway. Annu Rev Biochem 64, 621-651

Schindler C, Plumlee C (2008): Inteferons pen the JAK-STAT pathway. Semin Cell Dev Biol 19, 311-318

Schindler C, Fu X, Improta T, Aebersold R, Darnell J (1992 a): Proteins of transcription factor ISGF-3: one gene encodes the 91-and 84-kDa ISGF-3 proteins that are activated by interferon alpha. Proc Natl Acad Sci USA $\underline{89}$, 7836-7839

Schindler C, Shuai K, Prezioso V, Darnell JE (1992 b): Interferon-dependent tyrosine phosphorylation of a latent cytoplasmic transcription factor. Science 257, 809813

Schroder K, Hertzog PJ, Ravasi T, Hume DA (2004): Interferon-gamma: an overview of signals, mechanisms and functions. J Leukoc Biol 75, 163-189

Senda T, Shimazu T, Matsuda S, Kawano G, Shimizu H, Nakamura K, Mitsui Y (1990): Three-dimensional structure of recombinant murine interferon- $\beta$. EMBO J 11, 3193-3201

Shankaran V, Ikeda H, Bruce A, White J, Swanson P, Old L, Schreiber R (2001): IFNgamma and lymphocytes prevent primary tumour development and shape tumour immunogenicity. Nature 410, 1107-1111

Sheppard P, Kindsvogel W, Xu W, Henderson K, Schlutsmeyer S, Whitmore TE, Kuestner R, Garrigues U, Birks C, Roraback J (2003): IL-28, IL-29 and their class II cytokine receptor IL-28R. Nat Immunol $\underline{4}, 63-68$

Shuai K (2000): Modulation of STAT signaling by STAT-interacting proteins. Oncogene 19, 2638-2644

Shuai K, Schindler C, Prezioso V, Darnell JE (1992): Activation of transcription by IFN-gamma: tyrosine phosphorylation of a $91-\mathrm{kD}$ DNA binding protein. Science 258, 1808-1812

Shuai K, Stark GR, Kerr IM, Darnell J (1993): A single phosphotyrosine residue of Stat91 required for gene activation by interferon-gamma. Science 5129, 1744-1746 Shuai K, Horvath C, Huang L, Qureshi S, Cowburn D, Darnell JE (1994): Interferon activation of the transcription factor Stat91 involves dimerization through SH2phosphotyrosyl peptide interactions. Cell $\underline{76}$, 821-828 
Shuai K, Liao J, Song M (1996): Enhancement of antiproliferative activity of gamma interferon by the specific inhibition of tyrosine dephosphorylation of Stat1. Moll Cell Biol 16, 4932-4941

Shuai K, Liu B (2005): Regulation of gene-activation pathways by PIAS proteins in the immune system. Nat Rev Immunol 5, 593-605

Staab J (2011): Molecular determinants of dephosphorylation and gene activation of the signal transducer and activator of transcription 1. Naturwissenschaftliche. Diss. Marburg 2011

Staab J, Herrmann-Lingen C, Meyer T (2013): Clinically relevant dimer interface mutants of STAT1 transcription factor exhibit differential gene expression. PloS one $\underline{8}$, e69903

Starr R, Hilton DJ (1999): Negative regulation of the JAK/STAT pathway. BioEssays 21, 47-52

Strehlow I, Schindler C (1998): Amino-terminal signal transducer and activator of transcription (STAT) domains regulate nuclear translocation and STAT deactivation. J Biol Chem 273, 28049-28056

Takeda K, Noguchi K, Shi W, Tanaka T, Matsumoto M, Yoshida N, Kishimoto T, Akira S (1997): Targeted disruption of the mouse Stat3 gene leads to early embryonic lethality. Proc Natl Acad Sci USA 94, 3801-3804

Takezaki S, Yamada M, Kato M, Park M, Maruyama K, Yamazaki Y, Chida N, Ohara O, Kobayashi I, Ariga T (2012): Chronic mucocutaneous candidiasis caused by a gain-of-function mutation in the STAT1 DNA-binding domain. J Immunol $\underline{189}, 1521-1526$

Teglund S, McKay C, Schuetz E, van Deursen JM, Stravopodis D, Wang D, Brown M, Bodner S, Grosveld G, Ihle JN (1998): Stat5a and Stat5b proteins have essential and nonessential, or redundant, roles in cytokine responses. Cell $\underline{93}$, 841-850

ten Hoeve J, de Jesus Ibarra-Sanchez M, Fu Y, Zhu W, Tremblay M, David M, Shuai K (2002): Identification of a nuclear Stat1 protein tyrosine phosphatase. Moll Cell Biol 22, 5662-5668

Thierfelder W, van Deursen J, Yamamoto K, Tripp R, Sarawar S, Carson R, Sangster M, Vignali D, Doherty P, Grosveld G, Ihle J (1996): Requirement for Stat4 in interleukin-12-mediated responses of natural killer and T cells. Nature $\underline{382}$, 171174

Tsumura M, Okada S, Sakai H, Yasunaga S, Ohtsubo M, Murata T, Obata H, Yasumi T, Kong XF, Abhyankar A (2012): Dominant-negative STAT1 SH2 domain mutations in unrelated patients with mendelian susceptibility to mycobacterial disease. Hum Mutat 33, 1377-1387 
Van de Veerdonk FL, Plantinga TS, Hoischen A, Smeekens SP, Joosten LA, Gilissen C, Arts P, Rosentul DC, Carmichael AJ, Smits-van der Graaf CAA (2011): STAT1 mutations in autosomal dominant chronic mucocutaneous candidiasis. N Engl J Med 365, 54-61

Velazquez L, Fellous M, Stark GR, Pellegrini S (1992): A protein tyrosine kinase in the interferon $\alpha / \beta$ signaling pathway. Cell 70, 313-322

Vinkemeier U, Moarefi I, Darnell J, Kuriyan J (1998): Structure of the aminoterminal protein interaction domain of STAT-4. Science 279, 1048-1052

Weis K (1998): Importins and exportins: how to get in and out of the nucleus. Trends Biochem Sci 23, 185-189

Wen Z, Zhong Z, Darnell JE (1995): Maximal activation of transcription by statl and stat3 requires both tyrosine and serine phosphorylation. Cell $\underline{82}$, 241-250

Wenta N, Strauss H, Meyer S, Vinkemeier U (2008): Tyrosine phosphorylation regulates the partitioning of STAT1 between different dimer conformations. Proc Natl Acad Sci USA 105, 9238-9243

Wente S, Rout M (2010): The nuclear pore complex and nuclear transport. Cold Spring Harb Perspect Biol 2, a000562

Wilks A, Harpur A, Kurban R, Ralph S, Zurcher G, Ziemiecki A (1991): Two novel protein-tyrosine kinases, each with a second phosphotransferase-related catalytic domain, define a new class of protein kinase. Moll Cell Biol 11, 2057-2065

Wormald S, Hilton DJ (2004): Inhibitors of cytokine signal transduction. J Bio Chem 279, 821-824

Wu TR, Hong YK, Wang XD, Ling MY, Dragoi AM, Chung AS, Campbell AG, Han ZY, Feng GS, Chin YE (2002): SHP-2 is a dual-specificity phosphatase involved in Stat1 dephosphorylation at both tyrosine and serine residues in nuclei. J Bio Chem 277, 47572-47580

Xu X, Sun Y, Hoey T (1996): Cooperative DNA binding and sequence-selective recognition conferred by the STAT amino-terminal domain. Science 273, 794-797 Yan R, Small S, Desplan C, Dearolf CR, Darnell JE (1996): Identification of a Stat gene that functions in drosophila development. Cell 84, 421-430

Yang E, Wen Z, Haspel R, Zhang J, Darnell J (1999): The linker domain of Stat1 is required for gamma interferon-driven transcription. Moll Cell Biol 19, 5106-5112 Yang E, Henriksen MA, Schaefer O, Zakharova N, Darnell J (2002): Dissociation time from DNA determines transcriptional function in a STAT1 linker mutant. J Bio Chem 277, 13455-13462 
Zhang JJ, Vinkemeier U, Gu W, Chakravarti D, Horvath CM, Darnell JE (1996):

Two contact regions between Stat1 and CBP/p300 in interferon gamma signaling. Proc Natl Acad Sci USA 93, 15092-15096

Zhang J, Zhao Y, Chait B, Lathem WW, Ritzi M, Knippers R, Darnell JE (1998): Ser727-dependent recruitment of MCM5 by Stat1alpha in IFN-gamma-induced transcriptional activation. EMBO J 17, 6963- 6971

Zhong M, Henriksen MA, Takeuchi K, Schaefer O, Liu B, ten Hoeve J, Ren Z, Mao X, Chen X, Shuai K, Darnell JE (2005): Implications of an antiparallel dimeric structure of nonphosphorylated STAT1 for the activation-inactivation cycle. Proc Natl Acad Sci USA 102, 3966-3971

Zhu M, John S, Berg M, Leonard WJ (1999): Functional association of Nmi with Stat5 and Stat1 in IL-2- and IFN $\gamma$-mediated signaling. cell 96, 121-130 


\section{Danksagung}

Allen voran gilt mein tiefer Dank meinem Doktorvater und Betreuer Prof. Dr. Dr. Dr. Thomas Meyer für das Heranführen und die Einarbeitung in diesen spannenden Teil der Grundlagenforschung. Über die letzten drei Jahre stand er mir mit unermüdlichem Eifer als zuverlässiger Mentor und Diskussionspartner zur Seite und stand mir für wissenschaftliche Fragen stets Rede und Antwort.

Ebenso geht mein Dank an Prof. Dr. Christoph Hermann-Lingen für sein wissenschaftliches Engagement und das Interesse an meiner Doktorarbeit.

Ich danke Dr. Julia Staab für die hilfreiche Unterstützung bei den Real-TimeExperimenten, die gute Einarbeitung in die Laborarbeit sowie die Einführung in das wissenschaftliche Arbeiten.

Ein recht herzliches Dankeschön geht an unsere medizinisch-technischen Assistentinnen Anke Gregus und Heike Hühn, die mich mit stetem Einsatz und guten Ratschlägen in den Höhen und Tiefen des Laboralltags treu unterstützen.

Ich bedanke mich bei den Arbeitsgruppen der Abteilung 'Neurodegeneration', 'Neuroimmunology/IMSF' und 'Neurophysiology' für die großzügige Möglichkeit der Nutzung ihrer Laborgeräte.

Zuletzt geht mein Dank an Joscha Liedtke, der ebenfalls einen wichtigen Beitrag zur Fertigstellung dieser Arbeit geleistet hat. Danke für dein wissenschaftliches Interesse und deine Unterstützung bezüglich der technischen Umsetzung dieser Doktorarbeit. 


\section{Lebenslauf}

Mein Name ist Jessica Grebe, und ich wurde am 14.09.1987 als viertes von fünf Kindern der Eheleute Ellen Grebe und Wolfgang Grebe in Göppingen geboren.

Von 1994-1997 besuchte ich die Stauferschule in Wäschenbeuren und wechselte anschließend auf das Freihof-Gymnasium Göppingen, wo ich 2006 erfolgreich das Abitur absolvierte. Nach meiner Schulzeit verbrachte ich zehn Monate in Montpellier, Südfrankreich. Dort arbeitete ich im Rahmen eines freiwilligen sozialen Jahres in einem Heim für geistig behinderte Erwachsene. Anschließend begann ich im Wintersemester 2007/2008 Sonderschullehramt mit dem Förderschwerpunkt Geistigbehindertenpädagogik an der Julius-Maximilians-Universität Würzburg zu studieren.

Ich entschied mich für einen Studienfachwechsel und begann im Sommersemester 2008 mein Medizinstudium an der Georg-August-Universität in Göttingen. Ich absolvierte den Ersten Abschnitt der Ärztlichen Prüfung in Regelstudienzeit mit der Note "gut". Im Rahmen meines Studiums war ich sowohl als Tutorin für Chemie in der Vorklinik als auch als Tutorin im Modul "ärztliche Basisfertigkeiten"während des klinischen Abschnitts tätig. Ebenso arbeitete ich im Studentenpool als Sitzwache in der Universitätsmedizin Göttingen. Im Verlauf meines Studiums hatte ich die Möglichkeit, einen Teil meiner Famulaturen und Praktika im Ausland zu absolvieren, unter anderen in Frankreich und Tunesien. Ebenso famulierte ich in der Psychiatrie, Kardiologie, Innere Medizin sowie in der Kinderheilkunde. Mein praktisches Jahr absolvierte ich in der Kinderklinik der Universitätsmedizin Göttingen, in der Klinik für Innere Medizin des St.Bernward Krankenhauses in Hildesheim, sowie in der Unfallchirurgie/Orthopädie des Centre Hospitalier Universitaire auf Guadeloupe/Frankreich.

Im Februar 2012 begann ich mit dem experimentellen Teil meiner Doktorarbeit unter der Leitung von Prof. Dr. Dr. Dr. Thomas Meyer im Labor für molekulare Psychokardiologie in der Abteilung Psychosomatische Medizin und Psychotherapie der Georg-August-Universität Göttingen.

Im Herbst 2014 konnte ich mein Medizinstudium erfolgreich beenden und arbeite aktuell in der Kinderklinik des St.Bernward Krankenhauses Hildesheim. 